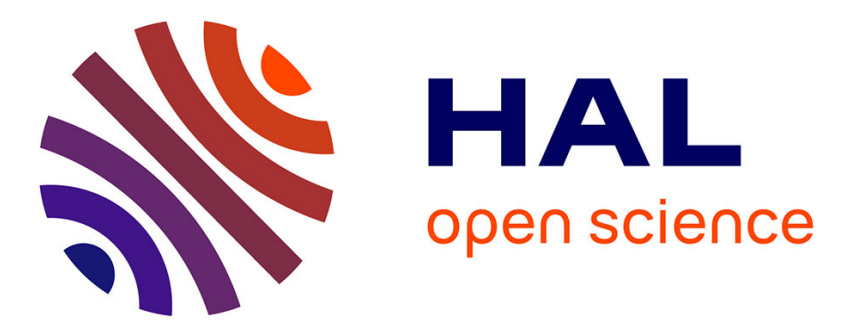

\title{
Two-dimensional oxide quasicrystal approximants with tunable electronic and magnetic properties
}

Thiago Trevizam Dorini, Florian Brix, Corentin Chatelier, Anton Kokalj, Émilie Gaudry

\section{To cite this version:}

Thiago Trevizam Dorini, Florian Brix, Corentin Chatelier, Anton Kokalj, Émilie Gaudry. Twodimensional oxide quasicrystal approximants with tunable electronic and magnetic properties. Nanoscale, 2021, 13 (24), pp.10771-10779. 10.1039/D1NR02407H . hal-03316952

\section{HAL Id: hal-03316952 \\ https://hal.science/hal-03316952}

Submitted on 6 Aug 2021

HAL is a multi-disciplinary open access archive for the deposit and dissemination of scientific research documents, whether they are published or not. The documents may come from teaching and research institutions in France or abroad, or from public or private research centers.
L'archive ouverte pluridisciplinaire HAL, est destinée au dépôt et à la diffusion de documents scientifiques de niveau recherche, publiés ou non, émanant des établissements d'enseignement et de recherche français ou étrangers, des laboratoires publics ou privés. 


\section{Journal Name}

Cite this: DOI: $00.0000 / x x x x x x x x x x$

\section{Two-dimensional oxide quasicrystal approximants with tunable electronic and magnetic properties ${ }^{\dagger}$}

\author{
Thiago T. Dorini, ${ }^{a, b}$ Florian Brix, ${ }^{a, b}$ Corentin Chatelier, ${ }^{a, b}$ Anton Kokalj, ${ }^{b, c}$ Émilie \\ Gaudry*a,b
}

Received Date

Accepted Date

DOI: 00.0000/xxxxxxxxxx

\begin{abstract}
Recently, the discovery of the quasiperiodic order in ultra-thin perovskite films reinvigorated the field of 2-dimensional oxides on metals, and raised the question of the reasons behind the emergence of the quasiperiodic order in these systems. The effect of size-mismatch between the two separate systems has been widely reported as a key factor governing the formation of new oxide structures on metals. Herein, we show that electronic effects can play an important role as well. To this end, the structural, thermodynamic, electronic and magnetic properties of freestanding twodimensional oxide quasicrystalline approximants and their characteristics when deposited over metallic substrates are systematically investigated to unveil the structure-property relationships within the series. Our thermodynamic approach suggests that the formation of these aperiodic systems is likely for a large range of compositions. In addition, the magnetic properties and work functions of the thin films can be controlled by tuning their chemical composition. This work provides well-founded general insights into the driving forces behind the emergence of the quasiperiodic order in ternary oxides grown on elemental metals and offers guidelines for the discovery of new oxide quasicrystalline ultra-thin films with interesting physical properties.
\end{abstract}

\section{Introduction}

Thin perovskite films, made of a few-layer thick nano-sheets, have attracted considerable attention due to their extensive structural and electronic variability, linked to the huge number of conceivable unique chemical compositions - more than $\simeq 10^{7}$, according to Li et al. ${ }^{1}$ The combination of the low dimension with the structural flexibility of this class of crystals opened the door to a rich spectrum of applications in many fields, such as energy transition and catalysis, ${ }^{2}$ correlated materials ${ }^{3}$ and electronic devices. ${ }^{4,5}$

Decreasing the thickness of two-dimensional (2D) perovskites down to the mono-layer limit is expected to deeply alter their structures and modify the physical and chemical properties, as already demonstrated in the case of other types of ultrathin 2D oxides films ${ }^{6-8}-\mathrm{TiO}_{x} / \mathrm{Pt}(111),{ }^{9} \mathrm{MnO}_{x} / \operatorname{Pd}(100){ }^{10}$ and $\mathrm{VO}_{x} / \operatorname{Pd}(111),{ }^{11,12}$ to name a few. This has recently led to the emergence of novel structures with aperiodic ordering, i.e. dodecagonal oxide quasicrystal interfaces in the $\mathrm{BaTiO}_{3} / \mathrm{Pt}(111)$ and $\mathrm{SrTiO}_{3} / \mathrm{Pt}(111)$ systems. ${ }^{13-16}$ The driving force for these

\footnotetext{
${ }^{a}$ Université de Lorraine, CNRS, Institut Jean Lamour - UMR 7198, F-54011, Nancy, France.E-mail: Emilie.Gaudry@univ-lorraine.fr

${ }^{b}$ International Associated Laboratory PACS2, CNRS UniversitÃ'l de Lorraine, Nancy, France

${ }^{c}$ Jožef Stefan Institute, Jamova cesta 39, 1000 Ljubljana, Slovenia

$\dagger$ Electronic Supplementary Information (ESI) available: [details of any supplementary information available should be included here]. See DOI: 00.0000/00000000.
}

unique structural modifications, resulting from thickness reduction, are far from being fully unveiled. Reduced bonding coordinations, possible strong surface polarizations, support effects and experimental conditions are supposed to play a role, but no clear picture has yet been drawn. ${ }^{6-8}$

A key parameter for the emergence of quasiperiodic order is the existence of double-well interaction potentials defining two different length-scales. ${ }^{17,18}$ The presence of at least two elements fulfil this criterion for intermetallic quasicrystals, ${ }^{19}$ whose aperiodic order can be transferred to $2 \mathrm{D}$ atomic or molecular overlayers, grown at their surfaces, like $\mathrm{Pb} / \mathrm{Ag}-\mathrm{In}-\mathrm{Yb},{ }^{20} \mathrm{~Pb} / \mathrm{Al}-\mathrm{Co}-$ $\mathrm{Ni}^{21}$ or $\mathrm{Pb} / \mathrm{Al}-\mathrm{Pd}-\mathrm{Mn} .{ }^{22}$ These are only scarce examples illustrating the formation of $2 \mathrm{D}$ quasiperiodic films on periodic substrates. Most of the them deals with molecular assembly - fullerenes organised as 2D small patches of a quasicrystalline triangle-square tiling on $\mathrm{Pt}_{3} \mathrm{Ti}(111)^{23}$ and molecules aperiodically organised by Ce-directed assembly on $\mathrm{Ag}(111) .{ }^{24,25}$ The case of the 2D Oxide QuasiCrystals (OQCs) on dense metallic surfaces remains unique. ${ }^{13}$ The stoichiometric ratio and concentration, as well as the coordinative plasticity, charge and ionic radii of cations, are invoked as key parameters towards the formation of quasiperiodic films. In the case of the $2 \mathrm{D} \mathrm{BaTiO}_{3} / \mathrm{Pt}(111) \mathrm{OQC}$, the frustration at the interface between two periodic materials is suggested to play a role in the formation of the OQC phase, as proposed previously in the $\mathrm{Ag} / \mathrm{GaAs}(110)$ system. ${ }^{26}$ Such argument is also sup- 
ported by experimental evidences of interface and support effects on the structure of the (thick) $\mathrm{BaTiO}_{3}$ films. ${ }^{27,28}$ However, no systematic structural and electronic investigations have been undertaken so far to evaluate the impact of elastic, electronic and chemical factors on the emergence of the quasiperiodic order, which is probably due to the complexity and the non-periodic character of the structures.

Periodic approximant structures to quasicrystals represent a very useful approach to deepen our understanding of quasicrystalline phases. When modelled with large crystal supercells, approximants exhibit atomic arrangements similar to those encountered in quasicrystals, hence they bridge the gap between periodic and aperiodic positional order. Due to their lattice periodicity, approximants can be studied by methods based on density functional theory (DFT). Focusing on OQCs, approximants have been experimentally observed and theoretically investigated in the $\mathrm{BaTiO}_{3} / \mathrm{Pt}(111), \mathrm{SrTiO}_{3} / \mathrm{Pt}(111)$ and $\mathrm{BaFeO}_{3} / \mathrm{Pt}(111)$ systems. ${ }^{14,16,29,30}$ Beyond these examples, and starting from the structural model derived for the $\mathrm{BaTiO}_{3} / \mathrm{Pt}(111)$ approximant, ${ }^{14}$ the structural, thermodynamic, electronic and magnetic properties of freestanding 2D Oxide Quasicrystalline Approximants (OQAs) $-A B \mathrm{O}_{3}$ where $A=\mathrm{Ba}, \mathrm{Ca}, \mathrm{Sr}$ and $B=\mathrm{Ti}, \mathrm{V}, \mathrm{Cr}, \mathrm{Mn}$, $\mathrm{Fe}, \mathrm{Ni}-$ as well as their characteristics when deposited over $\mathrm{Me}(111)$ substrates $(\mathrm{Me}=\mathrm{Pt}, \mathrm{Pd}, \mathrm{Au})$ are systematically investigated herein to unveil the structure-property relationships within the series. The relative stabilities of the supported OQAs, compared to those of periodic systems with similar compositions, suggest a good experimental feasibility for many of them. While size-mismatch is generally invoked as the main driving force towards the formation of ultra-thin oxide layers on metal, including OQAs, ${ }^{6,31}$ we show here that electronic effects (interfacial electron transfer and hybridisation) play a significant role in the stability and properties of the films. Our study reveals that tuning the magnetic properties and the work functions of these aperiodic-like metallic supported ultra-thin oxide films is achievable by controlling their chemical composition. This work provides well-founded general guidelines to the discovery of new OQCs with interesting physical and chemical properties.

\section{Relative stabilities of OQA films}

\subsection{Structures}

One of the aims of our study is to assess the relative thermodynamic stability of supported OQAs against the periodic systems with similar compositions. Hence, three types of structures are considered.

The 2D OQA series is studied using structural models derived from the one designed for $\mathrm{BaTiO}_{3} / \mathrm{Pt}(111) .{ }^{14}$ According to a combination of scanning tunnelling microscopy, low-energy electron diffraction, surface X-ray diffraction and ab initio calculations, it consists in a $3^{2}$.4.3.4 Archimedean tiling, with Ti atoms at the corners of each tiling element and threefold coordinated to oxygen atoms (Figs. 1a and S1). A wide variety of chemical compositions is considered herein, through atomic substitutions based on the $A_{5} B_{4} \mathrm{O}_{12}$ chemical motif, with $A=\mathrm{Ba}, \mathrm{Ca}, \mathrm{Sr}$ and $B=\mathrm{Ti}, \mathrm{V}, \mathrm{Cr}$, $\mathrm{Mn}, \mathrm{Fe}, \mathrm{Ni}$.
To evaluate the relative stability of the previous aperiodiclike single oxide layers against possible periodic arrangements, we considered a second model, which is an archetypal structure for 2D periodic ultra-thin oxide films. It consists of a single-layer hexagonal structured (SHS) $B_{2} \mathrm{O}_{3}$, doped with alkali earth elements $(A)$. Such a honeycomb structure, deposited on $\mathrm{Me}(111)$, has been experimentally observed for $\mathrm{Ti}_{2} \mathrm{O}_{3} / \mathrm{Au}(111)^{32}, \mathrm{Nb}_{2} \mathrm{O}_{3} / \mathrm{Au},{ }^{33} \mathrm{FeWO}_{3} / \mathrm{Au}^{34}$ and copper oxide on $\mathrm{Au}^{35}$ (Fig. 1b). In contrast to the OQA model, the SHS model contains the $A$-element as a dopant. Thus, its content is much lower than the one of the $B$-element $\left(A B_{4} \mathrm{O}_{6}\right.$ is the surface cell motif).

The experimentally observed OQA structure of $\mathrm{BaTiO}_{3} / \mathrm{Pt}(111)$ is prepared from Thick $\mathrm{BaTiO}_{3}$ Perovskite Films (TPFs) grown by RF magnetron sputter deposition. ${ }^{36}$ The TPFs are modelled here by $7 \AA$ A-thick films. TPFs films are built with the $[a b c]$ direction of the bulk crystal perpendicular to the Me(111) termination planes, with $[a b c]=[111]$ for cubic perovskites and $[a b c]=[100]$ for hexagonal perovskites (Figs. 1c-1d). The simulation box contains two interfaces: Me/TPF and TPF/void. Since bulk perovskite crystals are described by a stacking of two types of planes along the $[a b c]$ direction - low-density pure $B$-element planes and $A \mathrm{O}_{3}$ planes - several configurations are possible. We chose $A \mathrm{O}_{3} / \mathrm{Me}$ and $A \mathrm{O}_{3} /$ void interfaces, because the atomic density of the $A_{3}$ planes are much higher than the pure $B$-element ones.

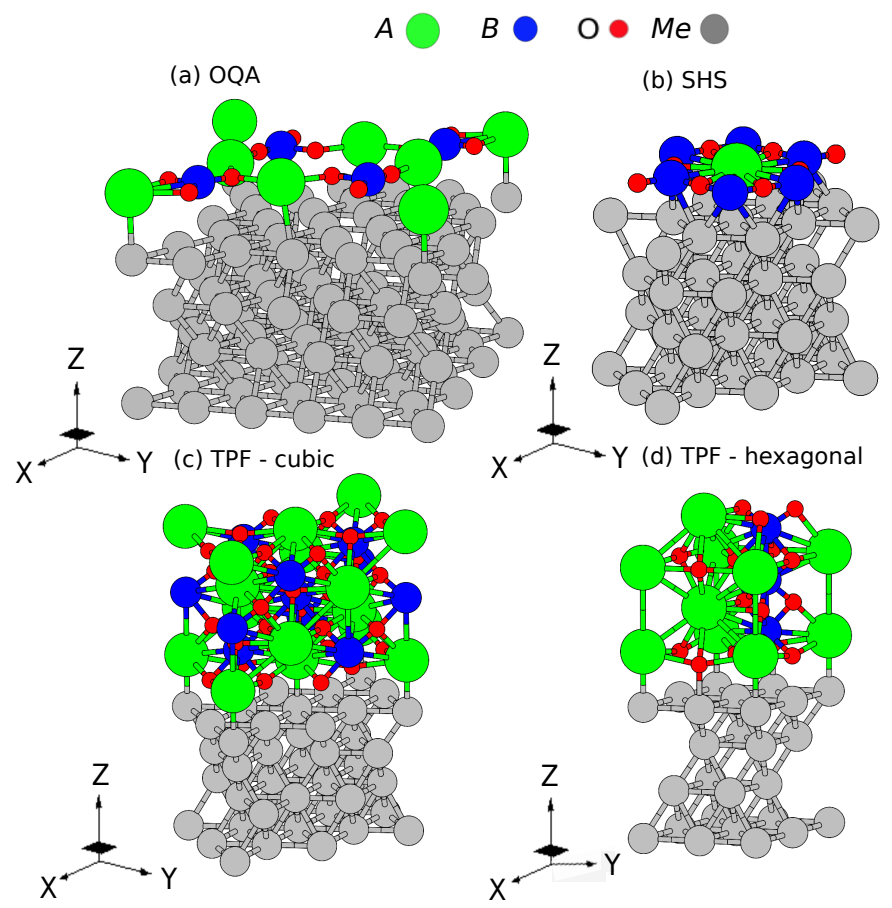

Fig. 1 Structural models for the oxide films grown on Pt(111), plotted using XCrySDen: ${ }^{37}$ OQA (a), SHS (b), TPF built from the cubic perovskite structure (c) and TPF built from the hexagonal perovskite structure (d).

\subsection{Formation enthalpies}

The formation energies of the freestanding and supported $2 \mathrm{D}$ oxides $\left(\Delta H_{\mathrm{f}}^{\text {free }}\right.$ and $\Delta H_{\mathrm{f}}^{\text {sup }}$, respectively), in both OQA and SHS con- 
figurations, are calculated for different compositions using the $\mathrm{O}_{2}$ molecule and the elemental solids as references $(X \in\{\mathrm{OQA}$, SHS\}), i.e.:

$$
\Delta H_{\mathrm{f}}^{\mathrm{free}}(X)=E\left(A_{x} B_{y} \mathrm{O}_{z}\right)-x E_{\mathrm{coh}}(A)-y E_{\mathrm{coh}}(B)-\frac{z}{2} \mu_{\mathrm{O}_{2}}
$$

and

$$
\Delta H_{\mathrm{f}}^{\text {sup }}(X)=\Delta H_{\mathrm{f}}^{\text {free }}(X)+E\left(\mathrm{Me}_{w} \mathrm{Ba}_{x} B_{y} \mathrm{O}_{z}\right)-E\left(\mathrm{Ba}_{x} B_{y} \mathrm{O}_{z}\right)-w E_{\mathrm{coh}}(\mathrm{Me}),
$$

where $E$ and $E_{\text {coh }}$ are the total and the cohesive energies, respectively, and $\mu_{\mathrm{O}_{2}}$ is the chemical potential of oxygen molecule. The formation energies are negative for all considered $B$-metals in the OQA freestanding layers (Tabs. 1 and S1, and Fig. S2), ranging from $-2.04 \mathrm{eV} /$ at. to $-0.84 \mathrm{eV} /$ at., thus indicating exothermic formation reactions. Formation enthalpies are less exothermic in the SHS freestanding series and even become endothermic for the late transition metals. The increasing endothermicity of $\Delta H_{\mathrm{f}}^{\text {free }}$ along the transition metal series is attributed to the increase of the electronegativity from $\mathrm{Ti}$ to $\mathrm{Ni}$ that provokes a decrease of the charge transfer in the series and, consequently, weakening of the $B-\mathrm{O}$ bonds. This will be demonstrated in the next section.

As for the freestanding layers, the endothermicity of the formation energy increases for the supported layers along the transition metal series. (Tabs. 1, S2-S4 and Fig. S3). In this case, the effect of the substrate-oxide interaction can be quantified through the adhesion energy ( $E_{\text {adh }}(X)$, Tabs. 1 and S5-S7). The latter can be calculated either from energy differences between the constituted oxide/metal system $(E(X / \mathrm{Me}))$ and its separated components bare metal substrate $(E(\mathrm{Me}))$ and freestanding oxide single-layer at its equilibrium lattice parameter $(E(X))$ or it can be evaluated from a Born-Haber cycle:

$$
\begin{aligned}
E_{\mathrm{adh}}(X / \mathrm{Me}) & =E(X / \mathrm{Me})-E(X)-E(\mathrm{Me}) \\
& =\Delta H_{\mathrm{f}}^{\text {sup }}(X / \mathrm{Me})-\Delta H_{\mathrm{f}}^{\text {free }}(X) .
\end{aligned}
$$

Adhesion is favoured in all cases $\left(E_{\mathrm{adh}}<0\right)$, although it is much weaker for OQA arrangements than for SHSs. It ranges from $-0.082 \mathrm{eV} / \AA^{2}\left(\mathrm{BaTiO}_{3} / \mathrm{Pt} \mathrm{OQA}\right)$ to $-0.033 \mathrm{eV} / \AA^{2}\left(\mathrm{BaNiO}_{3} / \mathrm{Au}\right.$ OQA) and from $-0.435 \mathrm{eV} / \AA^{2}\left(\mathrm{BaTiO}_{3} / \mathrm{Pt} \mathrm{SHS}\right)$ to $-0.128 \mathrm{eV} / \AA^{2}$ $\left(\mathrm{BaCoO}_{3} / \mathrm{Au} \mathrm{SHS}\right)$. This trend is consistent with the fact that $B$ metals in SHSs are all located in favourable threefold adsorption sites on Me, because the dense surface of close-packed Me and the SHSs are both periodic and commensurate. In contrast, the approximant structure makes it unmanageable to locate all $B$ metals of OQAs in the favourable hollow sites of the substrate, thus weakening adhesion.

Irrespectively of the substrate and alkaline earth element $(A$ $=\mathrm{Ba}, \mathrm{Sr}, \mathrm{Ca}$ ), adhesion is systematically stronger for oxide films from the beginning of the transition metal series ( $\mathrm{Ti}, \mathrm{V})$. In addition, adhesion does not seem to vary significantly in the OQA with different substrates or alkali earth elements $(A)$. Nonetheless, the change of the substrate in the SHS from Pt to Au results in a clearly stronger interaction with $\mathrm{Pt}$, as also shown in the work by Goniakowski and Noguera. ${ }^{38}$ Adhesion is impacted by both the strength of the direct metal-oxide interaction at the interface and the elastic strain of the freestanding single-layer, necessary to match its in-plane lattice parameter with the metal substrate. The contribution from elastic strain, non favourable for adhesion, is calculated from the energy difference between the strained and freestanding single-layer. Elastic strain is alleviated by the film rumpling. This has been checked using the freestanding layer of the $\mathrm{BaTiO}_{3} \mathrm{OQA}$, for which the contributions of the elastic strain (30 meV/at.) is much lower than that of the rumpling (152 meV/at.). A deeper analysis of the film rumpling and charge transfer is detailed below (section 3 ).

\subsection{Gibbs free energies}

The exothermic formation energy of OQAs is a necessary but not sufficient condition to assess the stability of the system. In a second step, we calculate the OQAs formation enthalpies with respect to the competing periodic phases (SHSs, PTFs), taking into account the experimental conditions (pressure, temperature). Experimentally, $\mathrm{BaTiO}_{3}$ TPF is first grown by RF magnetron sputter deposition ${ }^{14,36}$ and then the OQA is formed by annealing in ultrahigh vacuum (UHV). ${ }^{15}$ By exposing the 2D OQA at elevated temperatures to $\mathrm{O}_{2}$, a rapid transition back into $3 \mathrm{D} \mathrm{BaTiO}_{3}$ islands occurs. ${ }^{15}$

According to experiments, key parameters for the OQA and SHS formation includes the oxygen pressure, the temperature, and the number of annealing cycles. We evaluate the formation Gibbs free energies of the $A B O_{3}$ OQAs and SHSs for several compositions $\left(\mathrm{BaTiO}_{3}, \mathrm{SrTiO}_{3}, \mathrm{BaFeO}_{3}, \mathrm{BaCoO}_{3}, \mathrm{BaNiO}_{3}\right)$ by considering the following reactions:

$$
\begin{gathered}
n_{\mathrm{TPF}} \mathrm{TPF} / \mathrm{Me} \longrightarrow n_{X / \mathrm{Me}} X / \mathrm{Me}+n_{\mathrm{Ba} B O_{3}} \mathrm{BaBO}_{3}+n_{\mathrm{O}_{2}} \mathrm{O}_{2}+n_{\mathrm{Ba}} \mathrm{Ba} \\
\Delta G_{\mathrm{f}}^{X / \mathrm{Me}}=n_{X / \mathrm{Me}} E(X / \mathrm{Me})+n_{\mathrm{Ba} B O_{3}} E\left(\mathrm{BaBO}_{3}\right)+n_{\mathrm{O}_{2}} \mu_{\mathrm{O}_{2}}+n_{\mathrm{Ba}} \mu_{B a}-n_{\mathrm{TPF}} E(\mathrm{TPF})
\end{gathered}
$$

This description was chosen, since it corresponds to the experimental setup in which the bulk perovskite and the oxygen partial pressure are controlled. The pressure is included in the model through the chemical potential of oxygen gas, accounting for only its rotational and translational contributions to the partition function. Within the standard DFT approach, and considering the stable perovskite bulk structures, the formation Gibbs free energies $\left(\Delta G_{\mathrm{f}}^{\mathrm{OQA} / \mathrm{Me}}\right)$ are all positive, in the range $[0.15 ; 0.19] \mathrm{eV} /$ at. and
[0.07;0.11] eV/at. for the Pt and Au substrates, respectively, at $T=300 \mathrm{~K}$ and $P=10^{-10} \mathrm{mbar}$. It means that the formation of single-layer oxide films is not likely under these conditions. Instead, the growth of thick $\mathrm{BaBO}_{3}$ perovskite layers is predicted. This is in agreement with the experimental results, which report a $\mathrm{BaTiO}_{3}(111)-(1 \times 1)$ structure on $\mathrm{Pt}(111)-(2 \times 2)$, observed by Low Energy Electron Diffraction. ${ }^{36}$

Increasing the temperature under UHV conditions makes the 
Table 1 Formation enthalpies $\Delta H_{\mathrm{f}}$ (eV/at.), Gibbs free energies $\Delta G_{\mathrm{f}}$ (eV/at.) and adhesion energies $E_{\text {adh }}\left(\mathrm{eV} / \AA^{2}\right)$ for the $\mathrm{Ba} B \mathrm{O}_{3}$ quasicrystalline approximant and honeycomb freestanding and supported layers, at $T=300 \mathrm{~K}$ and $P=10^{-10}$ bar.

\begin{tabular}{|c|c|c|c|c|c|c|c|c|c|c|}
\hline & \multicolumn{5}{|c|}{ OQA } & \multicolumn{5}{|c|}{ SHS } \\
\hline$A$ & $\mathrm{Ba}$ & $\mathrm{Sr}$ & $\mathrm{Ba}$ & $\mathrm{Ba}$ & $\mathrm{Ba}$ & $\mathrm{Ba}$ & $\mathrm{Sr}$ & $\mathrm{Ba}$ & $\mathrm{Ba}$ & $\mathrm{Ba}$ \\
\hline $\bar{B}$ & $\mathrm{Ti}$ & $\mathrm{Ti}$ & $\mathrm{Fe}$ & Co & $\mathrm{Ni}$ & $\mathrm{Ti}$ & $\overline{\mathrm{Ti}}$ & $\mathrm{Fe}$ & Co & $\mathrm{Ni}$ \\
\hline & \multicolumn{5}{|c|}{ Freestanding layer } & \multicolumn{5}{|c|}{ Freestanding layer } \\
\hline$\Delta H_{\mathrm{f}}^{\text {free }}$ & -2.02 & -2.04 & $\begin{array}{l}-1.14 \\
\text { t substra }\end{array}$ & -1.12 & -0.84 & -1.05 & -1.20 & $\begin{array}{c}0.00 \\
\text { t substra }\end{array}$ & -0.39 & 0.38 \\
\hline$E_{\mathrm{adh}}$ & -0.082 & -0.075 & -0.051 & -0.068 & -0.051 & -0.435 & -0.403 & -0.209 & -0.157 & -0.152 \\
\hline$\Delta H_{\mathrm{f}}^{\text {sup }}$ & -0.42 & -0.41 & -0.24 & -0.26 & -0.20 & -0.84 & -0.84 & -0.28 & -0.31 & -0.11 \\
\hline$\Delta G_{\mathrm{f}}$ & +0.12 & +0.13 & +0.15 & +0.15 & +0.13 & +0.46 & +0.48 & +0.43 & +0.43 & +0.41 \\
\hline & \multicolumn{5}{|c|}{ Au substrate } & \multicolumn{5}{|c|}{ Au substrate } \\
\hline$E_{\mathrm{adh}}$ & -0.077 & -0.076 & -0.045 & -0.049 & -0.033 & -0.322 & -0.299 & -0.174 & -0.128 & -0.134 \\
\hline$\Delta H_{\mathrm{f}}^{\text {sup }}$ & -0.42 & -0.42 & -0.24 & -0.25 & -0.18 & -0.72 & -0.73 & -0.24 & -0.28 & -0.08 \\
\hline$\Delta G_{\mathrm{f}}$ & +0.08 & +0.07 & +0.11 & +0.10 & +0.08 & +0.47 & +0.48 & +0.40 & +0.38 & +0.37 \\
\hline
\end{tabular}

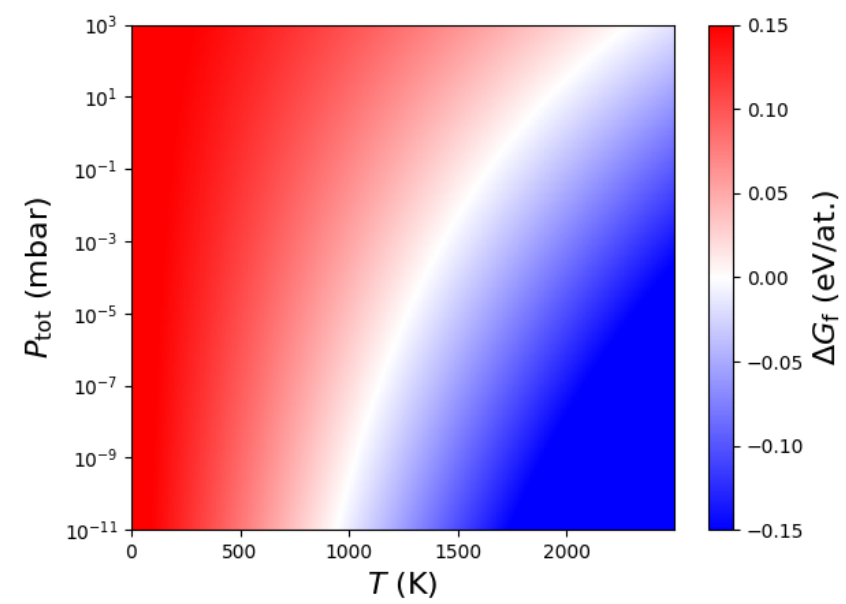

Fig. 2 Gibbs free energy $\left(\Delta G_{\mathrm{f}}^{\mathrm{OQA} / \mathrm{Pt}}\right)$, as a function of the temperature and $\mathrm{O}_{2}$ partial pressure, for the formation of the $\mathrm{BaTiO}_{3}$ oxide quasicrystal approximant on $\mathrm{Pt}(111)$.

$\Delta G_{\mathrm{f}}^{\mathrm{OQA} / \mathrm{Me}}$ exergonic (Fig. 2, Figs. S4-S7) thus favouring the growth of the OQAs. The theoretical formation temperature $\left(T_{\text {form }}\right)$ at which the OQAs are formed, that is, the temperature at which $\Delta G_{\mathrm{f}}^{\mathrm{OQA} / \mathrm{Me}}<0$, is calculated to be $986 \mathrm{~K}$ (using $\mu_{B a}=E_{c o h}(\mathrm{Ba})$ ) for $\mathrm{BaTiO}_{3} / \mathrm{Pt}$ at $P=10^{-10}$ mbar, as shown in Fig. 2. This temperature is in reasonable agreement with the experimental one $\left(T_{\text {form }}^{\exp }=1250 \mathrm{~K}\right) .{ }^{14}$ The formation temperature does not vary much within the series, i.e., it ranges from $737 \mathrm{~K}$ $\left(\mathrm{SrTiO}_{3} / \mathrm{Au}\right)$ to $1164 \mathrm{~K}\left(\mathrm{BaFeO}_{3} / \mathrm{Pt}\right)$. (Fig. 3). A similar analysis performed for SHSs (Figs. S8-S11) shows that the temperatures at which they grow $\left(\Delta G_{\mathrm{f}}^{\mathrm{SHS} / \mathrm{Me}}<0\right)$ are systematically higher than the ones for OQAs. It suggests that OQAs can be formed over SHSs. This assumption is also supported by the positive formation enthalpy $\left(\Delta H_{f}=1.12 \mathrm{eV} / \mathrm{at}\right)$ calculated for the following reaction:

$$
\mathrm{BaTiO}_{3} / \mathrm{Pt} \mathrm{OQA}+n_{\mathrm{BaTiO}_{3}} \mathrm{BaTiO}_{3}+n_{\mathrm{O}_{2}} \mathrm{O}_{2} \rightarrow \mathrm{SHS}+n_{\mathrm{Ba}} \mathrm{Ba}
$$

At a given temperature, the increase of the $\mathrm{O}_{2}$ pressure leads to an increase of $\Delta G_{\mathrm{f}}^{\mathrm{OQA} / \mathrm{Me}}$, up to positive values. It reveals a nearly isothermal reversibility between a $2 \mathrm{D}$ quasicrystal and a periodic 3D island structure, controlled by an external parameter - here the oxygen chemical potential — as observed experimentally. ${ }^{15}$

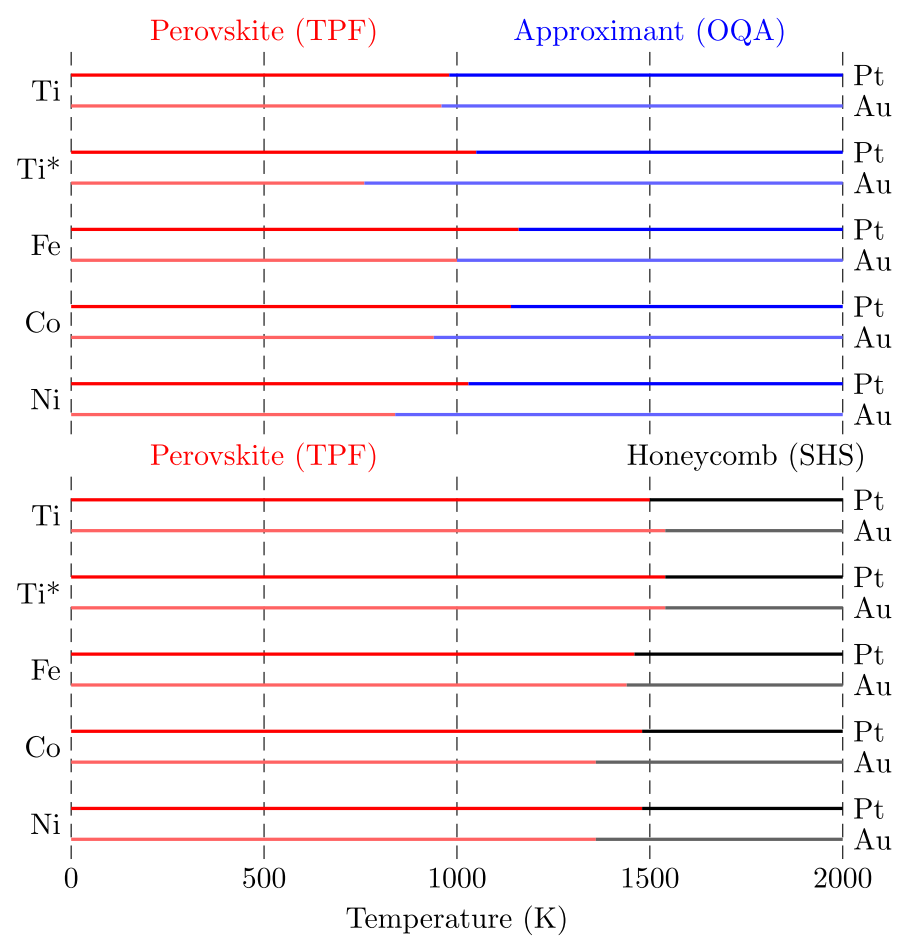

Fig. 3 Relative stabilities of the OQA/TPF (upper panel) and SHS/TPF (lower panel) systems. TPFs are stable at lower temperatures, whereas OQAs and SHSs are stable at higher temperatures. B-elements $(\mathrm{Ti}, \mathrm{Fe}$, $\mathrm{Co}$, or $\mathrm{Ni}$ ) are stated on the left and the metal substrates (Pt or $\mathrm{Au}$ ) are stated on the right. The alkali earth is $A=\mathrm{Ba}$, except when Ti is labelled as Ti* for which $A=\mathrm{Sr}$. The pressure is $P=10^{-10} \mathrm{mbar}$.

\section{Driving forces for the formation of OQAs}

Up to now, experimentalists have mainly considered the $\mathrm{BaTiO}_{3}$ and $\mathrm{SrTiO}_{3}$ perovskites to grow OQAs on $\mathrm{Pt}$, because of the small oxide-metal lattice mismatch. ${ }^{31}$ However, the thermodynamic approach presented above, predicted that a wide range of OQA compositions are stable on $\mathrm{Pt}$ and $\mathrm{Au}$.

As a general principle, the formation of new 2D oxide struc- 
tures has been attributed to size-mismatch. A severe lattice mismatch between the oxide and the metal surface tends to avoid the formation of ordered oxide films over metals. A typical example is $\mathrm{CaO}$ deposited on $\mathrm{Mo}(001) .{ }^{39}$ Amorphous $\mathrm{CaO}$ films are formed at low growth temperature, but a rocksalt-type $\mathrm{Ca}_{3} \mathrm{MoO}_{4}$ structure, with a small oxide-metal lattice mismatch, is obtained after annealing at high temperature. Here, a detailed analysis of the structural properties of OQA freestanding and supported systems has been performed to address the question of how the size-mismatch impacts the OQAs formation. In this section, we also address the influence of electronic effects on the OQAs formation, through charge transfer and density of states analyses.

\subsection{Size-mismatch and rumpling}

Atomic relaxations of the freestanding OQA layers lead to flat planes, distorted from the initial orthorhombic lattice, with parameters larger than the ones of the substrate. This result is in agreement with the literature, at least for the $\mathrm{BaFeO}_{3} / \mathrm{Pt}$ OQA. ${ }^{30}$ The $B-O$ first neighbour distances are almost identical in all systems (Tab. S8), due to the similarity of the transition metal (B) ionic radii, with only a weak systematic decrease along the transition metal series. In contrast, the distances between the alkaline earth metals $(A)$ and their oxygen neighbours ( $A-\mathrm{O}$ distances) increase consistently with the $A$ ionic radii $\left(r_{\mathrm{Ca}}>r_{\mathrm{Sr}}>r_{\mathrm{Ba}}\right)$.

The surface cell mismatch $(\Delta)$ is defined as:

$$
\Delta=\frac{\|\vec{a} \wedge \vec{b}\|_{\text {sub }}-\|\vec{a} \wedge \vec{b}\|_{\text {free }}}{\|\vec{a} \wedge \vec{b}\|_{\text {sub }}}
$$

where $\vec{a}$ and $\vec{b}$ are the in-plane lattice vectors of the relaxed freestanding layer (labelled by subscript free) and of the substrate (sub). Cell mismatch can reach quite high values (up to $50 \%$ ). It remains around 20 to $35 \%$ for a number of systems, being higher when the OQA layer is supported on Au rather than on Pt or Pd.

With respect to the perfectly planar geometry of the freestanding films, supported OQAs display significant structural relaxations, quantified by the vertical separation (rumpling, $R=$ $z^{+}-z^{-}$) between the average $z$-position of the anions $\left(z^{-}\right)$and cation $\left(z^{+}\right)$, where $z$-coordinate represents the surface normal direction. Overall, in most systems, on average, the cations are closer to the substrate than the oxygen atoms, thus resulting in negative values for $R$. A more detailed analysis shows that the oxygen atoms are positioned either in one plane or in two planes separated by about $1.4 \AA$ ( $\mathrm{BaTiO}_{3}$ OQA). The $\mathrm{B}-\mathrm{O}$ and $\mathrm{Ba}-\mathrm{O}$ distances in the supported films are similar to the ones in the freestanding layer (but slightly longer by c.a. $0.05 \AA$ and $0.11 \AA$, respectively). This is consistent with a contraction of interatomic distances when the atomic coordination decreases. ${ }^{40}$ It also highlights that lattice mismatches can be rather easily accommodated by the rumpling of the film, the bending distortions being of much lower energies than bond-length modifications. ${ }^{41}$ However, no clear correlation has been found between the surface cell mismatch and the rumpling (Fig. S12), suggesting that electronic effects also influence the atomic structure of the OQAs.

\subsection{Charge transfer}

The structural distortions described in the previous section can be understood as a response to the electrostatic dipole produced by the interface charge transfer. ${ }^{42,43}$ A negatively charged substrate $\left(Q_{\mathrm{Me}}<0\right)$ attracts the cations and thus tends to produce a negative rumpling $(R<0)$ whereas a positive rumpling is expected for a positive charging of the substrate. The negative rumpling calculated for all investigated OQAs and SHSs series is then attributed to a charge transfer from the oxide film to the substrate. This picture is in agreement with the planar integrated charge density differences, which indicates that the net electron charge is being concentrated in the oxide/metal bonding region with the predominant electron donation coming from the oxide layer (Figs. S13S14).

The aforementioned hypothesis of the oxide-to-substrate charge transfer is also consistent with the Bader charge analysis (Tabs. S5-S7). While in the freestanding layer, the positive charge of $A$ - and $B$-type atoms originates from an "in plane" electron transfer toward the more electronegative oxygen atoms, the picture is slightly altered in the supported films, in which the charge transfer also occurs towards the substrate. In comparison to the freestanding film, the $B$-metal of supported OQAs and SHSs carry a higher positive charge, and the oxygen atoms have a less negative charge, thus leading to interfacial Me atoms carrying an excess of electrons. The charge transfer decreases in the transition metal series, but is similar for all considered substrates (Au, Pt, Pd). In contrast, the charges on the alkaline earth atoms (Ba, Sr, Ca) are quite constant (1.5-1.6 e), suggesting that they only weakly participate to the oxide/metal interaction.

The charge transfer is an important parameter that controls the atomic structure of the OQA. It is shown in Fig. 4, where a correlation is evidenced between the film rumpling $(R)$ and the Bader charge carried by $B$ atoms. The charge transfer also influences the thermodynamics through the adhesion energy. Overall, a stronger adhesion of the film indeed corresponds to a larger $Q_{B}$ (Fig. S15). The size mismatch does not show clear correlations with the adhesion energy (Fig. S16), while stronger adhesion energies are found for $R<0$ (Fig. S17).

\subsection{Electronic structure and oxide/metal bonding scheme}

Density of states (DOS) calculations have been performed for the complete set of OQAs freestanding and supported layers. They show hybridisations within the oxide layer (mainly between $B$ and $\mathrm{O}$ atoms). Associated with the interfacial electron transfer, the local density of states of the freestanding oxide singlelayers (Fig. S21) are substantially modified in supported OQAs (Figs. S18-20). The most obvious effect is probably the widening of the bands. For example, while hybridisation between $\mathrm{Ti}$ and $\mathrm{O}$ states occurs in the $[-4.4,-2.0] \mathrm{eV}$ range in the freestanding oxide single-layer, it extends from $-5.5 \mathrm{eV}$ to the Fermi energy for the $\mathrm{BaTiO}_{3}$ OQA supported on Pt. This observation is less clear for late transition metals $(B=\mathrm{Fe}, \mathrm{Co}$ ), because the $B$-states of the freestanding layer are displayed in a wider energy range, up to about $1 \mathrm{eV}$. DOS analysis clearly reveals that $A$ are cations, because their DOS below the Fermi energy is quite low thus cor- 


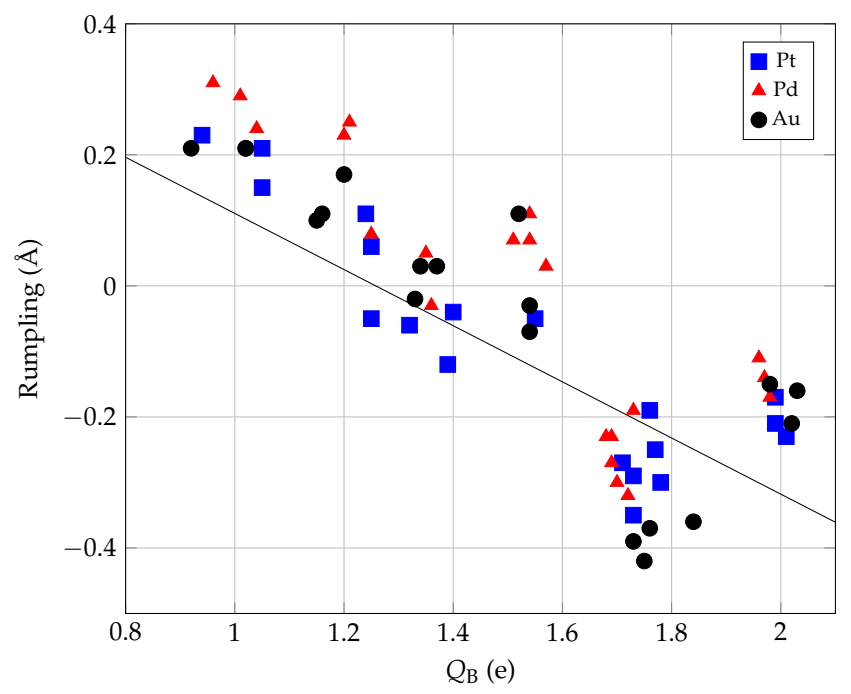

Fig. 4 Plot of the film rumpling $(R)$ as a function of the Bader charge carried by $B$-type atoms $\left(Q_{B}\right.$; note that positive $Q_{B}$ values correspond to cations). The data located around $Q_{B}=1.8$ and $Q_{B}=2.0$ correspond to $B=\mathrm{V}$ and $B=\mathrm{Ti}$, respectively.

roborating the Bader analysis. Their DOS becomes appreciable only about $2 \mathrm{eV}$ above the $E_{\mathrm{F}}$ and beyond. Overall, the interaction with the substrate leads to OQAs with a metallic character, with a strong overlap between $\mathrm{O}$ - and $B$-states, indicating a strong interaction. For $\mathrm{BaTiO}_{3} / \mathrm{Pt}$, this is in agreement with the hybridisation of $\mathrm{O}-2 \mathrm{p}$ and Ti-3d states and with the occupied Ti-3d states at $E_{\mathrm{F}}$ that have been experimentally observed. ${ }^{44}$

Within the transition metal series, the spin-up contribution from the $B$-type atoms of the OQAs is progressively shifted away from the Fermi energy, from $\mathrm{Ti}$ to $\mathrm{Ni}$, in agreement with the filling of d-states and the magnetic properties of the oxide layer. By combining the previous trends with the variations induced by the different substrates, we can obtain insight into the MeOQA interactions. The decreasing work function from Pt to Pd $\left(W_{\mathrm{Pt}(111)}=5.644 \mathrm{eV} \text { and } W_{\mathrm{Pd}(111)}=5.207 \mathrm{eV}\right)^{45}$ shifts the metal Fermi energy slightly upwards. This comes in addition to the bandwidth increase from $4 \mathrm{~d}$ to $5 \mathrm{~d}$ metals. As a consequence, the overlap between the states of the oxide layer and the substrate, which is effective for $\mathrm{BaTiO}_{3}$ and $\mathrm{BaVO}_{3}$, start to be weaker from $B=\mathrm{Cr}$, in agreement with the predicted lower adhesion. This effect is stronger for $\mathrm{Me}=\mathrm{Pd}$ than for $\mathrm{Me}=\mathrm{Pt}$, in relation to the larger bandwidth of Pt compared to Pd. The situation is slightly different in the case of gold, since its d-band centre is significantly downshifted and is located considerably below the Fermi energy. Here, the weaker Me-OQA interaction is attributed to the small overlap in the region just below $E_{\mathrm{F}}\left(-2 \mathrm{eV} \leq E \leq E_{\mathrm{F}}\right)$.

The interactions between the ultra-thin films and the metallic substrates has also been analysed in terms of COHP (Crystal Orbital Hamilton Population, Figs. S22-S27) and their energyintegrated counterparts (ICOHP, Fig. 5). COHP is a partitioning of the band-structure energy in terms of orbital-pair contributions. The energy-resolved $\operatorname{COHP}(E)$ plots facilitate the identification of bonding, non bonding and anti bonding contributions, while the energy-integrated ICOHP is a useful measure of the interaction strength, i.e., the more negative is the ICOHP value, the stronger is the interaction. Fig. 5 therefore reveals that, overall, the interaction is stronger for $\mathrm{Me}-\mathrm{O}$ bonds than for $\mathrm{Me}-B$ ones. In addition, the trends in the $3 \mathrm{~d}$ series differs for the two bond types. When the atomic number of the $B$-species increases, the Me- $B$ bonds gradually weakens, in agreement with a smaller orbital overlap consistent with the smaller radii of the $B$-type elements. In contrast, the Me-O bonds get stronger in the series, in agreement with the shorter Me-O bonds, on average, over the series. Overall, substrate-oxide interactions are weaker on Au than on Pt, in agreement with the lower adhesion energy calculated on $\mathrm{Au}$ than on Pt. In summary, the bonding picture at the OQAsubstrate interface is complex, and likely results from the balance between in-plane and out-of-plane interactions (Fig. S30).

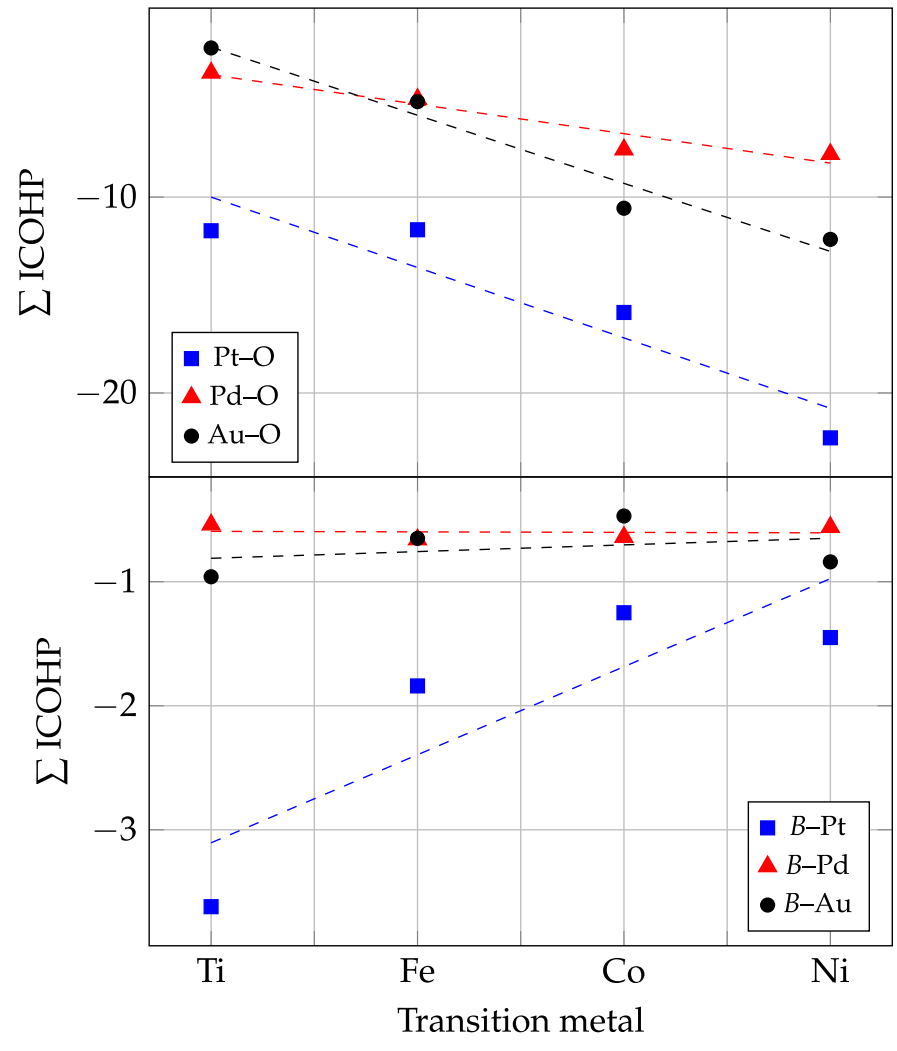

Fig. 5 Interaction between the OQA layer and the metallic substrate analysed with the ICOHP. The sum of ICOHPs ( $\sum$ ICOHP) for Me- $B$ and Me-O bonds is plotted for several $\mathrm{BaBO}_{3} / \mathrm{Me}$ systems with $B \in\{\mathrm{Ti}, \mathrm{Fe}$, $\mathrm{Co}, \mathrm{Ni}\}$ and $\mathrm{Me} \in\{\mathrm{Pt}, \mathrm{Pd}, \mathrm{Au}\}$. The sum of ICOHPs covers all bonds of a given type, with a bond length $\left(R_{i j}\right)$ smaller than $4 \AA$ : $\sum \mathrm{ICOHP}=$ $\sum_{R_{i j}<4} \operatorname{ICOHP}\left(R_{i j}\right)$.

\section{Work functions and magnetic properties}

The knowledge of materials work functions provides an absolute electron energy-level reference relative to the vacuum energy, which is important for device applications. Due to their low work functions, perovskites - especially $\mathrm{SrVO}_{3}$ - have already been identified as promising materials for new electron emission cathodes. ${ }^{46}$ DFT calculations show a decrease of the $A B \mathrm{O}_{3} / \mathrm{Me}$ work function in comparison to the bare metallic surface. The 
change of the work function $\left(\Delta W=W_{\mathrm{OQA} / \mathrm{Me}}-W_{\mathrm{Me}}\right.$, Fig. 6 and Tabs. S5-S7) is about $2 \mathrm{eV}$. It is impacted by the nature of $A$, in agreement with what has been reported for the adsorption of alkali metal atoms deposited on ultra-thin oxide films. ${ }^{47}$ The work functions are strongly correlated to the electronic surface dipoles. The latter are non negligible in all investigated systems and both the rumpling and the charge transfer contribute to their values. ${ }^{38}$

Perovskites are also well-known for the remarkable variety of magnetic properties. Magnetism persists down to the single-layer limit (Fig. 7, Tab. S11). Magnetic properties of the films are induced by the shift between the majority and minority spin states that occurs for all OQA except those with $B \in\{\mathrm{Ti}, \mathrm{V}\}$. This is further confirmed by the magnetic moments calculated on $B$-type atoms $(B \notin\{\mathrm{Ti}, \mathrm{V}\})$, which show a great diversity of magnetic coupling, attributed both to electronic effects (number of electrons) and geometric effects (rumpling and interatomic distance between the cations). Focusing on the $\mathrm{BaFeO}_{3} \mathrm{OQA}$, a magnetic moment of $3.3 \mu_{\mathrm{B}}$ per Fe atom has been calculated, in good agreement with the literature $\left(3.3 \mu_{\mathrm{B}}\right.$ per $\mathrm{Fe}$ atom $\left.{ }^{44}\right)$. It is slightly smaller than for the SHS system (3.63 $\mu_{\mathrm{B}}$ per Fe atom). A polarisation of the $\mathrm{O}$ - and Pt-atoms in the vicinity is also noticeable, similarly to what has been pointed by Ref. 44 .

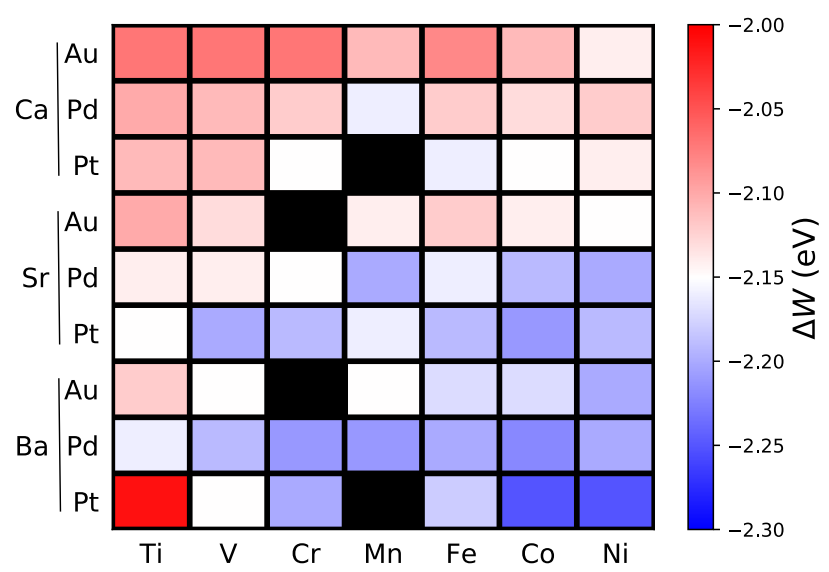

Fig. 6 Work function change $\left(\Delta W=W_{\mathrm{OQA} / \mathrm{Me}}-W_{\mathrm{Me}}\right)$ of the OQAs supported on Pt, Pd and Au. Black rectangles are missing data.

\section{Conclusion}

In this study, more than $80 A B O_{3} /$ Me materials ( $A \equiv$ alkali earth metal, $B \equiv$ transition metal, Me $\equiv$ metal substrate) have been computationally explored. The relative stability of aperiodic oxide ultra-thin films, described with the approximant models, have been assessed against periodic atomic arrangement with similar compositions, and insights have been given to understand how the OQA chemistry influences their atomic structures and properties.

The rumpling of the oxide film, the interfacial electron transfer and the adhesion energies display general trends within the series. Magnetic properties are influenced by the nature of the substrate and the $B$-metal, whereas the type of earth alkaline metal $A$

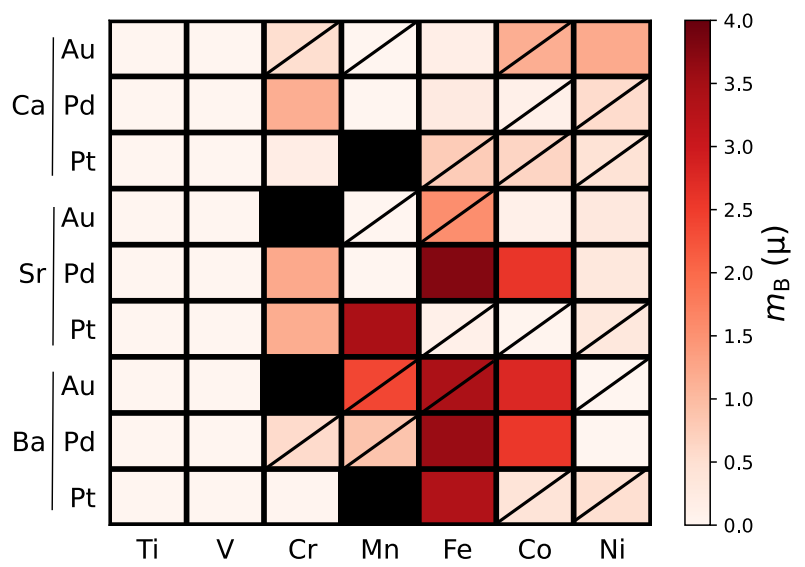

Fig. $7 B$-element average magnetic moment calculated for several $\mathrm{OQA} / \mathrm{Me}$ systems. The crossed squares indicate an anti-ferromagnetic ordering. Black rectangles are missing data.

impacts $\Delta W$, i.e. the change in the metallic substrate work function induced by the deposition of the oxide film.

Notably, no clear correlation was found between the surface cell mismatch and the rumpling or the adhesion energies (Figs. S12, S15-S17) although size-mismatch is generally believed to be the main driving force towards the formation of ultra-thin oxide layers on metals, including OQAs. In contrast, electronic effects were identified as important parameters that influence the formation of OQAs. In particular, the rumpling and the adhesive energies roughly correlate with the charge transfer, determined through the charge on the $B$-type metal.

Up to now, experimentalists have mainly focused on $\mathrm{BaTiO}_{3} / \mathrm{Pt}$ and $\mathrm{SrTiO}_{3} / \mathrm{Pt}$, because of the small size mismatch with Pt. This strategy accounts for the formation at an initial stage of a thick perovskite film on the metallic substrate. However, since electronic effects are predicted to play a key role over size-mismatch, we strongly believe that many complex 2D oxide quasiperiodic or approximant systems remain to be discovered.

\section{Computational Methods}

All calculations were performed with Density Functional Theory (DFT) using the Vienna ab initio simulation package (VASP) ${ }^{48-50}$ combined with the Atomic Simulation Environment (ASE). ${ }^{51}$ Spin-polarised calculations were performed with plane-wave basis set and projector-augmented wave (PAW) method, ${ }^{52,53}$ using the optPBE functional. ${ }^{54,55}$ The following electrons were treated explicitly: $5 s^{2} 5 p^{6} 6 s^{2}$ (Ba), $4 s^{2} 4 p^{6} 5 s^{2}$ (Sr), $3 s^{2} 3 p^{6} 4 s^{2}$ (Ca), $2 s^{2} 2 p^{4}$ (O), $3 s^{2} 3 p^{6} 4 s^{2} 3 d^{4}$ (Ti), $3 p^{6} 3 d^{4} 4 s^{1}$ (V), $3 p^{6} 3 d^{5} 4 s^{1}$ (Cr), $3 p^{6} 4 s^{2} 3 d^{7}$ (Mn), $3 d^{7} 4 s^{1}$ (Fe), $3 d^{8} 4 s^{1}$ (Co), $3 d^{9} 4 s^{1}$ (Ni), $5 d^{9} 6 s^{1}$ (Pt), $4 s^{1} 3 d^{9}$ (Pd), $4 s^{1} 3 d^{10}(\mathrm{Au})$. The strong on-site Coulomb interaction of localised electrons was treated through the GGA $+U$ approach, 56 using the values for $U$ from the literature: ${ }^{57,58} 1.0 \mathrm{eV}$ (Ti), $1.7 \mathrm{eV}$ (V), $3.0 \mathrm{eV}$ (Cr, Fe), $4.3 \mathrm{eV}$ (Mn, Co, Ni). These values differ from those of the bulk oxides, ${ }^{59}$ but give very convergent descriptions of the electronic structure of both freestanding and supported honeycomb layers, according to a comparison with the re- 
sults obtained using the hybrid HSE03 exchange-correlation functional. ${ }^{38,57}$ The one-electron Kohn-Sham orbitals were expanded in a plane-wave basis set with a kinetic energy cutoff of $500 \mathrm{eV}$. Total energies were minimised until the energy differences were less than $10^{-5} \mathrm{eV}$ between two electronic cycles. The reciprocal space integration was approximated with a Monkhorst-Pack k-point grid of $3 \times 3 \times 1$ and $6 \times 6 \times 1$ (surface cell $14.107 \AA \times 14.660$ $\AA$ ) for the structural relaxations and the density of state calculations for the approximant structures, respectively. For the cubic perovskites and honeycomb slabs we used a $8 \times 4 \times 1$ (surface cell $5.643 \AA \times 9.760 \AA$ ) respectively, and $8 \times 8 \times 1$ (surface cell $5.643 \AA$ $\times 5.643 \AA$ ) for the hexagonal perovskite slabs.

The $A B O_{3} / \mathrm{Me}(111)$ systems have been built using 5-layer thick asymmetric slabs consisting of four Me(111) layers and one oxide-layer with the approximant structure shown in Fig. 1 and detailed in Ref. 14. Adjacent slabs (along the surface normal direction) were separated by $20 \AA$ of vacuum and a dipole correction was applied to cancel an artificial electric field that develops due to imposed periodic boundary conditions in surface normal direction. All atomic positions, with the exception of the bottom layer of Me, were relaxed using the Conjugate Gradient Algorithm until all forces were less than $0.05 \mathrm{eV} / \AA^{2}$ (Pt and Pd substrates) and $0.1 \mathrm{eV} / \AA^{2}$ (Au substrate). This set-up gives cohesive energies and lattice parameters of bulk systems in good agreement with the experimental data (Tab. S9-S10).

\section{Conflicts of interest}

There are no conflicts to declare.

\section{Acknowledgements}

T.T.D. acknowledges the French PIA project "Lorraine Université d'Excellence" (ANR-15-IDEX-04-LUE) for financial support. The authors thank Vincent Fournée, Julian Ledieu and Muriel Sicot for fruitful discussions. This work is supported by the European Integrated Center for the Development of New Metallic Alloys and Compounds. E.G. acknowledge financial support through the COMETE project (COnception in silico de Matériaux pour l'EnvironnemenT et l'Énergie) co-funded by the European Union under the program FEDER-FSE Lorraine et Massif des Vosges 2014-2020. This work was granted access to the HPC resources of TGCC, CINES and IDRIS under the allocation 99642 attributed by GENCI (Grand Equipement National de Calcul Intensif). High Performance Computing resources were also partially provided by the EXPLOR centre hosted by the University de Lorraine (project 2017M4XXX0108).

\section{References}

1 W. Li, R. Jacobs and D. Morgan, Comp. Mater. Sci., 2018, 150, 454-463.

2 C. Heard, J. Cejka, M. Opanasenko, P. Nachtigall, G. Centi and S. Perathoner, Adv. Mater., 2019, 31, 1801712.

3 D. Ji, S. Cai, T. R. Paudel, H. Sun, C. Zhang, L. Han, Y. Wei, Y. Zang, M. Gu, Y. Zhang, W. Gao, H. Huyan, W. Guo, D. Wu, Z. Gu, E. Y. Tsymbal, P. Wang, Y. Nie and X. Pan, Nature, 2019, 570, 87-90.
4 S. Li, Y. Zhang, W. Yang, H. Liu and X. Fang, Adv. Mater, 2020, 32, 1905443.

5 T. Tybell, P. Paruch, T. Giamarchi and J.-M. Triscone, Phys. Rev. Lett., 2002, 89, 097601.

6 G. Barcaro and A. Fortunelli, Phys. Chem. Chem. Phys., 2019, 21, 11510.

7 Oxide Ultrathin Films: Science and Technology, ed. G. Pacchioni and S. Valeri, John Wiley \& Sons, Weinheim, Germany, 2012.

8 C. Tan, X. Cao, X.-J. Wu, Q. He, J. Yang, X. Zhang, J. Chen, W. Zhao, S. Han, G.-H. Nam, M. Sindoro and H. Zhang, Chem. Rev., 2017, 117, 6225-6331.

9 F. Sedona, G. A. Rizzi, S. Agnoli, F. X. L. i Xamena, A. Papageorgiou, D. Ostermann, M. Sambi, P. Finetti, K. Schierbaum and G. Granozzi, J. Phys. Chem. B, 2005, 109, 24411-24426.

10 F. Li, G. Parteder, F. Allegretti, C. Franchini, R. Podloucky, S. Surnev and F. P. Netzer, J. Phys.: Condens. Matter, 2009, 21, 134008.

11 S. Surnev, G. Kresse, M. G. Ramsey and F. P. Netzer, Phys. Rev. Lett., 2001, 87, 086102.

12 G. Kresse, S. Surnev, M. Ramsey and F. Netzer, Surf. Sci., 2001, 329, 329-344.

13 S. Förster, K. Meinel, R. Hammer, M. Trautmann and W. Widdra, Nature, 2013, 502, 216-218.

14 S. Förster, M. Trautmann, S. Roy, W. Adeagbo, E. Zollner, R. Hammer, F. Schumann, K. Meinel, S. Nayak, K. Mohseni, W. Hergert, H. Meyerhei and W. Widdra, Phys. Rev. Lett., 2016, 117, 095501.

15 S. Förster, J. Flege, E. Zollner, F. Schumann, R. Hammer, A. Bayat, K.-M. Schindler, K.-M. Falta and W. Widdra, Ann. Phys., 2017, 529, 1600250.

16 S. Schenk, S. Förster, K. Meinel, R. Hammer, B. Leibundgut, M. Paleschke, J. Pantzer, C. Dresler, F. O. Schumann and W. Widdra, J. Phys. Condens. Matter, 2017, 29, 134002.

17 M. Engel, P. F. Damasceno, C. L. Phillips and S. C. Glotzer, Nat. Mater., 2015, 14, 109-116.

18 W. Steurer, Acta Crystallogr. Sect. A : Found. Crystallogr., 2018, 74, 1-11.

19 C. Janot, Quasicrystals, A Primer, Oxford Science Publications, Oxford, 1992, p. 187.

20 H. R. Sharma, K. Nozawa, J. A. Smerdon, P. J. Nugent, I. McLeod, V. R. Dhanak, M. Shimoda, Y. Ishii, A. P. Tsai and R. McGrath, Nat. Commun., 2013, 4, 2715.

21 J. Smerdon, L. Leung, J. Parle, C. Jenks, R. McGrath, V. Fournée and J. Ledieu, Surf. Sci., 2008, 602, 2496 - 2501.

22 J. Ledieu, M. Krajčí, J. Hafner, L. Leung, L. Wearing, R. McGrath, T. Lograsso, D. Wu and V. Fournée, Phys. Rev. B, 2009, 79, 165430.

23 M. Paens, V. Caciuc, N. Atodiresei, M. Feuerbacher, M. Moors, R. Dunin-Borkowski, S. Blugel, R. Waser and S. Karthaüser, Nat. Comm., 2017, 8, 15367.

24 D. Écija, J. I. Urgel, A. C. Papageorgiou, S. Joshi, W. Auwärter, A. P. Seitsonen, S. Klyatskaya, M. Ruben, S. Fischer, S. Vijayaraghavan, J. Reichert and J. V. Barth, PNAS, 2013, 110, 6678-6681. 
25 L. Voigt, M. Kubus and K. S. Pedersen, Nat. Comm., 2020, 11, 4705.

26 A. R. Smith, K.-J. Chao, Q. Niu and C.-K. Shih, Science, 1996, 273, 226-228.

27 H. L. Meyerheim and F. Klimenta and A. Ernst and K. Mohseni and S. Ostanin and M. Fechner and S. Parihar and I. V. Maznichenko and I. Mertig and J. Kirschner, Phys. Rev. Lett., 2011, 106, 087203.

28 H. L. Meyerheim, A. Ernst, K. Mohseni, I. V. Maznichenko, J. Henk, S. Ostanin, N. Jedrecy, F. Klimenta, J. Zegenhagen, C. Schlueter, I. Mertig and J. Kirschner, Phys. Rev. Lett., 2013, 111, 105501.

29 E. Cockayne, M. Mihalkovic and C. L. Henley, Phys. Rev. B, 2016, 93, 020101.

30 W. A. Adeagbo, I. V. Maznichenko, H. BenHamed, I. Mertig, A. Ernst and W. Hergert, Phys. Status Solid B, 2020, 257, 1900649.

31 S. Förster and W. Widdra, in Oxide Materials at the TwoDimensional Limit, Springer, Switzerland, F. P. Netzer and A. Fortunelli edn, 2016, ch. Ultrathin Perovskites: From Bulk Structures to New Interface Concepts.

32 C. Wu, M. R. Castell, J. Goniakowski and C. Noguera, Phys. Rev. B, 2015, 91, 155424.

33 S. Wang, J. Goniakowski, C. Noguera and M. R. Castell, Phys. Rev. B, 2019, 100, 125408.

34 S. Pomp, D. Kuhness, G. Barcaro, L. Sementa, V. Mankad, A. Fortunelli, M. Sterrer, F. P. Netzer and S. Surnev, J. Phys. Chem. C, 2016, 120, 7629-7638.

35 C. Moller, H. Fedderwitz, C. Noguera, J. Goniakowski and N. Niliu, Phys.Chem.Chem.Phys., 2018, 20, 5636.

36 S. Förster and W. Widdra, Surf. Sci., 2010, 604, 2163-2169.

37 A. Kokalj, J. Mol. Graphics and Modell., 1999, 17, 176-179.

38 J. Goniakowski and C. Noguera, J. Phys. Chem. C, 2020, 124, 8186-8197.

39 X. Shao and N. Nilius and P. Myrach and H. J. Freund and U. Martinez and S. Prada and L. Giordano and G. Pacchioni, Phys. Rev. B, 2011, 83, 245407.

40 C. Noguera, Physics and Chemistry at Oxide Surfaces, Cambridge University Press, Cambridge, 2005.

41 J. Goniakowski and C. Noguera, J. Phys. Chem. C, 2019, 123, 9272-9281.
42 J. Goniakowski and C. Noguera, Phys. Rev. B, 2009, 79, 155433.

43 J. Goniakowski, C. Noguera, L. Giordano and G. Pacchioni, Phys. Rev. B, 2009, 80, 125403.

44 C.-T. Chiang and M. Ellguth and F. O. Schumann and Ch. Tusche and R. Kraska and S. Förster and W. Widdra, Phys. Rev. B, 2019, 100, 125149.

45 R. Tran, X.-G. Li, J. H. Montoya, D. Winston, K. A. Persson and S. P. Ong, Surf. Sci., 2019, 687, 48-55.

46 R. Jacobs, B. Zheng, B. Puchala, P. M. Voyles, A. B. Yankovich and D. Morgan, J. Phys. Chem. Letters, 2016, 7, 4483-4487.

47 U. Martinez, L. Giordano and G. Pacchioni, J. Chem. Phys., 2008, 128, 164707.

48 G. Kresse and J. Hafner, Phys. Rev. B, 1993, 47, 558-561.

49 G. Kresse and J. Furthmüller, Phys. Rev. B, 1996, 54, 11169 11186.

50 G. Kresse and J. Furthmüller, Comput. Mater. Sci., 1996, 6, 15-50.

51 A. H. Larsen, J. J. Mortensen, J. Blomqvist, I. E. Castelli, R. Christensen, M. Dulak, J. Friis, M. N. Groves, B. Hammer, C. Hargus, E. D. Hermes, P. C. Jennings, P. B. Jensen, J. Kermode, J. R. Kitchin, E. L. Kolsbjerg, J. Kubal, K. Kaasbjerg, S. Lysgaard, J. B. Maronsson, T. Maxson, T. Olsen, L. Pastewka, A. Peterson, C. Rostgaard, J. Schiotz, O. Schütt, M. Strange, K. S. Thygesen, T. Vegge, L. Vilhelmsen, M. Walter, Z. Zeng and K. W. Jacobsen, J. of Phys.: Condens. Matter, 2017, 29, 273002.

52 P. E. Blochl, Phys. Rev. B, 1994, 50, 17953-17979.

53 G. Kresse and D. Joubert, Phys. Rev. B, 1999, 59, 1758-1775.

54 J. Klimeš, D. R. Bowler and A. Michaelides, J. Phys.: Condens. Mat., 2010, 22, 022201.

55 J. Klimeš, D. R. Bowler and A. Michaelides, Phys. Rev. B, 2011, 83, 195131.

56 S. L. Dudarev, G. A. Botton, S. Y. Savrasov, C. J. Humphreys and A. P. Sutton, Phys. Rev. B, 1998, 57, 1505.

57 J. Goniakowski and C. Noguera, J. Phys. Chem. C, 2018, 123, 7898-7910.

58 O. Köksal, S. Baidya and R. Pentcheva, Phys. Rev. B, 2018, 97, 035126.

59 G. Barcaro, I. O. Thomas and A. Fortunelli, J. Chem. Phys., 2010, 132, 124703. 


\section{Two-dimentional oxide quasicrystal approximants}

\section{with tunable electronic and magnetic properties}

\section{Supporting information}

Thiago T. Dorini ${ }^{a, b}$, Florian Brix ${ }^{a, b}$, Corentin Chatelier ${ }^{a, b}$, Anton Kokalj $^{b, c}$, Émilie Gaudry $^{* a, b}$

\section{Structure of the OQA/Me}

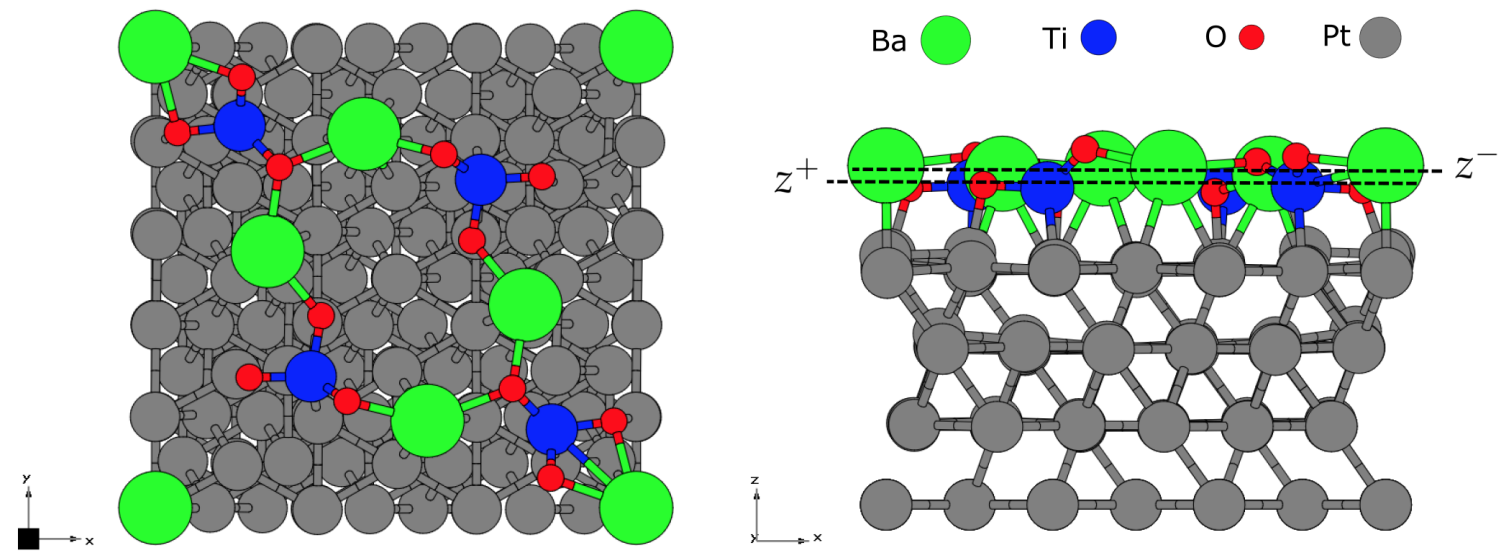

Figure S1: Top and side views of the relaxed $\mathrm{BaTiO}_{3} / \mathrm{Pt}(111)$ structure.

${ }^{a}$ Université de Lorraine, CNRS, Institut Jean Lamour - UMR 7198, F-54011, Nancy, France. Email: Emilie.Gaudry@univ-lorraine.fr

${ }^{b}$ International Associated Laboratory PACS2, CNRS Université de Lorraine, Nancy, France

c Jožef Stefan Institute, Jamova cesta 39, 1000 Ljubljana, Slovenia

${ }^{a}$ Université de Lorraine, CNRS, Institut Jean Lamour - UMR 7198, F-54011, Nancy, France. E-mail: Emilie.Gaudry@univ-lorraine.fr

${ }^{b}$ International Associated Laboratory PACS2, CNRS Université de Lorraine, Nancy, France

${ }^{c}$ Jožef Stefan Institute, Jamova cesta 39, 1000 Ljubljana, Slovenia 


\section{Formation enthalpies}

\section{Freestanding layers}

Reaction 0 ( $r 0$ ): Oxide Quasicrystal Approximant (OQA): 5/2 $\mathrm{Ba}+4 B+6 \mathrm{O}_{2} \rightarrow \mathrm{Ba}_{5} B_{4} \mathrm{O}_{12}$

Reaction 0' $\left(r^{\prime} 0\right)$ : Single-layer Oxide Honeycomb Structure (SHS) : $\mathrm{Ba}+4 B+3 \mathrm{O}_{2} \rightarrow \mathrm{Ba}_{4} \mathrm{O}_{6}$

Table S1: Formation enthalpies $(T=0 \mathrm{~K})$ of the freestanding layers.

\begin{tabular}{c|ccccc}
\hline & $\mathrm{BaTiO}_{3}$ & $\mathrm{SrTiO}_{3}$ & $\mathrm{BaFeO}_{3}$ & $\mathrm{BaCoO}_{3}$ & $\mathrm{BaNiO}_{3}$ \\
\hline & & & $\mathrm{OQA}$ & & \\
$\Delta H_{\mathrm{f}}(\mathrm{eV} /$ at. $)$ & -2.02 & -2.04 & -1.14 & -1.12 & -0.84 \\
\hline & & & $\mathrm{SHS}$ & & \\
$\Delta H_{\mathrm{f}}$ (eV/at.) & -1.05 & -1.20 & 0.00 & -0.40 & 0.38 \\
\hline
\end{tabular}

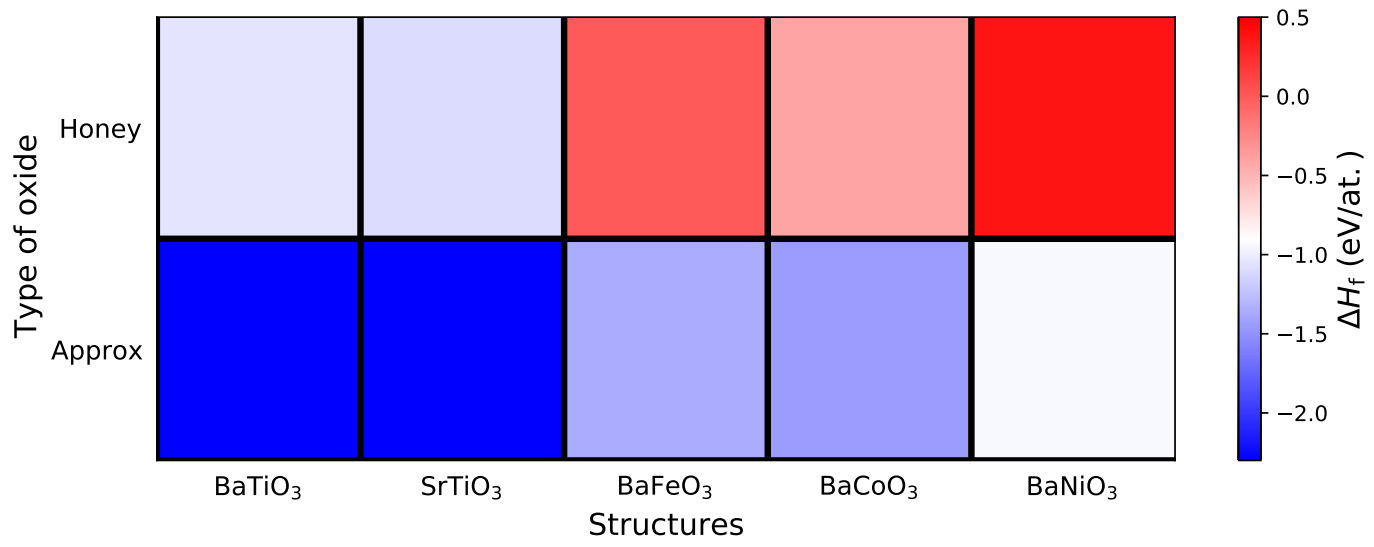

Figure S2: Formation enthalpies $(T=0 \mathrm{~K})$, according to r0 and r'0. 


\section{Supported layers}

Reaction 1 (r1): Oxide Quasicrystal Approximant (OQA): $5 \mathrm{Ba}+4 B+6 \mathrm{O}_{2}+\mathrm{Pt}_{120} \rightarrow \mathrm{Pt}_{120} \mathrm{Ba}_{5} B_{4} \mathrm{O}_{12}$

Reaction 2 (r2): Thick Perovskite Film (TPF) : 8Ba $+6 B+6 \mathrm{O}_{2}+\mathrm{Pt}_{32} \rightarrow \mathrm{Pt}_{32} \mathrm{Ba}_{8} B_{6} \mathrm{O}_{24}$

Reaction 3 (r3): Single-layer Oxide Honeycomb Structure (SHS) : $\mathrm{Ba}+4 B+3 \mathrm{O}_{2}+\mathrm{Pt}_{32} \rightarrow \mathrm{Pt}_{32} \mathrm{Ba}_{4} \mathrm{O}_{6}$

Table S2: Formation enthalpy of the supported OQA $(T=0 \mathrm{~K})$, according to $5 \mathrm{Ba}+4 B+6 \mathrm{O}_{2}+\mathrm{Pt}_{120} \rightarrow$ $\mathrm{Pt}_{120} \mathrm{Ba}_{5} B_{4} \mathrm{O}_{12}$

\begin{tabular}{c|ccccc}
\hline & $\mathrm{BaTiO}_{3} / \mathrm{Me}$ & $\mathrm{SrTiO}_{3} / \mathrm{Me}$ & $\mathrm{BaFeO}_{3} / \mathrm{Me}$ & $\mathrm{BaCoO}_{3} / \mathrm{Me}$ & $\mathrm{BaNiO}_{3} / \mathrm{Me}$ \\
\hline & \multicolumn{5}{c}{ Pt substrate } \\
$\Delta H_{\mathrm{f}}(\mathrm{eV} /$ at. $)$ & -0.42 & -0.41 & -0.24 & -0.26 & 0.20 \\
\hline & & \multicolumn{5}{c}{ Au substrate } \\
$\Delta H_{\mathrm{f}}(\mathrm{eV} /$ at. $)$ & -0.42 & -0.42 & -0.24 & -0.24 & -0.17 \\
\hline
\end{tabular}

Table S3: Formation enthalpy of the supported TPF $(T=0 \mathrm{~K})$ according to $8 \mathrm{Ba}+6 B+6 \mathrm{O}_{2}+\mathrm{Pt}_{32} \rightarrow$ $\mathrm{Pt}_{32} \mathrm{Ba}_{8} B_{6} \mathrm{O}_{24}$

\begin{tabular}{c|ccccc}
\hline & $\mathrm{BaTiO}_{3} / \mathrm{Me}$ & $\mathrm{SrTiO}_{3} / \mathrm{Me}$ & $\mathrm{BaFeO}_{3} / \mathrm{Me}$ & $\mathrm{BaCoO}_{3} / \mathrm{Me}$ & $\mathrm{BaNiO}_{3} / \mathrm{Me}$ \\
\hline & \multicolumn{5}{c}{$\mathrm{Pt}$ substrate } \\
$\Delta H_{\text {f }}$ (eV/f.u.) & -1.52 & -1.56 & -0.94 & -0.99 & -0.79 \\
\hline & & \multicolumn{5}{c}{ Au substrate } \\
$\Delta H_{\text {f }}$ (eV/f.u.) & -1.48 & -1.50 & -0.91 & -0.92 & -0.73 \\
\hline
\end{tabular}

Table S4: Formation enthalpy of the supported SHS $(T=0 \mathrm{~K})$ according to $\mathrm{Ba}+4 B+3 \mathrm{O}_{2}+\mathrm{Pt}_{32} \rightarrow \mathrm{Pt}_{32} \mathrm{Ba}_{4} \mathrm{O}_{6}$

\begin{tabular}{c|ccccc}
\hline & $\mathrm{BaTiO}_{3} / \mathrm{Me}$ & $\mathrm{SrTiO}_{3} / \mathrm{Me}$ & $\mathrm{BaFeO}_{3} / \mathrm{Me}$ & $\mathrm{BaCoO}_{3} / \mathrm{Me}$ & $\mathrm{BaNiO}_{3} / \mathrm{Me}$ \\
\hline & \multicolumn{5}{c}{$\mathrm{Pt}$ substrate } \\
$\Delta H_{\mathrm{f}}(\mathrm{eV} /$ at. $)$ & -0.84 & -0.83 & -0.28 & -0.31 & -0.11 \\
\hline & \multicolumn{5}{c}{ Au substrate } \\
$\Delta H_{\mathrm{f}}(\mathrm{eV} /$ at. $)$ & -0.72 & -0.72 & -0.24 & -0.28 & -0.09 \\
\hline
\end{tabular}




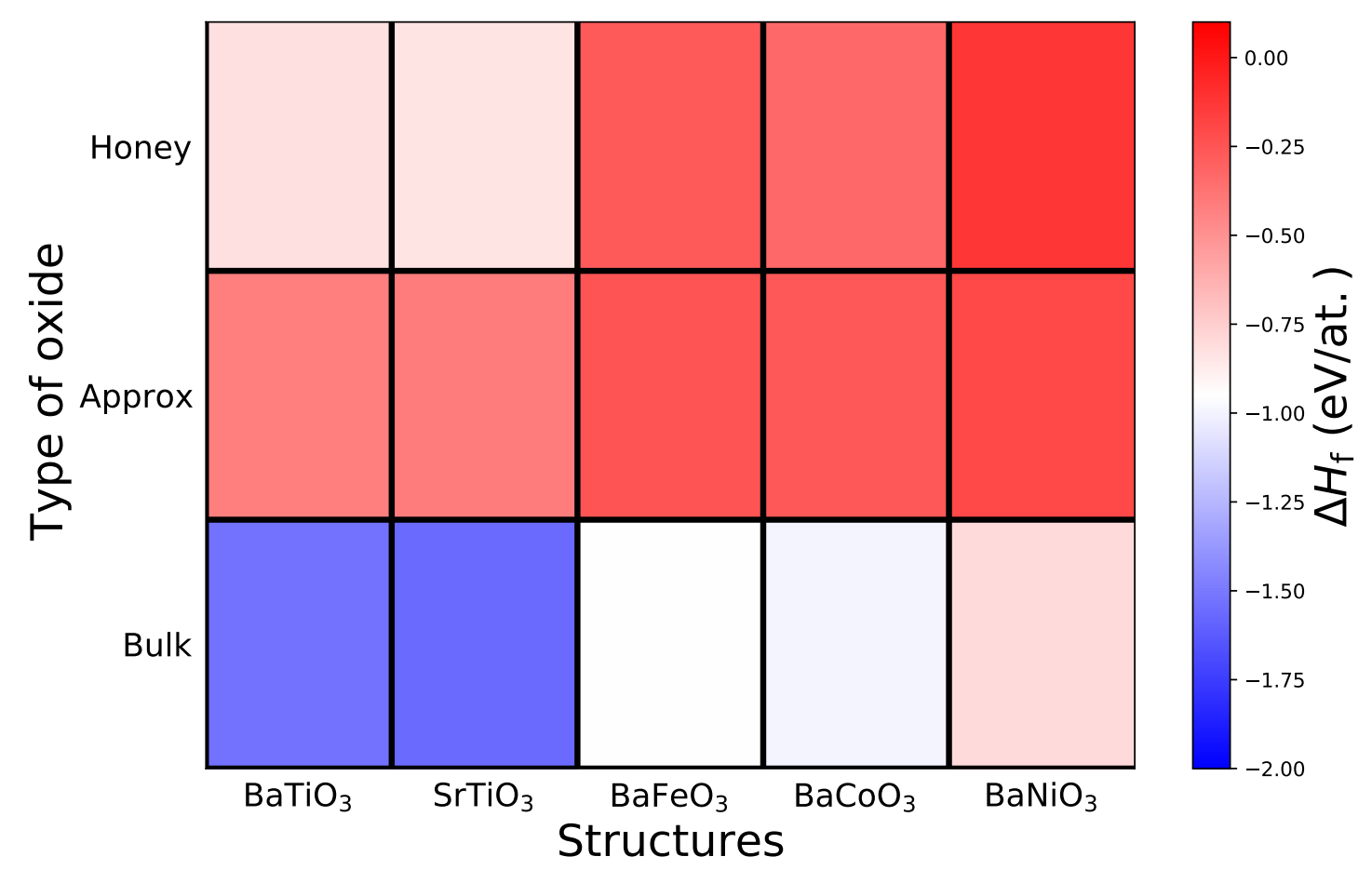

Figure S3: Formation enthalpies $(T=0 \mathrm{~K})$, according to $\mathrm{r} 1, \mathrm{r} 2, \mathrm{r} 3$ with the Pt substrate. 
Properties of OQA films 
Table S5: $\mathrm{BaBO}_{3} / \mathrm{Me}(111)$ systems $(B=\mathrm{Ti}, \mathrm{V}, \mathrm{Cr}, \mathrm{Mn}, \mathrm{Fe}, \mathrm{Co}, \mathrm{Ni}$ and $\mathrm{Me}=\mathrm{Pt}, \mathrm{Pd}, \mathrm{Au})$ : film rumplings $(R)$, Bader charges $(Q)$, enthalpies of formation at $0 \mathrm{~K}\left(\Delta H_{\mathrm{f}}\right)$, adhesion energies $\left(E_{\mathrm{adh}}\right)$, lattice mismatch, work function differences $(\Delta W)$, dipole moments in the surface normal direction $z\left(D_{z}\right)$, and atomic magnetic moments $(m)$. Bader charges are expressed in units of elementary charge (e), positive charges indicate cations. $Q_{\text {Me }}$ corresponds to the average charge of Me atoms in the topmost metal layer of $\mathrm{Me}(111) . Q_{B}$ and $m_{B}$ stand for Bader charge and magnetic moment of atom $B$ of $A B \mathrm{O}_{3}$, respectively. MS stands for the ground-state spin order $(\mathrm{NM} \equiv$ non-magnetic, FM $\equiv$ ferromagnetic, and AFM $\equiv$ anti ferromagnetic).

\begin{tabular}{|c|c|c|c|c|c|c|c|}
\hline & $\mathrm{BaTiO}_{3}$ & $\mathrm{BaVO}_{3}$ & $\mathrm{BaCrO}_{3}$ & $\mathrm{BaMnO}_{3}$ & $\mathrm{BaFeO}_{3}$ & $\mathrm{BaCoO}_{3}$ & $\mathrm{BaNiO}_{3}$ \\
\hline \multicolumn{8}{|c|}{ Freestanding layer } \\
\hline$Q_{\mathrm{Ba}}(\mathrm{e})$ & 1.58 & 1.60 & / & / & 1.63 & 1.63 & 1.63 \\
\hline$Q_{B}(\mathrm{e})$ & 1.96 & 1.39 & / & / & 1.18 & 1.13 & 1.05 \\
\hline$Q_{\mathrm{O}}(\mathrm{e})$ & -1.31 & -1.13 & / & / & -1.07 & -1.06 & -1.03 \\
\hline$m_{B}\left(\mu_{\mathrm{B}}\right)$ & 0.2 & 0.5 & / & / & 2.5 & 1.4 & 0.11 \\
\hline \multicolumn{8}{|c|}{ Pt substrate } \\
\hline$R(\AA)$ & -0.17 & -0.27 & -0.19 & / & -0.06 & 0.11 & 0.21 \\
\hline$Q_{\mathrm{Ba}}(\mathrm{e})$ & 1.54 & 1.53 & 1.50 & / & 1.52 & 1.54 & 1.51 \\
\hline$Q_{B}(\mathrm{e})$ & 1.98 & 1.71 & 1.76 & / & 1.37 & 1.16 & 0.94 \\
\hline$Q_{\mathrm{O}}(\mathrm{e})$ & -1.09 & -0.94 & -0.97 & / & -0.97 & -0.98 & -0.95 \\
\hline$Q_{\mathrm{Pt}}(\mathrm{e})$ & -0.10 & -0.12 & -0.11 & / & -0.07 & -0.03 & 0.00 \\
\hline$\Delta H_{\mathrm{f}}(\mathrm{eV})$ & -0.42 & -0.36 & -0.15 & / & -0.24 & -0.26 & -0.21 \\
\hline$E_{\mathrm{adh}}\left(\mathrm{meV} / \AA^{2}\right)$ & -81.73 & -81.56 & / & / & -50.96 & -67.53 & -50.76 \\
\hline mismatch $(\%)$ & 32.20 & 25.75 & 1 & / & 31.20 & 26.06 & 27.07 \\
\hline$\Delta W(\mathrm{eV})$ & 2.01 & 2.15 & 2.20 & / & 2.18 & 2.25 & 2.25 \\
\hline$D_{z}(e \AA)$ & -2.12 & -2.37 & -2.85 & 1 & -2.44 & -2.62 & -2.76 \\
\hline$m_{B}\left(\mu_{\mathrm{B}}\right)$ & 0.0 & 0.0 & 0.03 & / & 3.32 & 0.04 & 0.67 \\
\hline MS & NM & NM & AFM & / & FM & AFM & $\mathrm{AFM}$ \\
\hline \multicolumn{8}{|c|}{ Pd substrate } \\
\hline$R(\AA)$ & -0.11 & -0.23 & -0.18 & 0.03 & 0.07 & 0.25 & 0.31 \\
\hline$Q_{\mathrm{Ba}}(\mathrm{e})$ & 1.51 & 1.50 & 1.48 & 1.51 & 1.50 & 1.51 & 1.49 \\
\hline$Q_{B}(\mathrm{e})$ & 1.96 & 1.68 & 1.73 & 1.57 & 1.51 & 1.21 & 0.96 \\
\hline$Q_{\mathrm{O}}(\mathrm{e})$ & -1.12 & -0.95 & -0.97 & -1.04 & -0.94 & -0.98 & -0.91 \\
\hline$Q_{\mathrm{Pd}}(\mathrm{e})$ & -0.07 & -0.09 & -0.08 & -0.04 & -0.05 & -0.02 & 0.01 \\
\hline$\Delta H_{\mathrm{f}}(\mathrm{eV})$ & -0.41 & -0.35 & -0.14 & -0.23 & -0.24 & -0.26 & -0.20 \\
\hline$E_{\text {adh }}\left(\mathrm{meV} / \AA^{2}\right)$ & -78.08 & -75.99 & / & l & -50.06 & -68.46 & -55.29 \\
\hline mismatch $(\%)$ & 30.95 & 24.21 & / & / & 29.94 & 24.70 & 25.74 \\
\hline$\Delta W(\mathrm{eV})$ & 2.16 & 2.19 & 2.21 & 2.21 & 2.20 & 2.22 & 2.20 \\
\hline$D_{z}(e \AA)$ & -1.85 & -2.07 & -2.30 & -2.30 & -2.21 & -2.56 & -2.29 \\
\hline$m_{B}\left(\mu_{\mathrm{B}}\right)$ & 0.0 & 0.0 & 0.59 & 0.92 & 3.58 & 2.57 & 0.03 \\
\hline MS & $\mathrm{NM}$ & NM & $\mathrm{AFM}$ & $\mathrm{AFM}$ & $\mathrm{FM}$ & FM & AFM \\
\hline \multicolumn{8}{|c|}{ Au substrate } \\
\hline$R(\AA)$ & -0.16 & -0.36 & / & -0.03 & 0.03 & 0.17 & 0.21 \\
\hline$Q_{\mathrm{Ba}}(\mathrm{e})$ & 1.58 & 1.57 & / & 1.57 & 1.56 & 1.55 & 1.54 \\
\hline$Q_{B}(\mathrm{e})$ & 2.00 & 1.74 & / & 1.57 & 1.31 & 1.19 & 0.92 \\
\hline$Q_{\mathrm{O}}(\mathrm{e})$ & -1.14 & -0.97 & / & -1.09 & -1.03 & -1.00 & -0.99 \\
\hline$Q_{\mathrm{Au}}(\mathrm{e})$ & -0.08 & -0.11 & / & -0.07 & -0.06 & -0.04 & 0.00 \\
\hline$\Delta H_{\mathrm{f}}(\mathrm{eV})$ & -0.42 & -0.35 & 1 & -0.24 & -0.24 & -0.24 & -0.18 \\
\hline$E_{\mathrm{adh}}\left(\mathrm{meV} / \AA^{2}\right)$ & -76.72 & -68.72 & / & / & -45.03 & -49.00 & -32.54 \\
\hline mismatch (\%) & 38.22 & 32.18 & / & / & 37.32 & 32.62 & 33.55 \\
\hline$\Delta W(\mathrm{eV})$ & 2.12 & 2.15 & 1 & 2.15 & 2.17 & 2.17 & 2.20 \\
\hline$D_{z}(e \AA)$ & -1.58 & -1.94 & 1 & -1.95 & -2.25 & -2.13 & -2.46 \\
\hline$m_{B}\left(\mu_{\mathrm{B}}\right)$ & 0.0 & 0.0 & / & 1.17 & 3.40 & 2.76 & 0.05 \\
\hline MS & NM & NM & / & AFM & FM & $\mathrm{FM}$ & $\mathrm{AFM}$ \\
\hline
\end{tabular}


Table S6: $\mathrm{Sr}_{B} \mathrm{O}_{3} / \mathrm{Me}(111)$ systems $(B=\mathrm{Ti}, \mathrm{V}, \mathrm{Cr}, \mathrm{Mn}, \mathrm{Fe}, \mathrm{Co}, \mathrm{Ni}$ and $\mathrm{Me}=\mathrm{Pt}, \mathrm{Pd}, \mathrm{Au})$ : film rumplings $(R)$, Bader charges $(Q)$, enthalpies of formation at $0 \mathrm{~K}\left(\Delta H_{\mathrm{f}}\right)$, adhesion energies $\left(E_{\mathrm{adh}}\right)$, lattice mismatch, work function differences $(\Delta W)$, dipole moments in the surface normal direction $z\left(D_{z}\right)$, and atomic magnetic moments $(m)$. Bader charges are expressed in units of elementary charge (e), positive charges indicate cations. $Q_{\text {Me }}$ corresponds to the average charge of Me atoms in the topmost metal layer of $\mathrm{Me}(111) . Q_{B}$ and $m_{B}$ stand for Bader charge and magnetic moment of atom $B$ of $A B \mathrm{O}_{3}$, respectively. MS stands for the ground-state spin order $(\mathrm{NM} \equiv$ non-magnetic, FM $\equiv$ ferromagnetic, and AFM $\equiv$ anti ferromagnetic).

\begin{tabular}{|c|c|c|c|c|c|c|c|}
\hline & $\mathrm{SrTiO}_{3}$ & $\mathrm{SrVO}_{3}$ & $\mathrm{SrCrO}_{3}$ & $\mathrm{SrMnO}_{3}$ & $\mathrm{SrFeO}_{3}$ & $\mathrm{SrCoO}_{3}$ & $\mathrm{SrNiO}_{3}$ \\
\hline \multicolumn{8}{|c|}{ Freestanding layer } \\
\hline$Q_{\mathrm{Sr}}(\mathrm{e})$ & 1.60 & 1.61 & 1.63 & 1.62 & / & / & 1.61 \\
\hline$Q_{B}(\mathrm{e})$ & 1.90 & 1.44 & 1.61 & 1.60 & / & / & 1.12 \\
\hline$Q_{\mathrm{O}}(\mathrm{e})$ & -1.30 & -1.15 & -1.14 & -1.21 & / & / & -1.04 \\
\hline$m_{B}\left(\mu_{\mathrm{B}}\right)$ & 0.1 & 0.4 & 1.39 & 0.0 & / & / & 0.9 \\
\hline \multicolumn{8}{|c|}{ Pt substrate } \\
\hline$R(\AA)$ & -0.22 & -0.29 & -0.25 & -0.05 & -0.12 & -0.05 & 0.20 \\
\hline$Q_{\mathrm{Sr}}(\mathrm{e})$ & 1.56 & 1.56 & 1.54 & 1.56 & 1.57 & 1.57 & 1.57 \\
\hline$Q_{B}(\mathrm{e})$ & 1.99 & 1.71 & 1.77 & 1.55 & 1.36 & 1.25 & 0.92 \\
\hline$Q_{\mathrm{O}}(\mathrm{e})$ & -1.10 & -0.95 & -0.98 & -1.05 & -0.98 & -0.99 & -0.94 \\
\hline$Q_{\mathrm{Pt}}(\mathrm{e})$ & -0.10 & -0.12 & -0.11 & -0.06 & -0.07 & -0.05 & -0.04 \\
\hline$\Delta H_{\mathrm{f}}(\mathrm{eV})$ & -0.40 & -0.35 & -0.14 & -0.24 & -0.23 & -0.25 & 0.87 \\
\hline$E_{\mathrm{adh}}\left(\mathrm{meV} / \AA^{2}\right)$ & -75.8 & -74.74 & -50.28 & -51.8 & / & / & -49.22 \\
\hline mismatch $(\%)$ & 37.16 & 39.84 & 31.56 & 40.27 & / & / & 42.14 \\
\hline$\Delta W(\mathrm{eV})$ & 2.15 & 2.20 & 2.19 & 2.16 & 2.19 & 2.21 & 2.19 \\
\hline$D_{z}(e \AA)$ & -1.65 & -2.20 & -2.43 & -1.65 & -1.93 & -1.72 & -2.11 \\
\hline$m_{B}\left(\mu_{\mathrm{B}}\right)$ & 0.00 & 0.00 & 1.17 & 3.41 & 0.14 & 0.04 & 0.32 \\
\hline $\mathrm{MS}$ & NM & NM & FM & $\mathrm{FM}$ & AFM & $\mathrm{AFM}$ & AFM \\
\hline \multicolumn{8}{|c|}{ Pd substrate } \\
\hline$R(\AA)$ & -0.14 & -0.27 & -0.23 & 0.1 & 0.05 & 0.23 & 0.23 \\
\hline$Q_{\mathrm{Sr}}(\mathrm{e})$ & 1.56 & 1.53 & 1.56 & 1.55 & 1.53 & 1.54 & 1.54 \\
\hline$Q_{B}(\mathrm{e})$ & 1.97 & 1.69 & 1.69 & 1.54 & 1.35 & 1.20 & 1.04 \\
\hline$Q_{\mathrm{O}}(\mathrm{e})$ & -1.13 & -0.97 & -1.04 & -1.06 & -0.99 & -1.00 & -0.95 \\
\hline$Q_{\mathrm{Pd}}(\mathrm{e})$ & -0.02 & -0.10 & -0.07 & -0.05 & -0.05 & -0.03 & -0.03 \\
\hline$\Delta H_{\mathrm{f}}(\mathrm{eV})$ & -0.41 & -0.34 & -0.13 & -0.24 & -0.23 & -0.26 & -0.19 \\
\hline$E_{\text {adh }}\left(\mathrm{meV} / \AA^{2}\right)$ & -74.22 & -72.49 & -45.19 & -58.1 & / & / & -38.49 \\
\hline mismatch $(\%)$ & 36.01 & 38.74 & 30.31 & 39.18 & / & / & 41.08 \\
\hline$\Delta W(\mathrm{eV})$ & 2.14 & 2.14 & 2.15 & 2.20 & 2.16 & 2.19 & 2.20 \\
\hline$D_{z}(e \AA)$ & -1.45 & -1.61 & -1.89 & -1.30 & -2.09 & -2.16 & -2.13 \\
\hline$m_{B}\left(\mu_{\mathrm{B}}\right)$ & 0.00 & 0.00 & 1.23 & 0.00 & 3.76 & 2.59 & 0.48 \\
\hline MS & NM & NM & FM & $\mathrm{FM}$ & $\mathrm{FM}$ & FM & $\mathrm{FM}$ \\
\hline \multicolumn{8}{|c|}{$\mathrm{Au}$ substrate } \\
\hline$R(\AA)$ & -0.19 & -0.39 & / & 0.07 & -0.07 & 0.11 & 0.20 \\
\hline$Q_{\mathrm{Sr}}(\mathrm{e})$ & 1.58 & 1.57 & / & 1.57 & 1.57 & 1.57 & 1.56 \\
\hline$Q_{B}(\mathrm{e})$ & 1.99 & 1.73 & / & 1.57 & 1.34 & 1.12 & 0.95 \\
\hline$Q_{\mathrm{O}}(\mathrm{e})$ & -1.16 & -0.97 & / & -1.11 & -1.01 & -1.03 & -1.02 \\
\hline$Q_{\mathrm{Au}}(\mathrm{e})$ & -0.08 & -0.11 & / & -0.03 & -0.05 & -0.02 & 0.00 \\
\hline$\Delta H_{\mathrm{f}}(\mathrm{eV})$ & -0.42 & -0.36 & / & -0.24 & -0.22 & -0.23 & -0.18 \\
\hline$E_{\mathrm{adh}}\left(\mathrm{meV} / \AA^{2}\right)$ & -75.56 & -74.64 & / & -50.43 & / & / & -24.93 \\
\hline mismatch (\%) & 42.74 & 45.19 & / & 45.58 & / & / & 47.28 \\
\hline$\Delta W(\mathrm{eV})$ & 2.10 & 2.13 & / & 2.14 & 2.12 & 2.14 & 2.15 \\
\hline$D_{z}(e \AA)$ & -1.28 & -1.60 & / & -1.58 & -1.58 & -1.67 & -1.92 \\
\hline$m_{B}\left(\mu_{\mathrm{B}}\right)$ & 0.00 & 0.00 & / & 0.00 & 1.50 & 0.11 & 0.44 \\
\hline MS & NM & NM & / & AFM & AFM & $\mathrm{AFM}$ & FM \\
\hline
\end{tabular}


Table S7: $\mathrm{CaBO}_{3} / \mathrm{Me}(111)$ systems $(B=\mathrm{Ti}, \mathrm{V}, \mathrm{Cr}, \mathrm{Mn}, \mathrm{Fe}, \mathrm{Co}, \mathrm{Ni}$ and $\mathrm{Me}=\mathrm{Pt}, \mathrm{Pd}, \mathrm{Au})$ : film rumplings $(R)$, Bader charges $(Q)$, enthalpies of formation at $0 \mathrm{~K}\left(H_{\mathrm{for}}\right)$, adhesion energies $\left(E_{\text {madh }}\right)$, lattice mismatch, work function differences $(\Delta W)$, dipole moments in the $z$ direction $\left(D_{z}\right)$, and atomic magnetic moments $(m)$. Bader charges are expressed in units of elementary charge (e), positive charges indicate cations. $Q_{\mathrm{Me}}$ corresponds to the average charge of Me atoms in the topmost metal layer of $\mathrm{Me}(111) . Q_{B}$ and $m_{B}$ stands for Bade charge and magnetic moment of atom $B$ of $A B \mathrm{O}_{3}$. MS stands for the ground-state spin order

\begin{tabular}{|c|c|c|c|c|c|c|c|}
\hline & $\mathrm{CaTiO}_{3}$ & $\mathrm{CaVO}_{3}$ & $\mathrm{CaCrO}_{3}$ & $\mathrm{CaMnO}_{3}$ & $\mathrm{CaFeO}_{3}$ & $\mathrm{CaCoO}_{3}$ & $\mathrm{CaNiO}_{3}$ \\
\hline \multicolumn{8}{|c|}{ Freestanding layer } \\
\hline$Q_{\mathrm{Ca}}(\mathrm{e})$ & 1.55 & / & / & 1.57 & / & 1.58 & / \\
\hline$Q_{B}(\mathrm{e})$ & 1.94 & / & / & 1.64 & / & 1.32 & / \\
\hline$Q_{\mathrm{O}}(\mathrm{e})$ & -1.29 & / & / & -1.20 & / & -1.10 & / \\
\hline$m_{B}\left(\mu_{\mathrm{B}}\right)$ & 0.3 & / & / & 0.0 & / & 2.3 & / \\
\hline \multicolumn{8}{|c|}{ Pt substrate } \\
\hline$R(\AA)$ & -0.24 & -0.35 & -0.31 & / & -0.04 & 0.07 & 0.14 \\
\hline$Q_{\mathrm{Ca}}(\mathrm{e})$ & 1.53 & 1.53 & 1.51 & / & 1.54 & 1.54 & 1.54 \\
\hline$Q_{B}(\mathrm{e})$ & 2.01 & 1.73 & 1.78 & / & 1.40 & 1.25 & 1.05 \\
\hline$Q_{\mathrm{O}}(\mathrm{e})$ & -1.10 & -0.94 & -0.97 & / & -0.98 & -0.98 & -0.93 \\
\hline$Q_{\mathrm{Pt}}(\mathrm{e})$ & -0.09 & -0.12 & 0.11 & / & -0.06 & -0.05 & -0.04 \\
\hline$\Delta H_{\mathrm{f}}(\mathrm{eV})$ & -0.40 & -0.34 & -0.13 & / & -0.23 & -0.25 & -0.19 \\
\hline$E_{\mathrm{adh}}\left(\mathrm{meV} / \AA^{2}\right)$ & -78.59 & / & / & / & / & -61.11 & / \\
\hline mismatch (\%) & 43.55 & / & / & / & / & 45.49 & / \\
\hline$\Delta W(\mathrm{eV})$ & 2.11 & 2.11 & 2.15 & / & 2.16 & 2.15 & 2.14 \\
\hline$D_{z}(e \AA)$ & -1.25 & -1.62 & -1.82 & / & -1.90 & -1.83 & -1.68 \\
\hline$m_{B}\left(\mu_{\mathrm{B}}\right)$ & 0.0 & 0.0 & 1.55 & / & 0.22 & 0.11 & 1.44 \\
\hline MS & NM & NM & FM & / & AFM & AFM & FM \\
\hline \multicolumn{8}{|c|}{ Pd substrate } \\
\hline$R(\AA)$ & -0.17 & -0.30 & -0.32 & 0.07 & -0.02 & 0.07 & 0.29 \\
\hline$Q_{\mathrm{Ca}}(\mathrm{e})$ & 1.53 & 1.49 & 1.49 & 1.53 & 1.50 & 1.51 & 1.51 \\
\hline$Q_{B}(\mathrm{e})$ & 1.98 & 1.70 & 1.72 & 1.54 & 1.36 & 1.25 & 1.01 \\
\hline$Q_{\mathrm{O}}(\mathrm{e})$ & -1.13 & -0.97 & -0.99 & -1.06 & -1.00 & -1.02 & -0.95 \\
\hline$Q_{\mathrm{Pd}}(\mathrm{e})$ & -0.07 & -0.09 & -0.08 & -0.02 & -0.04 & -0.03 & -0.02 \\
\hline$\Delta H_{\mathrm{f}}(\mathrm{eV})$ & -0.40 & -0.34 & -0.14 & -0.24 & -0.23 & -0.24 & -0.20 \\
\hline$E_{\text {adh }}\left(\mathrm{meV} / \AA^{2}\right)$ & -81.14 & / & / & / & / & -64.81 & / \\
\hline mismatch (\%) & 42.51 & / & / & / & / & 44.49 & / \\
\hline$\Delta W(\mathrm{eV})$ & 2.10 & 2.11 & 2.12 & 2.16 & 2.12 & 2.13 & 2.12 \\
\hline$D_{z}(e \AA)$ & -1.00 & -1.13 & -1.06 & -0.89 & -1.26 & -1.37 & -1.35 \\
\hline$m_{B}\left(\mu_{\mathrm{B}}\right)$ & 0.00 & 0.00 & 1.14 & 0.00 & 0.26 & 0.12 & 1.45 \\
\hline MS & NM & NM & FM & FM & AFM & AFM & $\mathrm{AFM}$ \\
\hline \multicolumn{8}{|c|}{ Au substrate } \\
\hline$R(\AA)$ & -0.16 & -0.40 & -0.36 & 0.06 & 0.04 & 0.14 & 0.23 \\
\hline$Q_{\mathrm{Ca}}(\mathrm{e})$ & 1.55 & 1.54 & 1.53 & 1.55 & 1.54 & 1.54 & 1.53 \\
\hline$Q_{B}(\mathrm{e})$ & 2.03 & 1.75 & 1.80 & 1.59 & 1.38 & 1.15 & 1.02 \\
\hline$Q_{\mathrm{O}}(\mathrm{e})$ & -1.16 & -0.96 & -1.02 & -1.07 & -1.05 & -1.06 & -1.00 \\
\hline$Q_{\mathrm{Au}}(\mathrm{e})$ & -0.08 & -0.11 & -0.09 & -0.04 & -0.03 & 0.00 & 0.00 \\
\hline$\Delta H_{\mathrm{f}}(\mathrm{eV})$ & -0.40 & -0.34 & -0.12 & -0.25 & -0.23 & -0.23 & -0.18 \\
\hline$E_{\text {adh }}\left(\mathrm{meV} / \AA^{2}\right)$ & -68.16 & / & / & -61.77 & / & -41.80 & / \\
\hline mismatch (\%) & 48.56 & / & / & 47.51 & / & 50.33 & / \\
\hline$\Delta W(\mathrm{eV})$ & 2.07 & 2.07 & 2.07 & 2.11 & 2.08 & 2.11 & 2.14 \\
\hline$D_{z}(e \AA)$ & -0.93 & -1.03 & -0.92 & -0.73 & -1.11 & -1.39 & -1.68 \\
\hline$m_{B}\left(\mu_{\mathrm{B}}\right)$ & 0.00 & 0.00 & 0.65 & 0.00 & 0.17 & 1.33 & 1.24 \\
\hline MS & NM & NM & AFM & AFM & AFM & AFM & FM \\
\hline
\end{tabular}


Gibbs free energies 
(a) $\mathrm{BaTiO}_{3} / \mathrm{Pt}(111)$

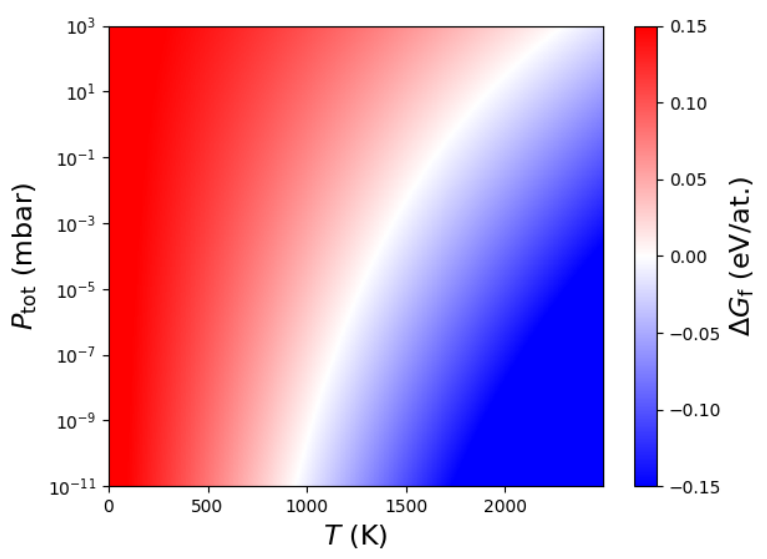

(c) $\mathrm{SrTiO}_{3} / \mathrm{Pt}(111)$

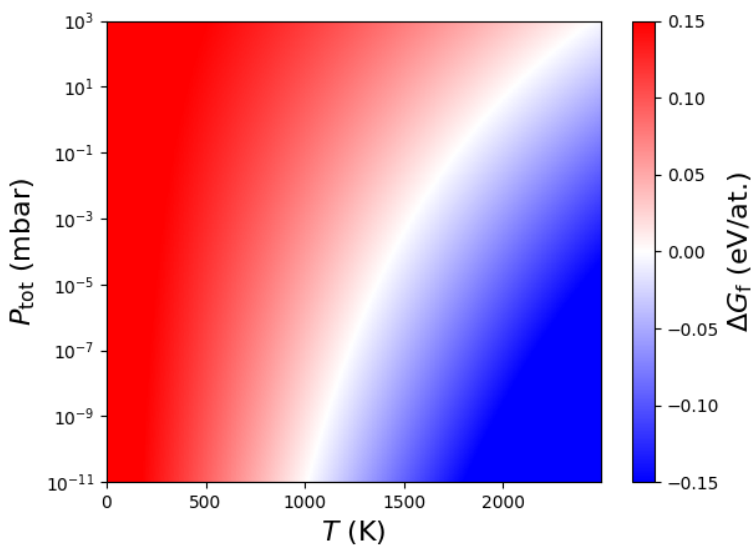

(e) $\mathrm{BaFeO}_{3} / \mathrm{Pt}(111)$

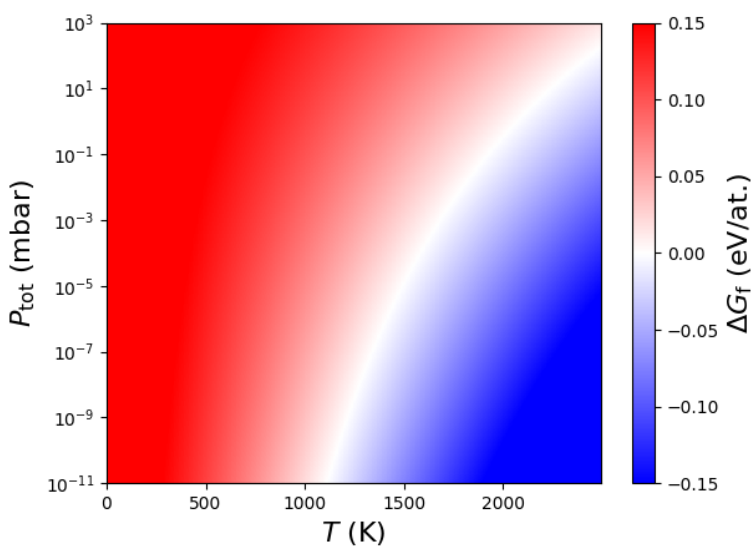

(b) $\mathrm{BaTiO}_{3} / \mathrm{Au}(111)$

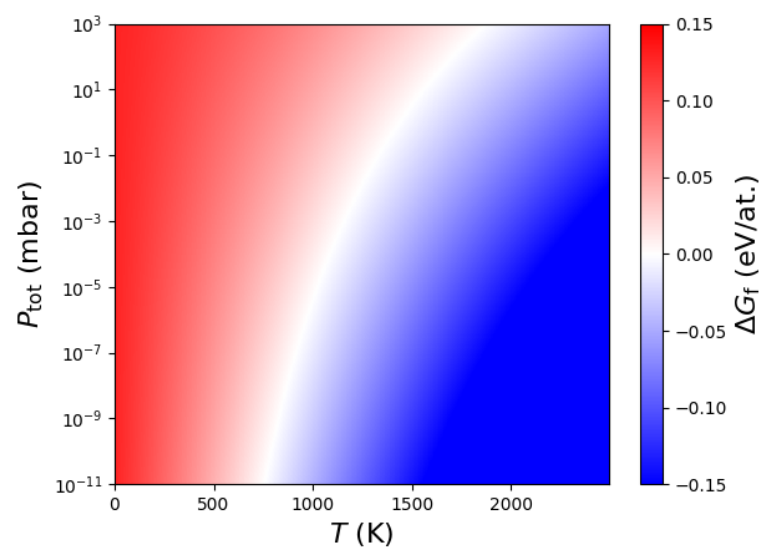

(d) $\mathrm{SrTiO}_{3} / \mathrm{Au}(111)$

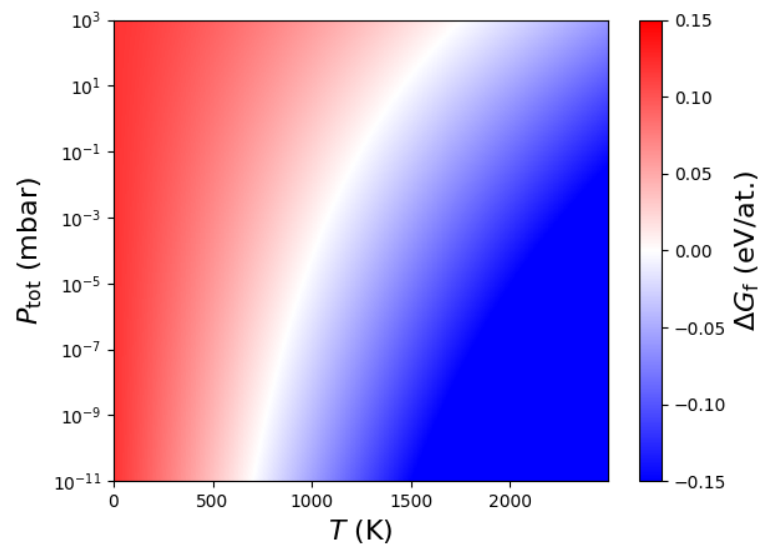

(f) $\mathrm{BaFeO}_{3} / \mathrm{Au}(111)$

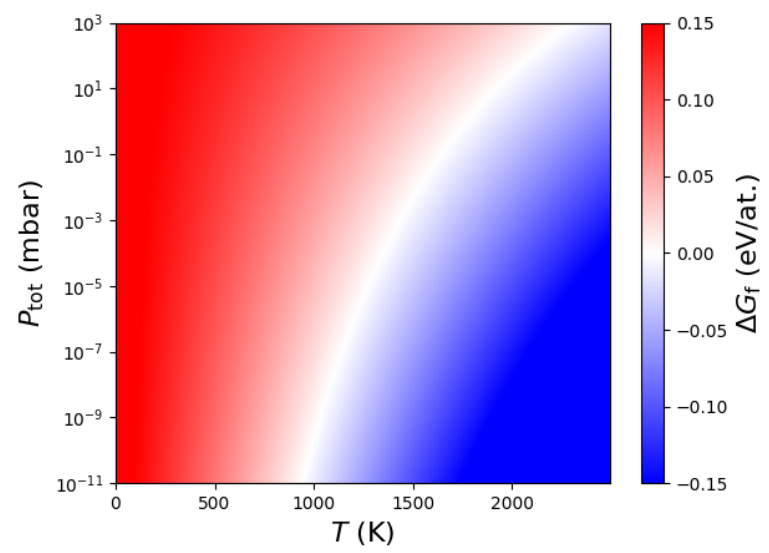

Figure S4: Gibbs free energy of the following reaction : $15 \mathrm{Pt}_{32} \mathrm{Ba}_{8} B_{6} \mathrm{O}_{24} \rightarrow 4 \mathrm{Pt}_{120} \mathrm{Ba}_{5} B_{4} \mathrm{O}_{12}+74 \mathrm{Ba}_{3} \mathrm{O}_{3}+45$ $\mathrm{O}_{2}+26 \mathrm{Ba}$. The thick $A B \mathrm{O}_{3}$ film is more stable than the OQA in the red region. The OQA is more stable than the thick $A B \mathrm{O}_{3}$ film in the blue region. 
(a) $\mathrm{BaCoO}_{3} / \mathrm{Pt}(111)$

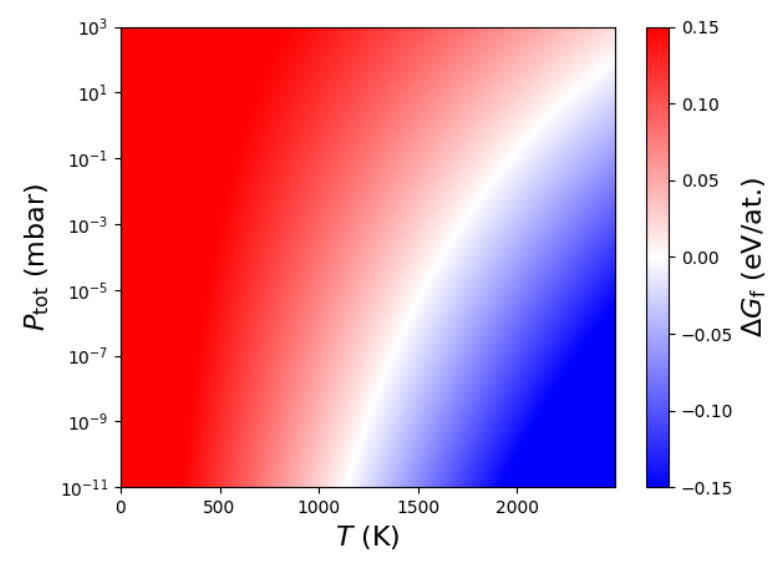

(c) $\mathrm{BaNiO}_{3} / \mathrm{Pt}(111)$

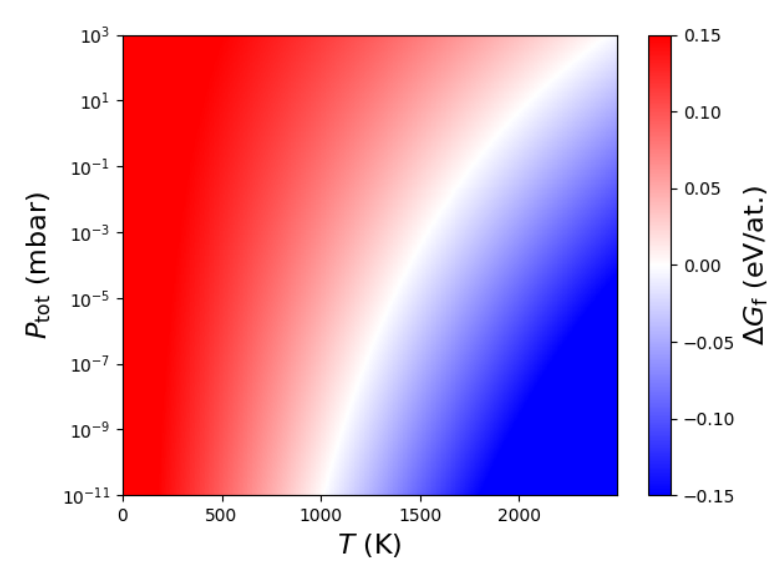

(b) $\mathrm{BaCoO}_{3} / \mathrm{Au}(111)$

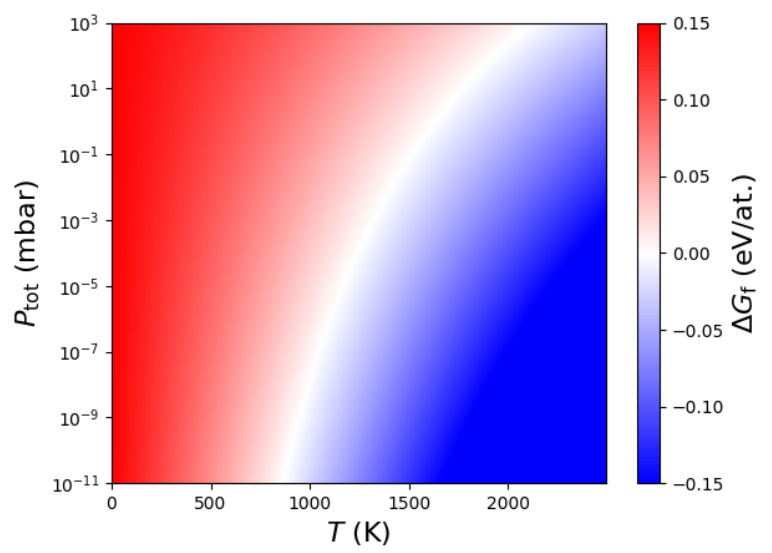

(d) $\mathrm{BaNiO}_{3} / \mathrm{Au}(111)$

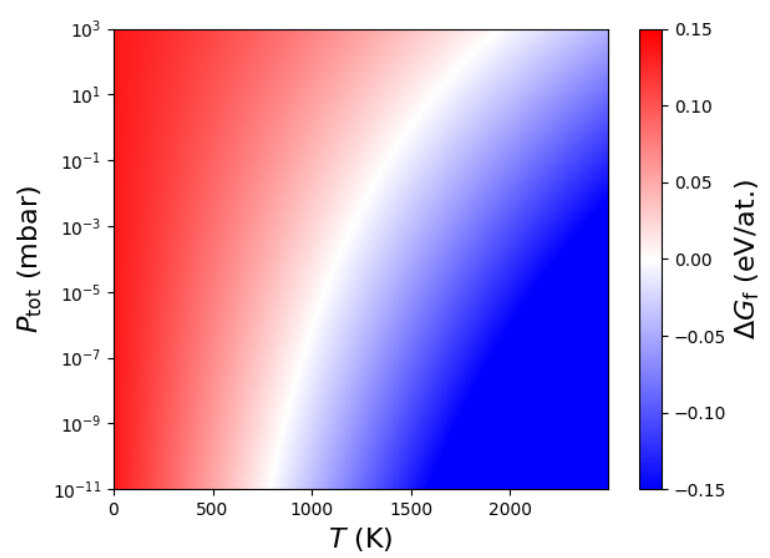

Figure S5: Gibbs free energy of the following reaction : $15 \mathrm{Pt}_{32} \mathrm{Ba}_{8} B_{6} \mathrm{O}_{24} \rightarrow 4 \mathrm{Pt}_{120} \mathrm{Ba}_{5} B_{4} \mathrm{O}_{12}+74 \mathrm{BaBO}_{3}+45$ $\mathrm{O}_{2}+26 \mathrm{Ba}$. The thick $A B \mathrm{O}_{3}$ film is more stable than the OQA in the red region. The OQA is more stable than the thick $A B \mathrm{O}_{3}$ film in the blue region. 


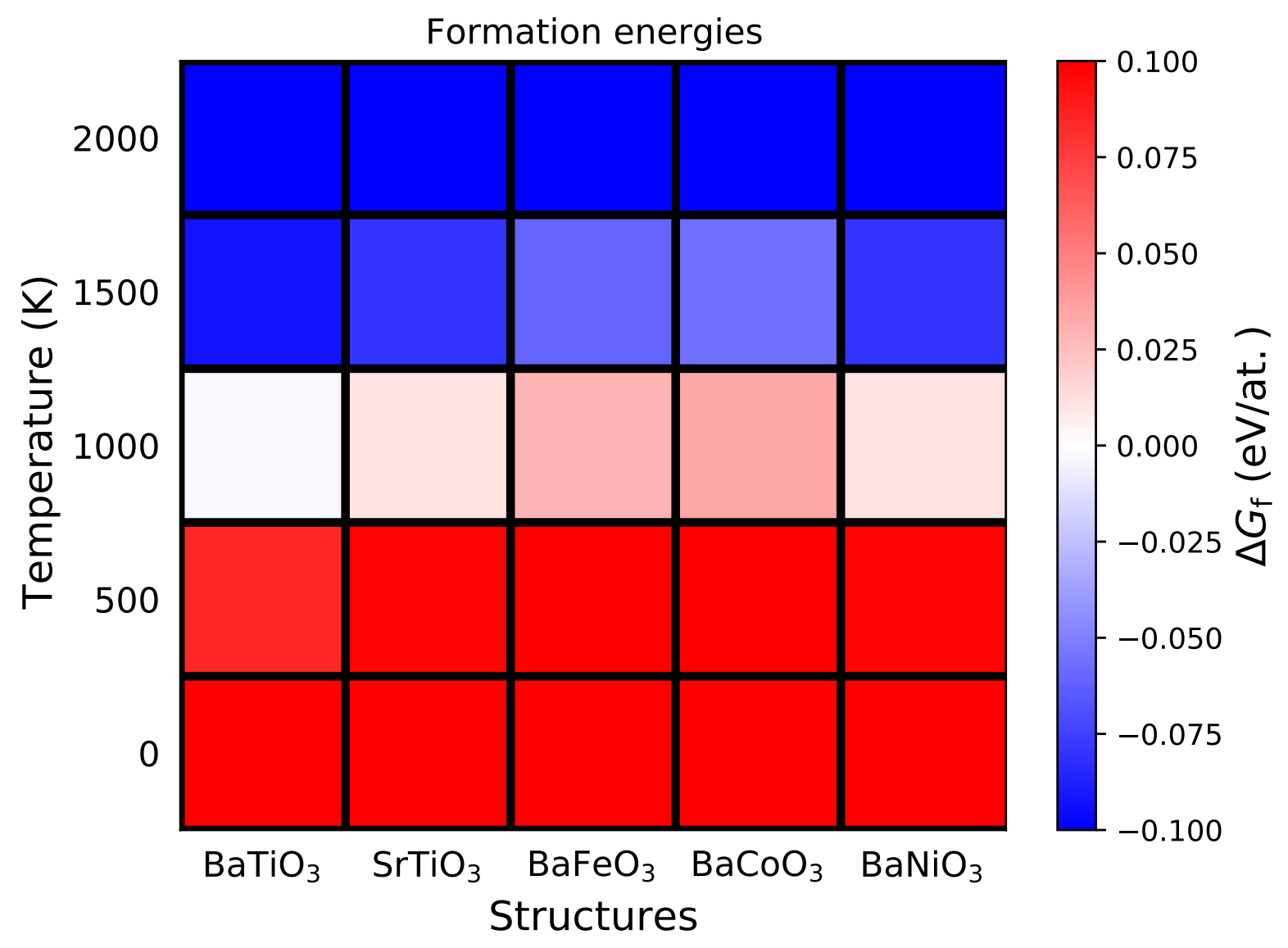

Figure S6: Gibbs free energy corresponding to the following reaction : $15 \mathrm{Pt}_{32} \mathrm{Ba}_{8} B_{6} \mathrm{O}_{24} \rightarrow 4 \mathrm{Pt}_{120} \mathrm{Ba}_{5} B_{4} \mathrm{O}_{12}+74$ $\mathrm{BaBO}_{3}+45 \mathrm{O}_{2}+26 \mathrm{Ba}\left(P=10^{-10}\right.$ mbar $)$. 


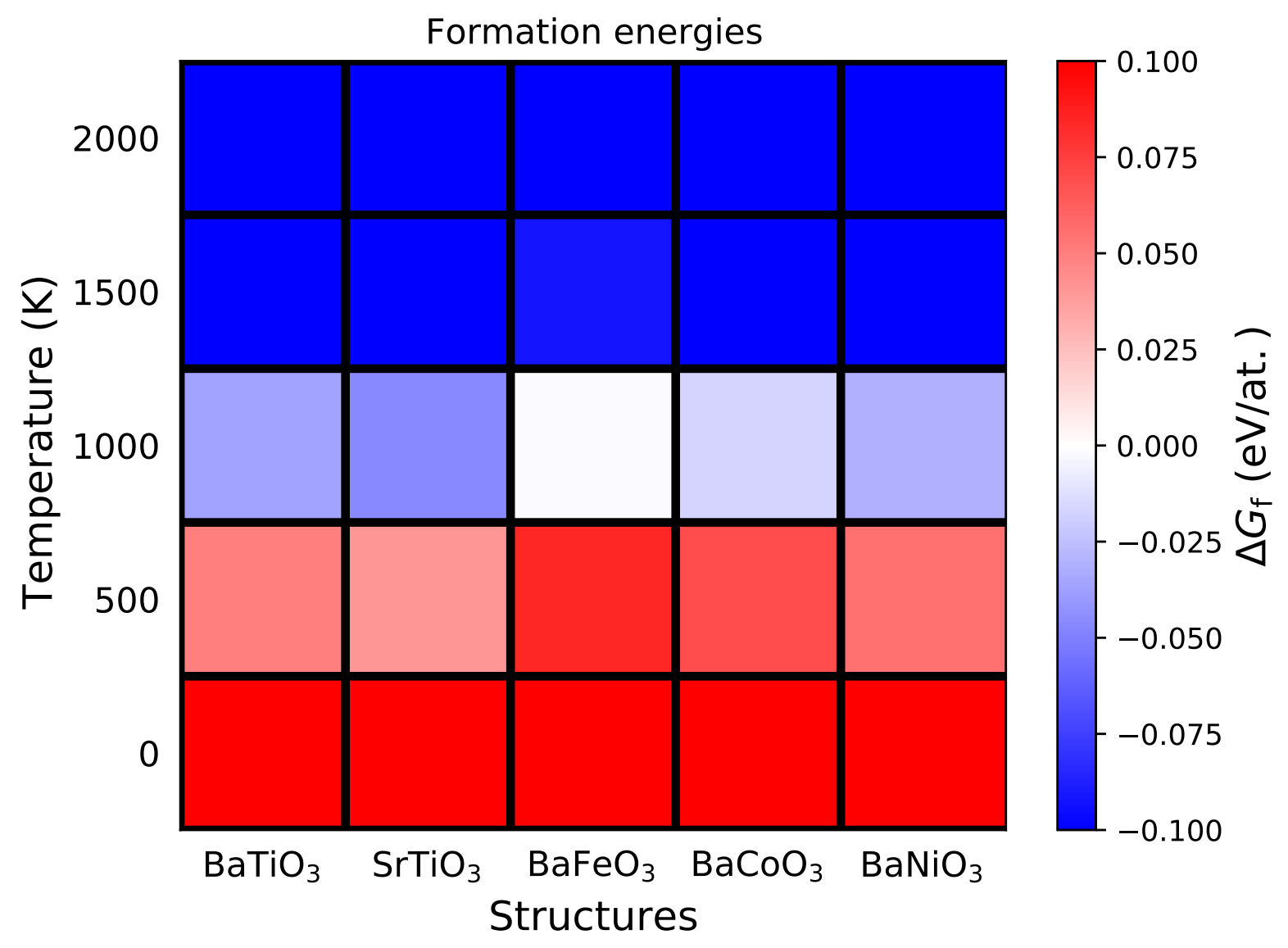

Figure S7: Gibbs free energy corresponding to the following reaction : $15 \mathrm{Au}_{32} \mathrm{Ba}_{8} B_{6} \mathrm{O}_{24} \rightarrow 4 \mathrm{Au}_{120} \mathrm{Ba}_{5} B_{4} \mathrm{O}_{12}+74$ $\mathrm{BaBO}_{3}+45 \mathrm{O}_{2}+26 \mathrm{Ba}\left(P=10^{-10}\right.$ mbar $)$. 
(a) $\mathrm{BaTiO}_{3} / \mathrm{Pt}(111)$

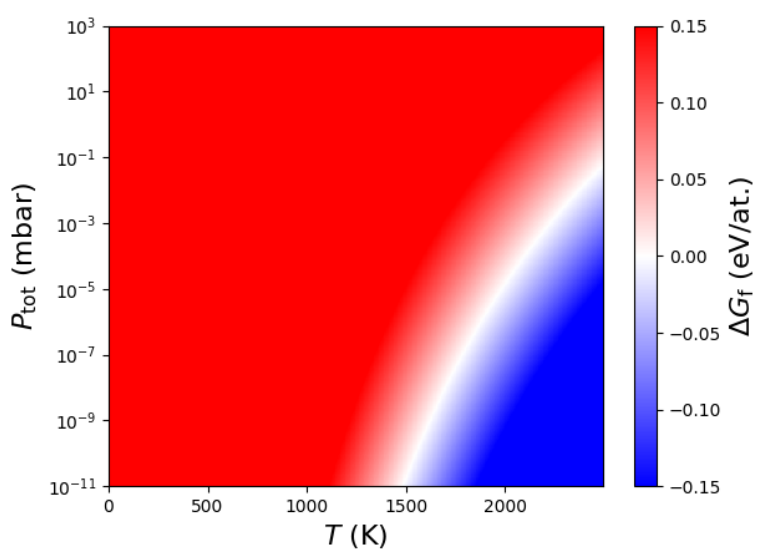

(c) $\mathrm{SrTiO}_{3} / \mathrm{Pt}(111)$

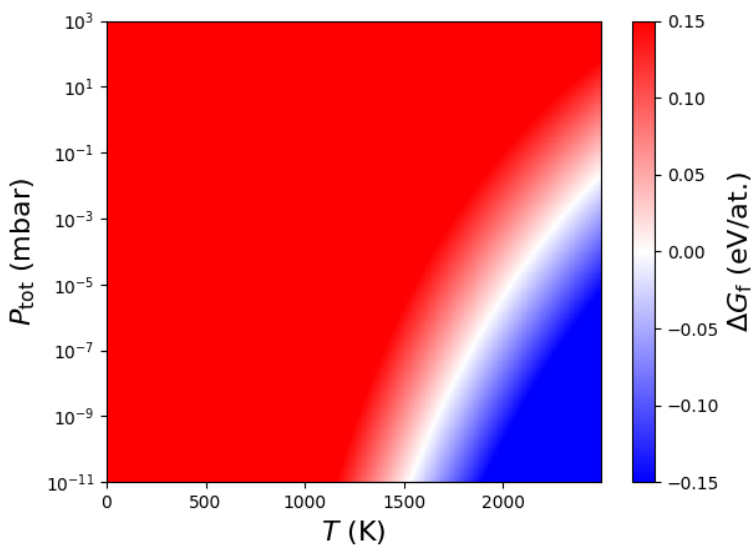

(e) $\mathrm{BaFeO}_{3} / \mathrm{Pt}(111)$

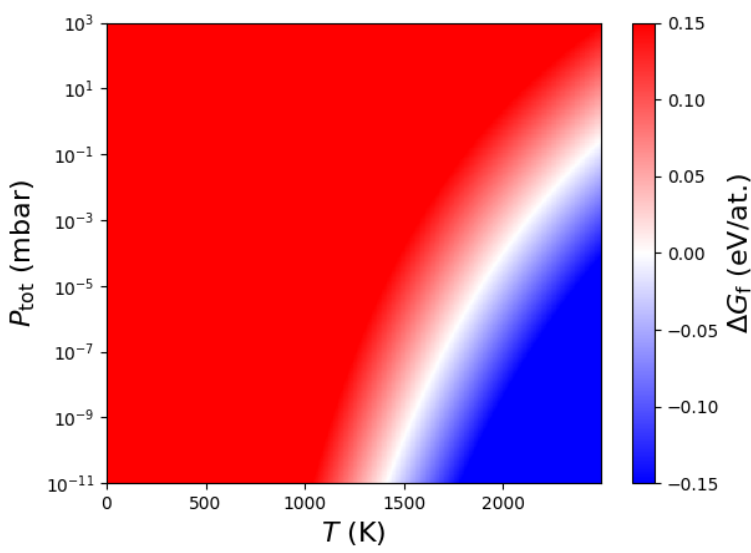

(b) $\mathrm{BaTiO}_{3} / \mathrm{Au}(111)$

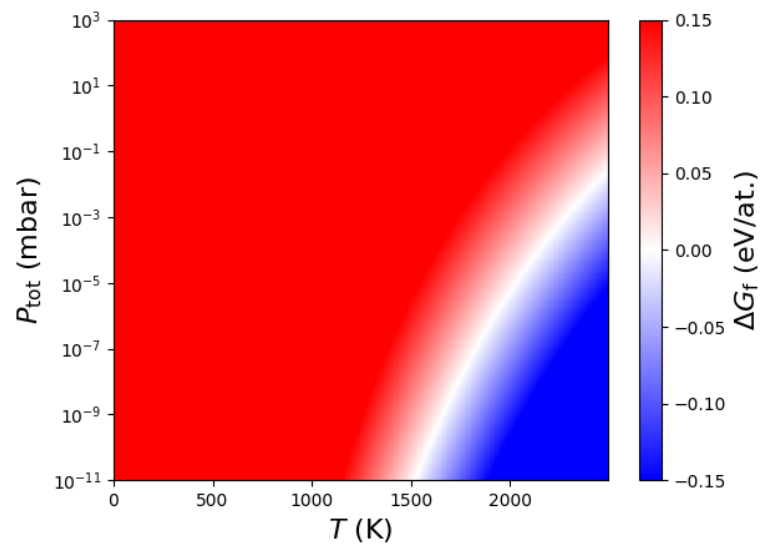

(d) $\mathrm{SrTiO}_{3} / \mathrm{Au}(111)$

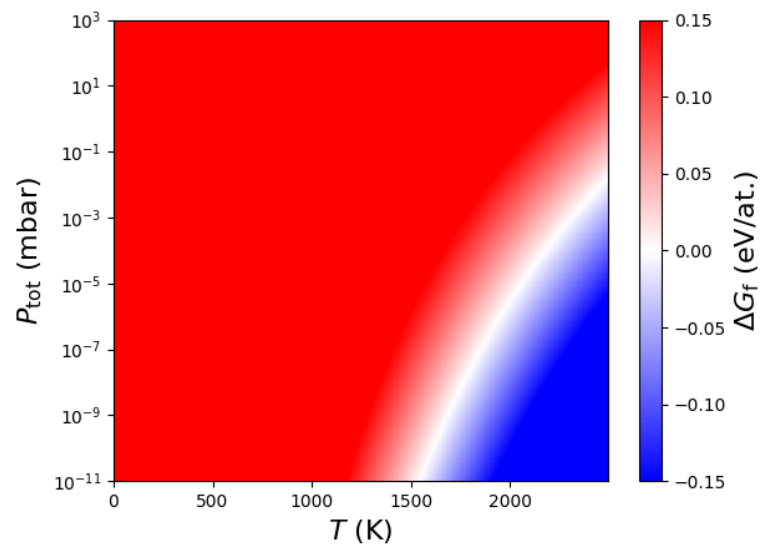

(f) $\mathrm{BaFeO}_{3} / \mathrm{Au}(111)$

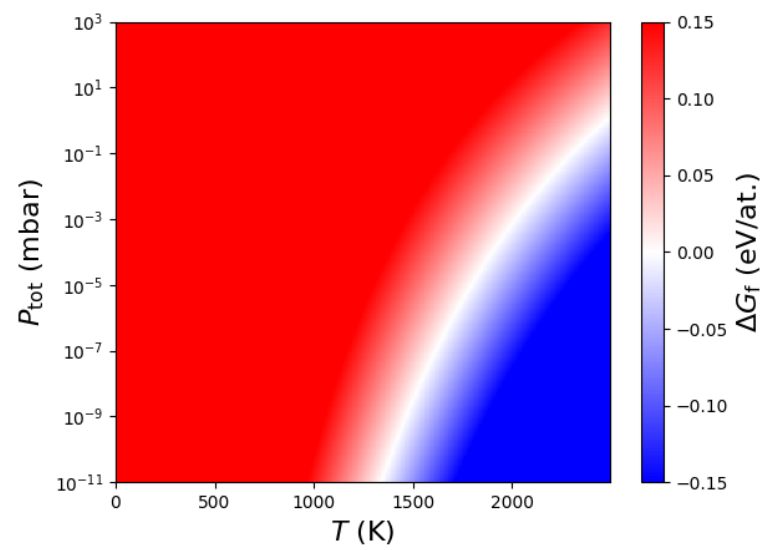

Figure S8: Gibbs free energy of the following reaction: $\mathrm{Pt}_{32} \mathrm{Ba}_{8} B_{6} \mathrm{O}_{24} \rightarrow \mathrm{Pt}_{32} \mathrm{Ba}_{4} \mathrm{O}_{6}+2 \mathrm{BaBO}_{3}+6 \mathrm{O}_{2}+5 / 2$ $\mathrm{Ba}$. The thick $\mathrm{ABO}_{3}$ film is more stable than the SHS in the red region. The SHS is more stable than the thick $A B \mathrm{O}_{3}$ film in the blue region. 
(a) $\mathrm{BaCoO}_{3} / \operatorname{Pt}(111)$

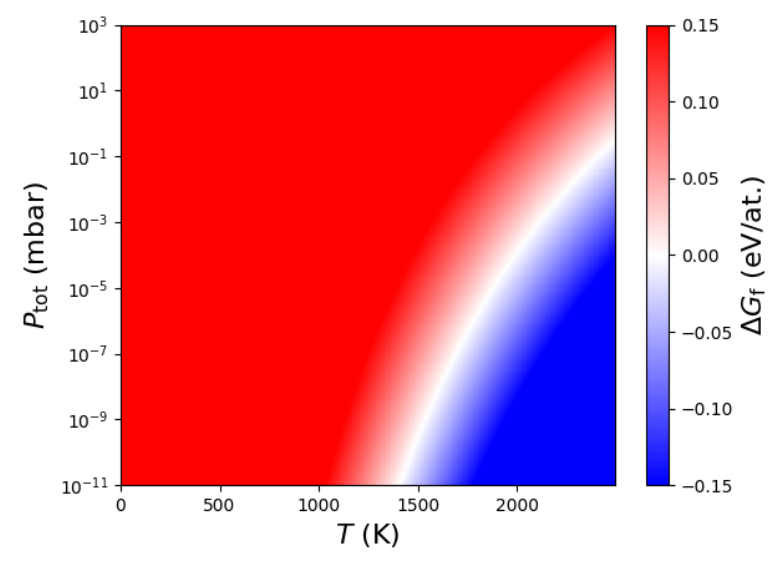

(c) $\mathrm{BaNiO}_{3} / \mathrm{Pt}(111)$

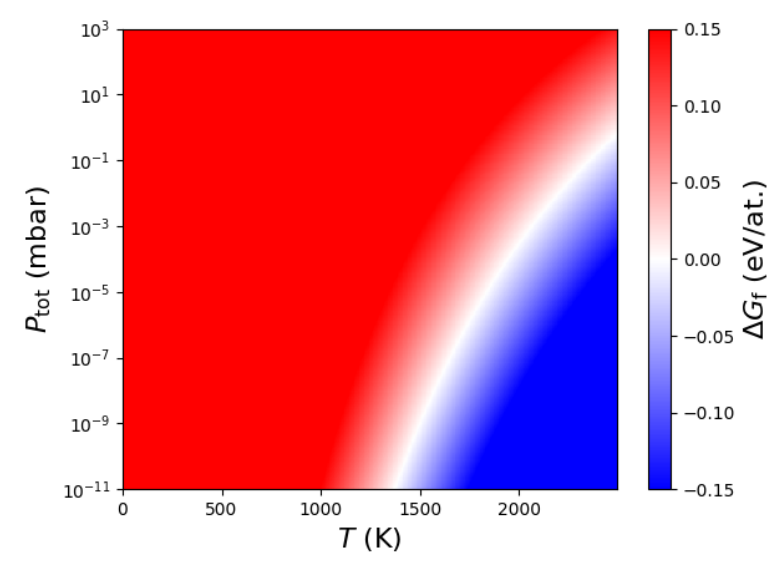

(b) $\mathrm{BaCoO}_{3} / \mathrm{Au}(111)$

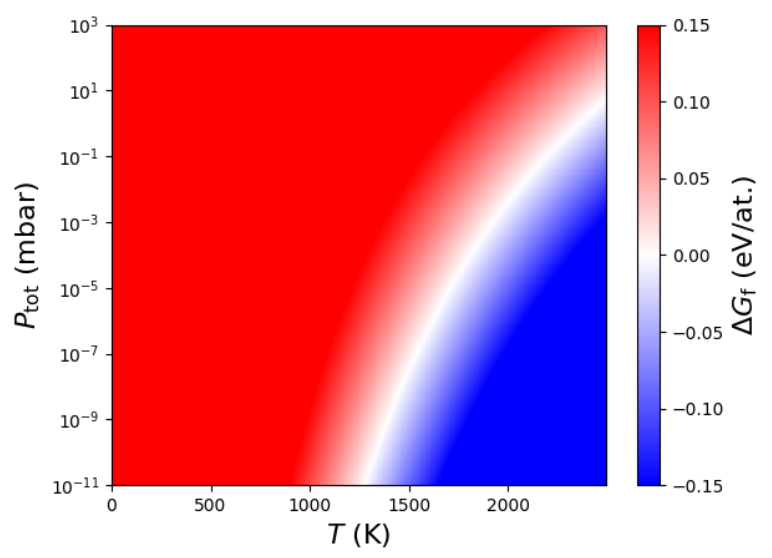

(d) $\mathrm{BaNiO}_{3} / \mathrm{Au}(111)$

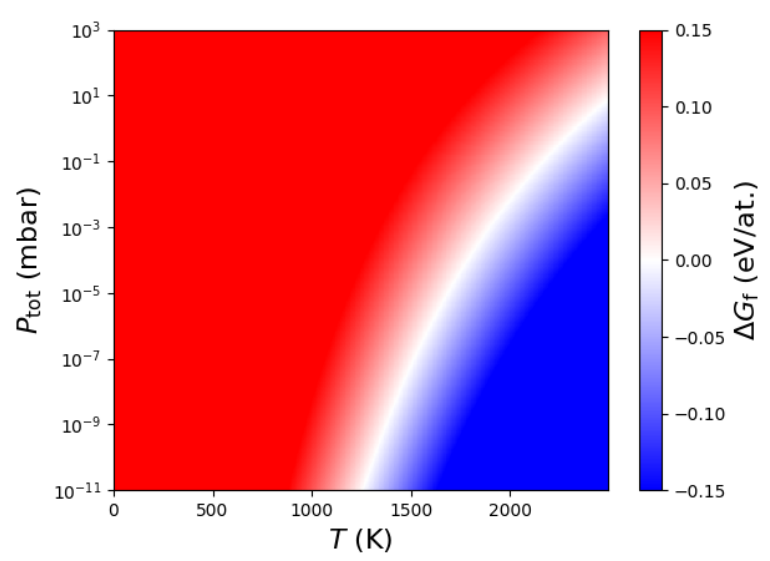

Figure S9: Gibbs free energy of the following reaction : $\mathrm{Pt}_{32} \mathrm{Ba}_{8} B_{6} \mathrm{O}_{24} \rightarrow \mathrm{Pt}_{32} \mathrm{Ba}_{4} \mathrm{O}_{6}+2 \mathrm{BaBO}_{3}+6 \mathrm{O}_{2}+5 / 2$ Ba. The thick $A B \mathrm{O}_{3}$ film is more stable than the SHS in the red region. The SHS is more stable than the thick $A B \mathrm{O}_{3}$ film in the blue region. 


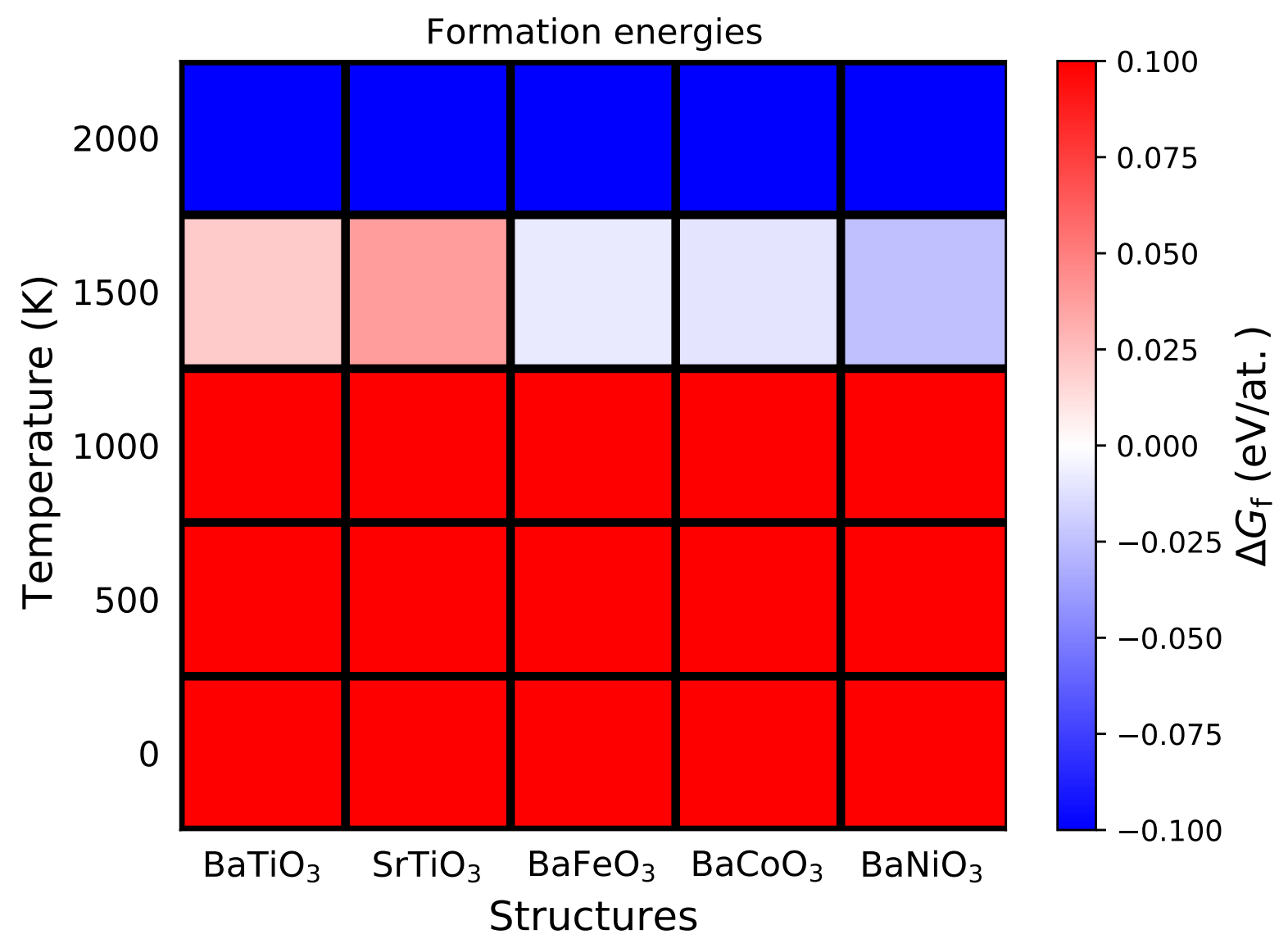

Figure S10: Gibbs free energy corresponding to the following reaction : $\mathrm{Pt}_{32} \mathrm{Ba}_{8} B_{6} \mathrm{O}_{24} \rightarrow \mathrm{Pt}_{32} \mathrm{Ba}_{4} \mathrm{O}_{6}+2 \mathrm{Ba}_{3} \mathrm{O}_{3}$ $+6 \mathrm{O}_{2}+5 / 2 \mathrm{Ba}\left(P=10^{-10}\right.$ mbar $)$. 


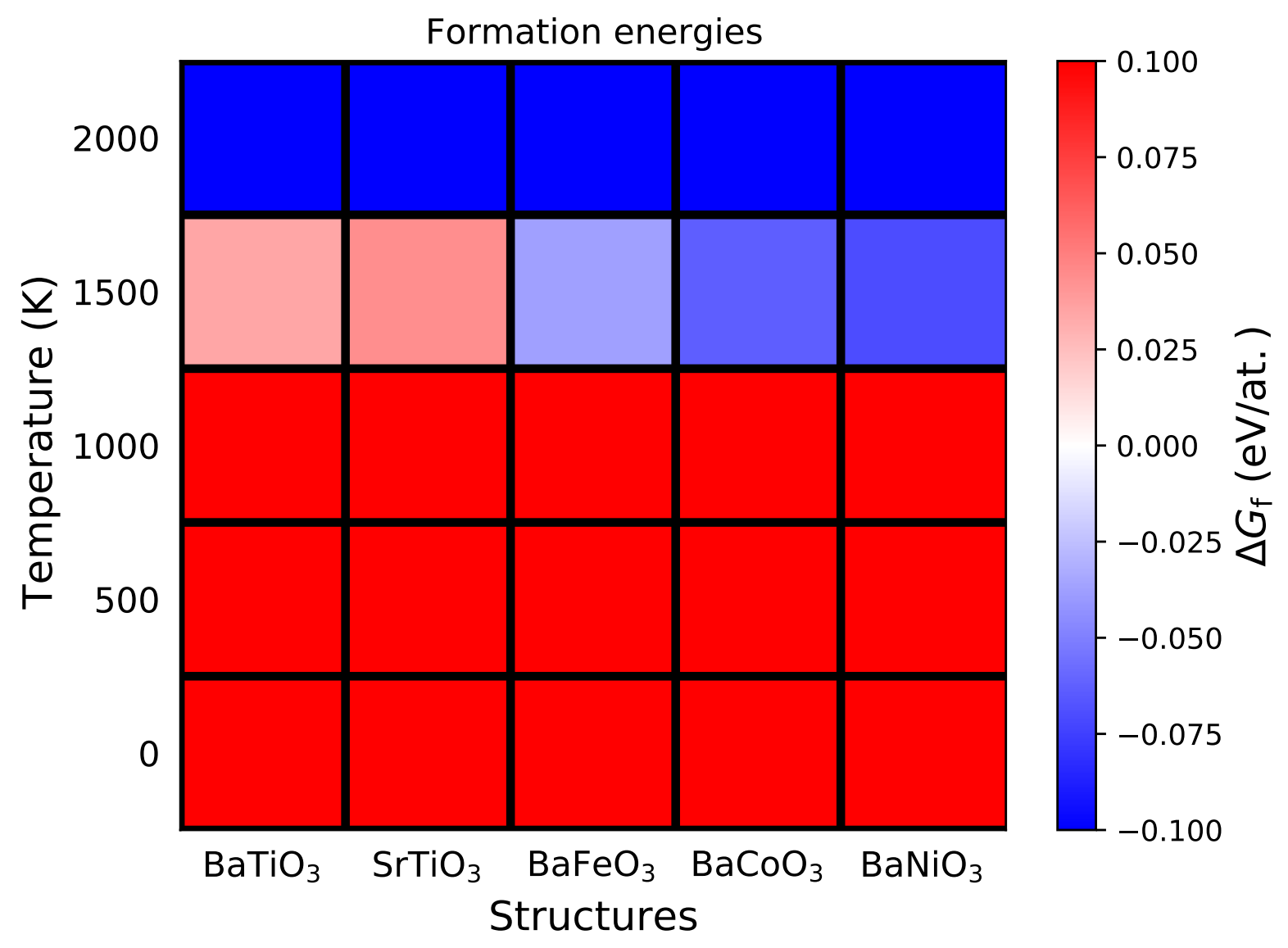

Figure S11: Gibbs free energy corresponding to the following reaction : $\mathrm{Au}_{32} \mathrm{Ba}_{8} B_{6} \mathrm{O}_{24} \rightarrow \mathrm{Au}_{32} \mathrm{Ba}_{4} \mathrm{O}_{6}+2 \mathrm{Ba}_{3} \mathrm{O}_{3}$ $+6 \mathrm{O}_{2}+5 / 2 \mathrm{Ba}\left(P=10^{-10}\right.$ mbar $)$. 
Atomic structures of OQAs 
Table S8: Average $A-\mathrm{O}, B-\mathrm{O}, A-\mathrm{Me}$, and $B-$ Me bond lengths, as well as the rumplings and average $\mathrm{O}-B-\mathrm{O}$ angles in all structures.

\begin{tabular}{|c|c|c|c|c|c|c|c|}
\hline & $\mathrm{BaTiO}_{3}$ & $\mathrm{BaVO}_{3}$ & $\mathrm{BaCrO}_{3}$ & $\mathrm{BaMnO}_{3}$ & $\mathrm{BaFeO}_{3}$ & $\mathrm{BaCoO}_{3}$ & $\mathrm{BaNiO}_{3}$ \\
\hline \multicolumn{8}{|c|}{ Freestanding layer } \\
\hline$B-\mathrm{O}(\AA)$ & 1.79 & 1.74 & l & / & 1.71 & 1.73 & 1.72 \\
\hline $\mathrm{Ba}-\mathrm{O}(\AA)$ & 2.64 & 2.64 & / & / & 2.7 & 2.55 & 2.63 \\
\hline $\mathrm{O}-\mathrm{B}-\mathrm{O}$ angle $\left({ }^{\circ}\right)$ & 120.0 & 120.0 & / & / & 120.0 & 120.0 & 120.0 \\
\hline \multicolumn{8}{|c|}{ Pt substrate } \\
\hline$B-\mathrm{O}(\AA)$ & 1.84 & 1.74 & 1.72 & / & 1.81 & 1.84 & 1.88 \\
\hline $\mathrm{Ba}-\mathrm{O}(\AA)$ & 2.7 & 2.78 & 2.78 & / & 2.66 & 2.67 & 2.7 \\
\hline$B-\operatorname{Pt}(\AA)$ & 3.06 & 2.82 & 2.9 & / & 2.91 & 2.98 & 2.88 \\
\hline $\mathrm{Ba}-\mathrm{Pt}(\AA ⿻)$ & 3.48 & 3.43 & 3.52 & / & 3.52 & 3.52 & 3.55 \\
\hline $\mathrm{O}-\mathrm{B}-\mathrm{O}$ angle $\left({ }^{\circ}\right)$ & 112.2 & 111.0 & 113.4 & / & 115.4 & 117.3 & 117.5 \\
\hline \multicolumn{8}{|c|}{ Pd substrate } \\
\hline$B-\mathrm{O}(\AA)$ & 1.83 & 1.74 & 1.71 & 1.77 & 1.79 & 1.82 & 1.87 \\
\hline$B-\operatorname{Pd}(\AA)$ & 3.02 & 2.95 & 2.91 & 3.02 & 2.92 & 2.99 & 2.87 \\
\hline $\mathrm{Ba}-\mathrm{O}(\AA)$ & 2.67 & 2.75 & 2.74 & 2.68 & 2.65 & 2.63 & 2.74 \\
\hline $\mathrm{Ba}-\mathrm{Pd}(\AA)$ & 3.51 & 3.5 & 3.49 & 3.48 & 3.57 & 3.59 & 3.55 \\
\hline $\mathrm{O}-\mathrm{B}-\mathrm{O}$ angle $\left({ }^{\circ}\right)$ & 113.8 & 111.4 & 114.3 & 117.3 & 116.9 & 118.8 & 118.1 \\
\hline \multicolumn{8}{|c|}{ Au substrate } \\
\hline$B-\mathrm{O}(\AA)$ & 1.82 & 1.72 & / & 1.79 & 1.77 & 1.79 & 1.86 \\
\hline$B-\mathrm{Au}(\AA)$ & 3.09 & 2.99 & / & 3.03 & 2.93 & 2.93 & 2.94 \\
\hline $\mathrm{Ba}-\mathrm{O}(\AA)$ & 2.74 & 2.76 & / & 2.72 & 2.7 & 2.7 & 2.71 \\
\hline $\mathrm{Ba}-\mathrm{Au}(\AA)$ & 3.54 & 3.42 & / & 3.55 & 3.54 & 3.55 & 3.56 \\
\hline $\mathrm{O}-\mathrm{B}-\mathrm{O}$ angle $\left({ }^{\circ}\right)$ & 115.3 & 112.2 & / & 118.8 & 118.5 & 119.7 & 118.9 \\
\hline & $\mathrm{SrTiO}_{3}$ & $\mathrm{SrVO}_{3}$ & $\mathrm{SrCrO}_{3}$ & $\mathrm{SrMnO}_{3}$ & $\mathrm{SrFeO}_{3}$ & $\mathrm{SrCoO}_{3}$ & $\mathrm{SrNiO}_{3}$ \\
\hline \multicolumn{8}{|c|}{ Freestanding layer } \\
\hline$B-\mathrm{O}(\AA)$ & 1.79 & 1.74 & 1.82 & 1.76 & / & / & 1.72 \\
\hline $\mathrm{Sr}-\mathrm{O}(\AA)$ & 2.46 & 2.58 & 2.43 & 2.5 & / & / & 2.53 \\
\hline $\mathrm{O}-\mathrm{B}-\mathrm{O}$ angle $\left({ }^{\circ}\right)$ & 120.0 & 120.0 & 120.0 & 120.0 & / & / & 120.0 \\
\hline \multicolumn{8}{|c|}{ Pt substrate } \\
\hline$B-\mathrm{O}(\AA)$ & 1.85 & 1.75 & 1.73 & 1.86 & 1.82 & 1.85 & 1.84 \\
\hline$B-\operatorname{Pt}(\AA)$ & 3.06 & 2.98 & 2.91 & 3.02 & 2.91 & 2.97 & 2.95 \\
\hline $\mathrm{Sr}-\mathrm{O}(\AA)$ & 2.55 & 2.69 & 2.67 & 2.5 & 2.54 & 2.53 & 2.49 \\
\hline $\mathrm{Sr}-\mathrm{Pt}(\AA)$ & 3.34 & 3.27 & 3.27 & 3.34 & 3.31 & 3.34 & 3.33 \\
\hline $\mathrm{O}-\mathrm{B}-\mathrm{O}$ angle $\left({ }^{\circ}\right)$ & 113.6 & 111.6 & 114.4 & 118.0 & 116.2 & 117.8 & 118.2 \\
\hline \multicolumn{8}{|c|}{ Pd substrate } \\
\hline$B-\mathrm{O}(\AA)$ & 1.84 & 1.74 & 1.77 & 1.82 & 1.8 & 1.82 & 1.8 \\
\hline$B-\mathrm{Pd}(\AA)$ & 3.04 & 3.01 & 2.97 & 3.0 & 2.92 & 2.89 & 2.98 \\
\hline $\mathrm{Sr}-\mathrm{O}(\AA)$ & 2.51 & 2.64 & 2.7 & 2.47 & 2.5 & 2.48 & 2.49 \\
\hline $\mathrm{Sr}-\mathrm{Pd}(\AA)$ & 3.31 & 3.31 & 3.42 & 3.29 & 3.27 & 3.3 & 3.3 \\
\hline $\mathrm{O}-\mathrm{B}-\mathrm{O}$ angle $\left({ }^{\circ}\right)$ & 114.3 & 112.5 & 114.5 & 118.7 & 117.6 & 119.0 & 118.9 \\
\hline \multicolumn{8}{|c|}{ Au substrate } \\
\hline$B-\mathrm{O}(\AA)$ & 1.83 & 1.72 & 1 & 1.86 & 1.79 & 1.85 & 1.86 \\
\hline$B-\mathrm{Au}(\AA)$ & 3.12 & 3.01 & / & 3.07 & 2.93 & 2.86 & 2.97 \\
\hline $\mathrm{Sr}-\mathrm{O}(\AA)$ & 2.54 & 2.58 & / & 2.48 & 2.56 & 2.51 & 2.45 \\
\hline $\mathrm{Sr}-\mathrm{Au}(\AA)$ & 3.29 & 3.23 & / & 3.4 & 3.29 & 3.32 & 3.36 \\
\hline $\mathrm{O}-\mathrm{B}-\mathrm{O}$ angle $\left({ }^{\circ}\right)$ & 116.0 & 113.6 & 1 & 119.5 & 119.1 & 119.7 & 119.0 \\
\hline & $\mathrm{CaTiO}_{3}$ & $\mathrm{CaVO}_{3}$ & $\mathrm{CaCrO}_{3}$ & $\mathrm{CaMnO}_{3}$ & $\mathrm{CaFeO}_{3}$ & $\mathrm{CaCoO}_{3}$ & $\mathrm{CaNiO}_{3}$ \\
\hline \multicolumn{8}{|c|}{ Freestanding layer } \\
\hline$B-\mathrm{O}(\AA)$ & 1.8 & / & / & 1.77 & / & 1.72 & 1 \\
\hline $\mathrm{Ca}-\mathrm{O}(\AA)$ & 2.14 & / & / & 2.26 & / & 2.26 & 1 \\
\hline $\mathrm{O}-\mathrm{B}-\mathrm{O}$ angle $\left({ }^{\circ}\right)$ & 120.0 & / & / & 120.0 & / & 120.0 & / \\
\hline & & & Pt substre & & & & \\
\hline$R(\AA)$ & -0.24 & -0.35 & -0.31 & / & -0.17 & -0.10 & -0.07 \\
\hline$B-\mathrm{O}(\AA)$ & 1.86 & 1.75 & 1.73 & / & 1.85 & 1.88 & 1.91 \\
\hline$B-\operatorname{Pt}(\AA)$ & 3.07 & 2.96 & 2.9 & / & 2.91 & 2.95 & 2.95 \\
\hline $\mathrm{Ca}-\mathrm{O}(\AA)$ & 2.43 & 2.5 & 2.46 & / & 2.42 & 2.39 & 2.35 \\
\hline $\mathrm{Ca}-\mathrm{Pt}(\AA)$ & 3.17 & 3.13 & 3.1 & / & 3.17 & 3.18 & 3.19 \\
\hline $\mathrm{O}-B-\mathrm{O}$ angle $\left({ }^{\circ}\right)$ & 115.3 & 112.5 & 114.9 & / & 117.1 & 118.3 & 119.0 \\
\hline & & & Pd substr & & & & \\
\hline$R(\AA)$ & -0.22 & -0.33 & -0.30 & -0.11 & -0.13 & -0.06 & 0.00 \\
\hline$B-\mathrm{O}(\AA)$ & 1.84 & 1.75 & 1.73 & 1.85 & 1.82 & 1.85 & 1.78 \\
\hline$B-\operatorname{Pd}(\AA)$ & 3.05 & 3.01 & 2.92 & 3.01 & 2.95 & 2.94 & 2.81 \\
\hline $\mathrm{Ca}-\mathrm{O}(\AA)$ & 2.38 & 2.5 & 2.56 & 2.34 & 2.35 & 2.34 & 2.29 \\
\hline $\mathrm{Ca}-\mathrm{Pd}(\AA)$ & 3.2 & 3.12 & 3.08 & 3.2 & 3.16 & 3.13 & 3.14 \\
\hline $\mathrm{O}-\mathrm{B}-\mathrm{O}$ angle $\left({ }^{\circ}\right)$ & 116.0 & 113.9 & 116.2 & 119.2 & 118.4 & 119.0 & 128.4 \\
\hline & & & $\mathrm{Au}$ substr & & & & \\
\hline$R(\AA)$ & -0.13 & -0.36 & -0.26 & -0.12 & 0.01 & 0.13 & 0.14 \\
\hline$B-\mathrm{O}(\AA)$ & 1.84 & 1.73 & 1.73 & 1.94 & 1.86 & 1.92 & 1.89 \\
\hline$B-\mathrm{Au}(\AA)$ & 3.13 & 3.06 & 3.04 & 2.98 & 2.95 & 2.85 & 2.92 \\
\hline $\mathrm{Ca}-\mathrm{O}(\AA)$ & 2.33 & 2.32 & 2.37 & 2.46 & 2.39 & 2.33 & 2.3 \\
\hline $\mathrm{Ca}-\mathrm{Au}(\AA)$ & 3.23 & 3.05 & 3.08 & 3.18 & 3.2 & 3.2 & 3.24 \\
\hline $\mathrm{O}-\mathrm{B}-\mathrm{O}$ angle $\left({ }^{\circ}\right)$ & 116.8 & 114.0 & 117.0 & 119.3 & 119.5 & 119.5 & 122.4 \\
\hline
\end{tabular}


Size mismatch and rumpling for OQAs

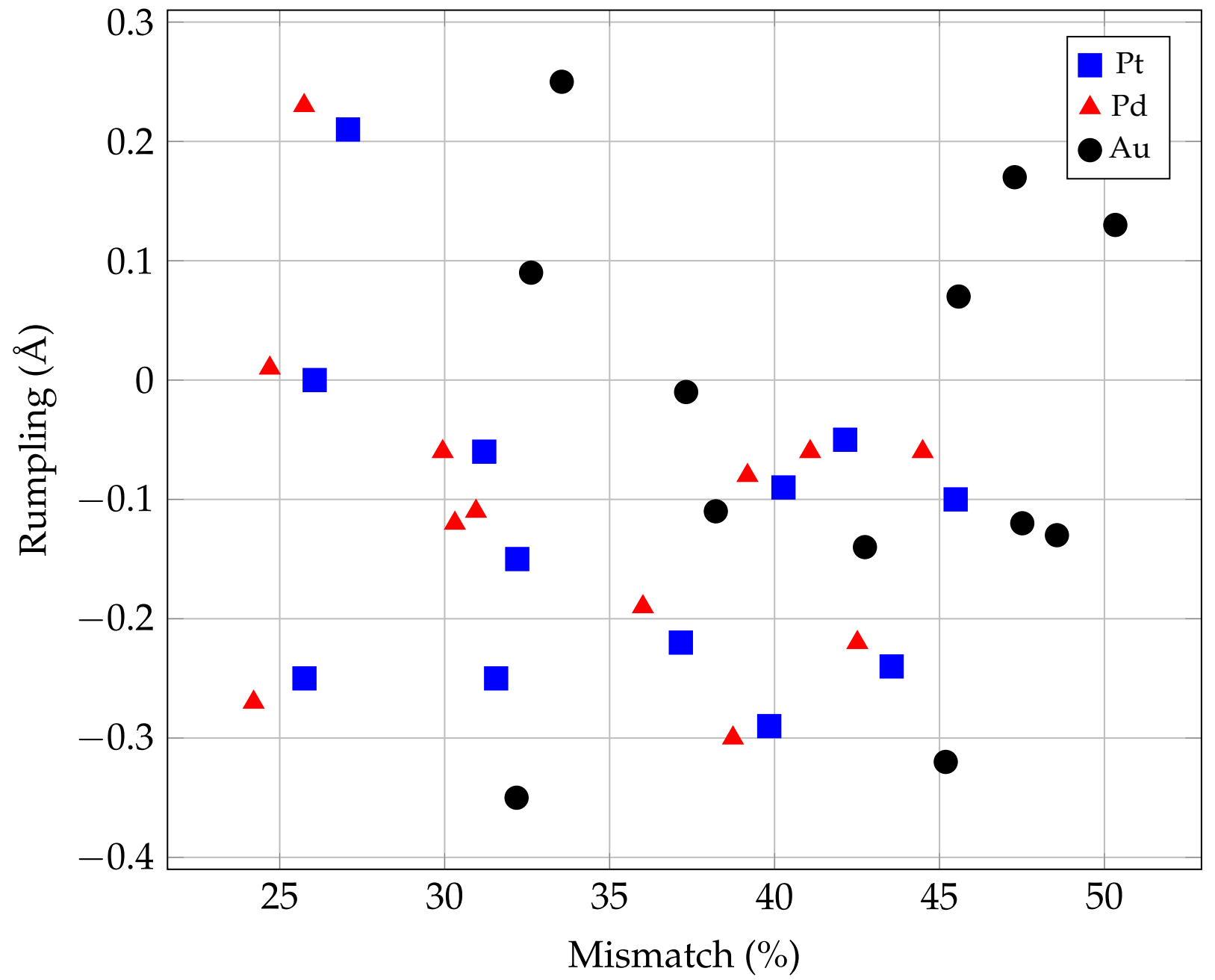

Figure S12: Plot of the rumpling as a function of the size mismatch for selected structures. 


\section{Averaged planar differences}

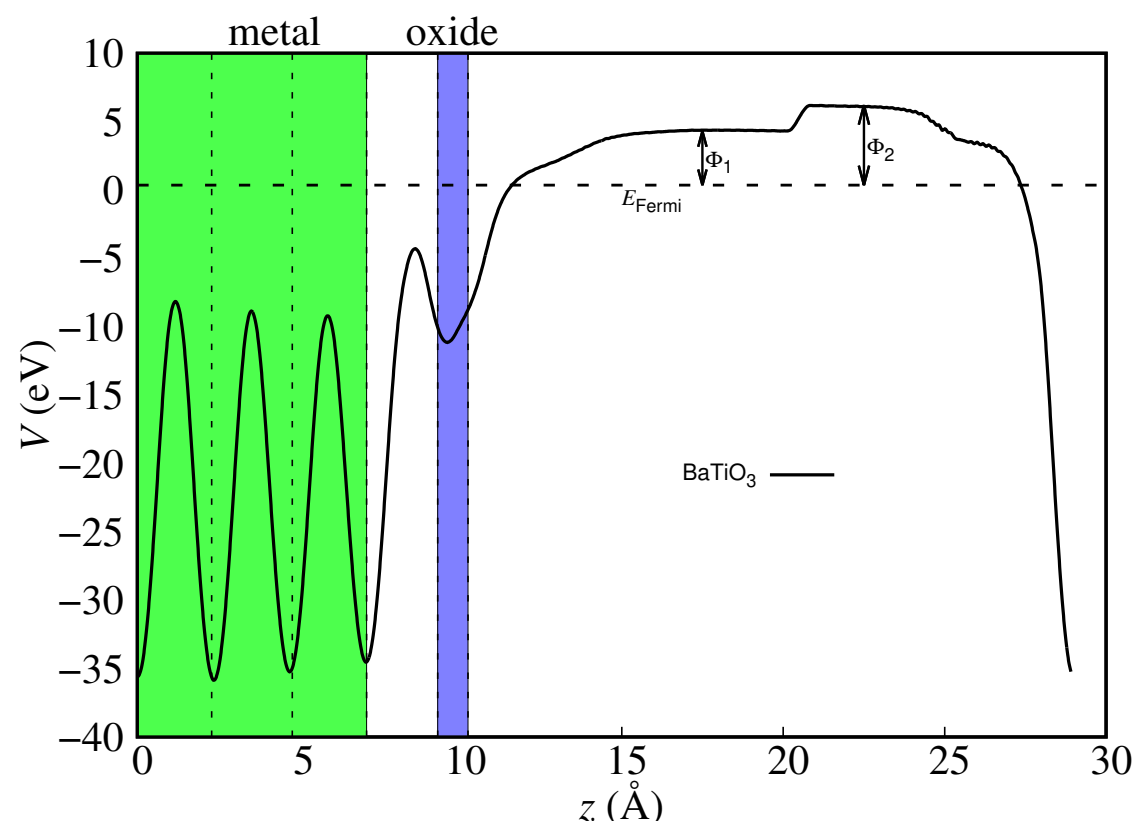

Figure S13: Planar averaged electrostatic potential $\left(\bar{V}(z)=\frac{1}{A} \int_{A} V(x, y, z) \mathrm{d} x \mathrm{~d} y\right.$, where $A$ is the surface area) for $\mathrm{BaTiO}_{3}$ on Pt. Green band represents the $\mathrm{Pt}(111)$ slab and blue stripe indicates the position of the OQA layer. $\Phi_{1}$ and $\Phi_{2}$ are the values in the plateau of the average electrostatic potential in the vacuum level (with the Fermi energy as a reference in zero) for the metal-oxide and metal systems, respectivelly.

(a)

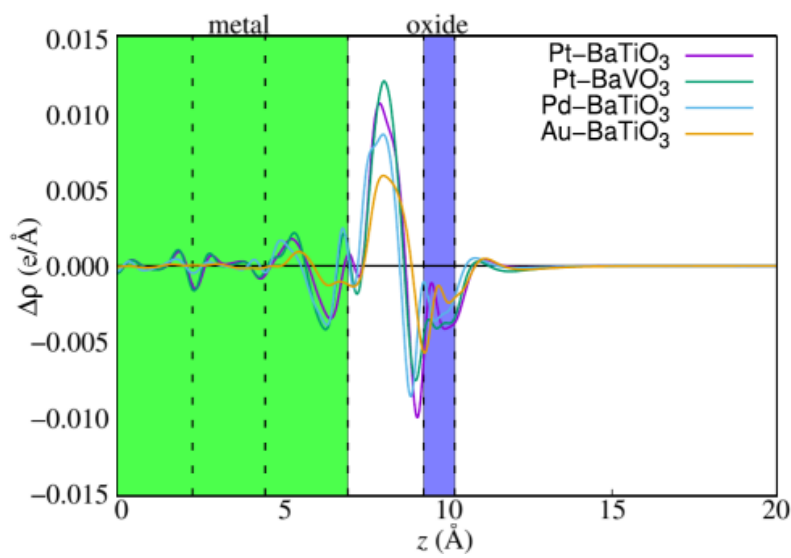

(b)

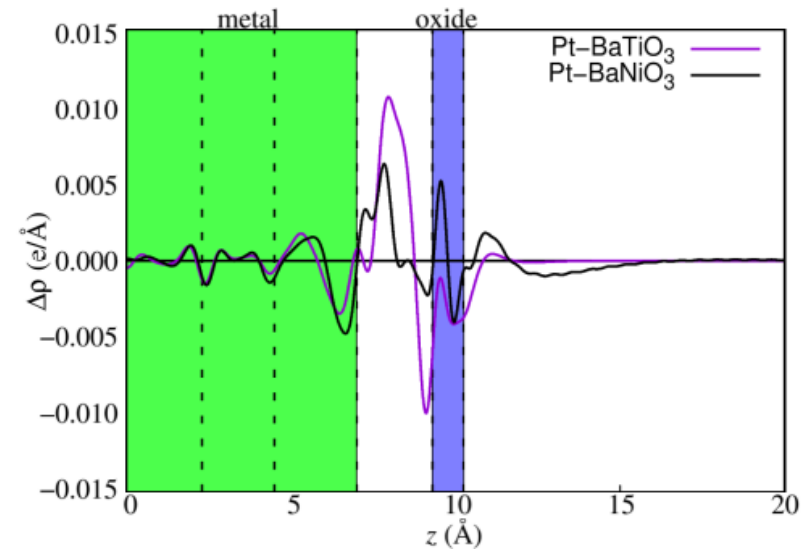

Figure S14: Planar averaged electron charge density differences $\left(\Delta \rho(z)=\int_{A} \Delta \rho(x, y, z) \mathrm{d} x \mathrm{~d} y\right.$, where integration was performed over the area (A) spanned by the surface supercell) for several OQA structures studied in this work. Green represents the $\mathrm{Pt}(111)$ slab and blue stripe indicates the position of the OQA layer. 
Adhesion energies as a function of size mismatch, rumpling and charge transfer

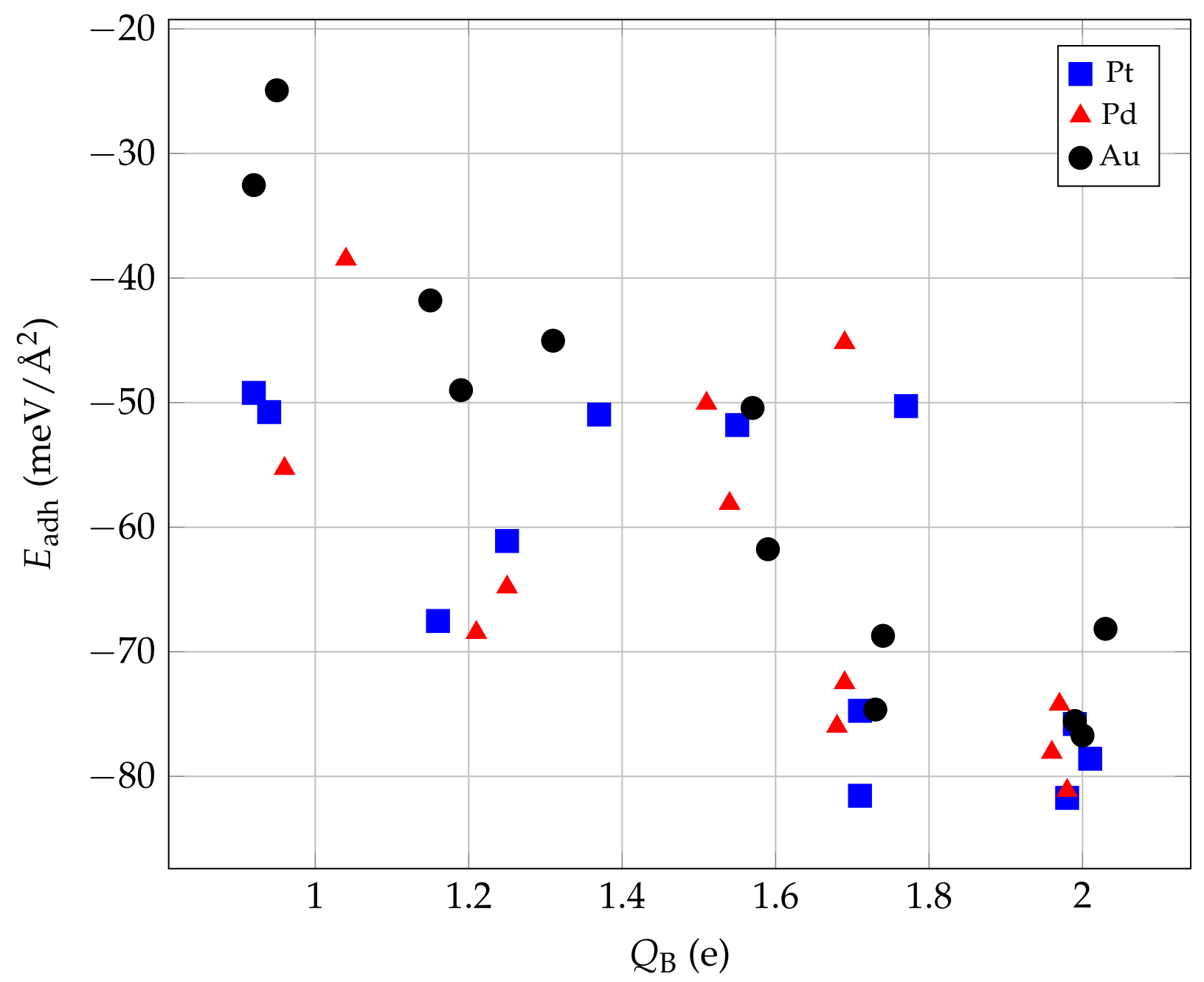

Figure S15: Plot of the adhesion energy $\left(E_{\mathrm{adh}}\right)$ as a function of the Bader charge of $B$ atom $\left(Q_{\mathrm{B}}\right)$. 


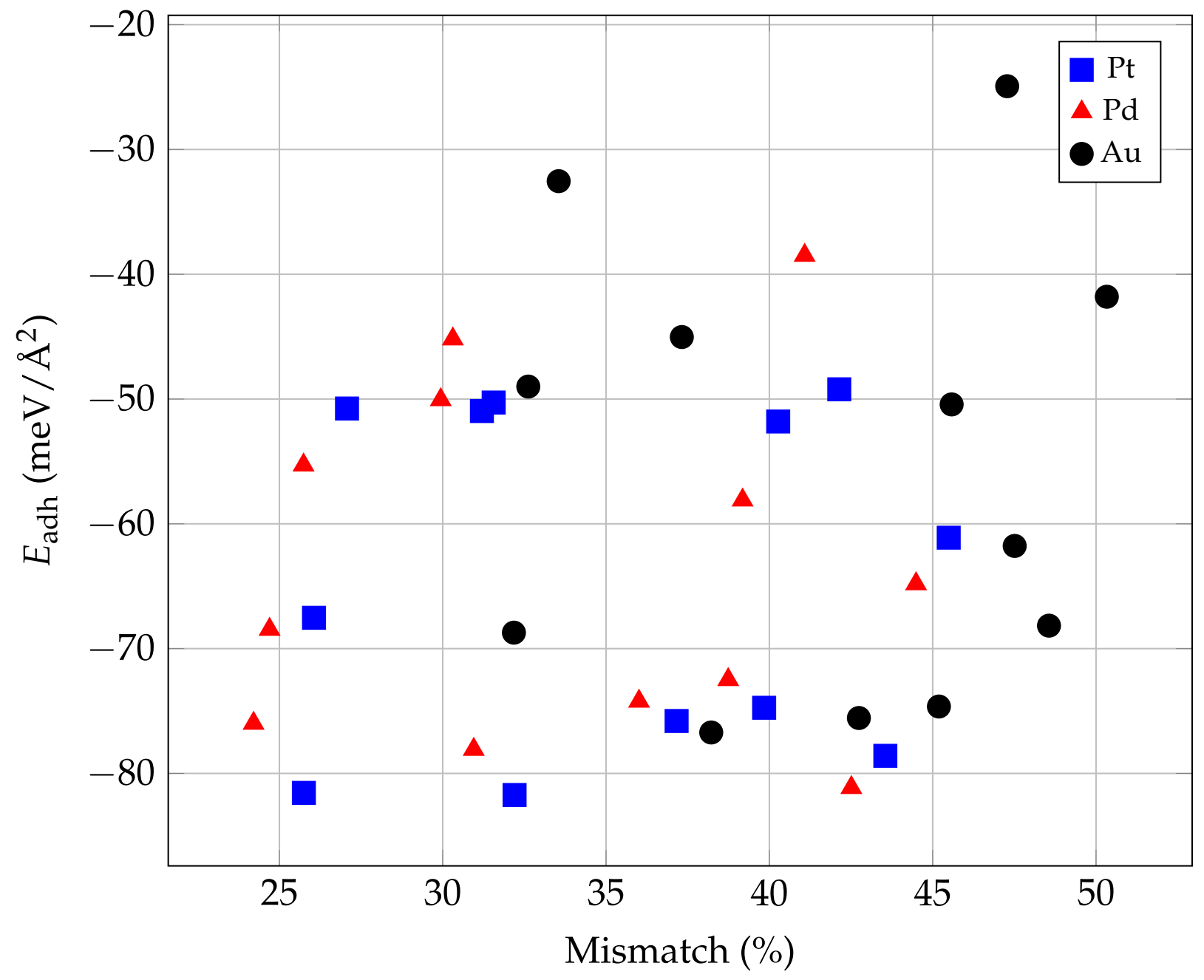

Figure S16: Plot of the adhesion energy $\left(E_{\mathrm{adh}}\right)$ as a function of the size mismatch for selected structures. 


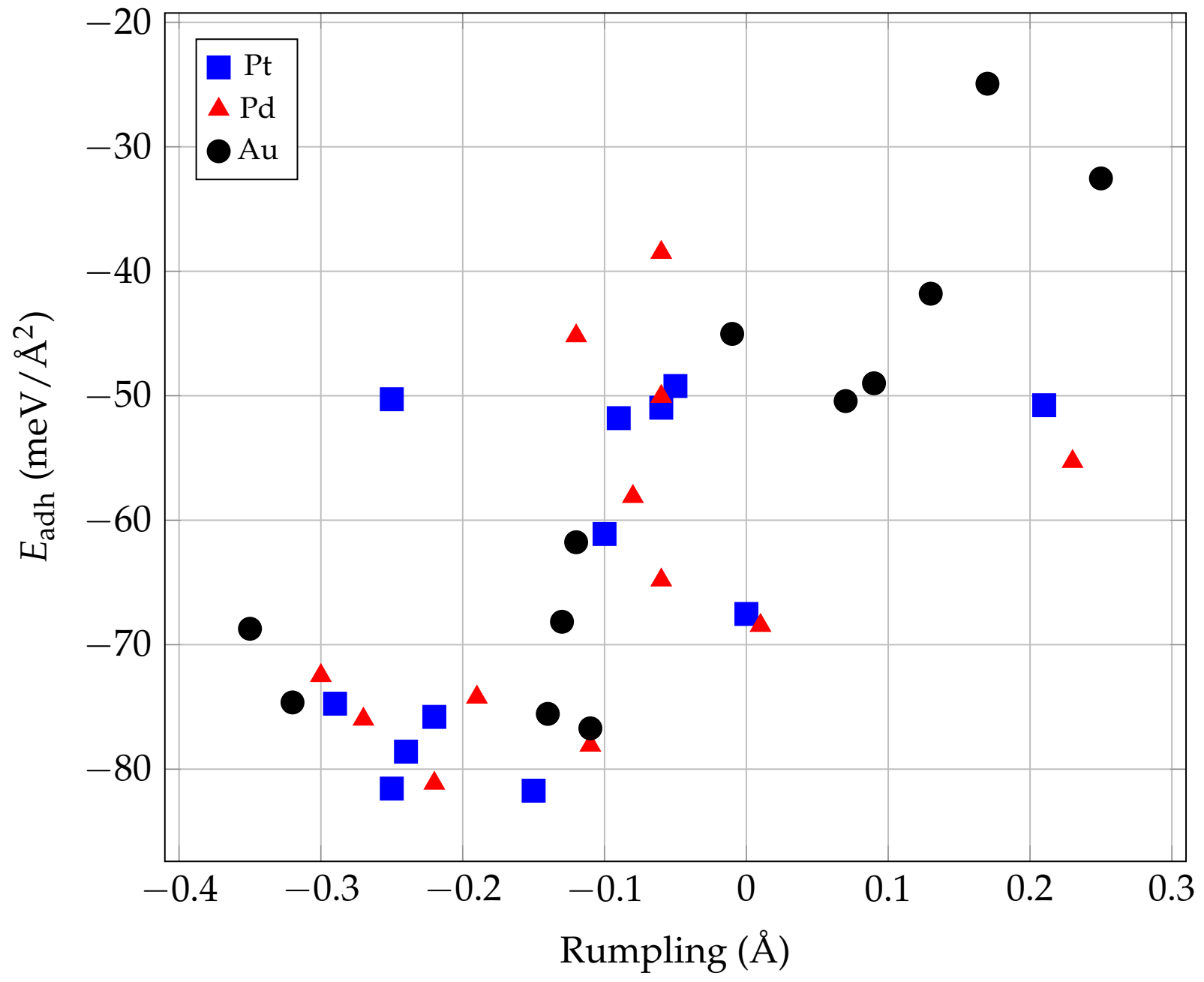

Figure S17: Plot of the adhesion energy $\left(E_{\mathrm{adh}}\right)$ as a function of the rumpling $(R)$ for selected structures. 
Electronic properties

Density of states 

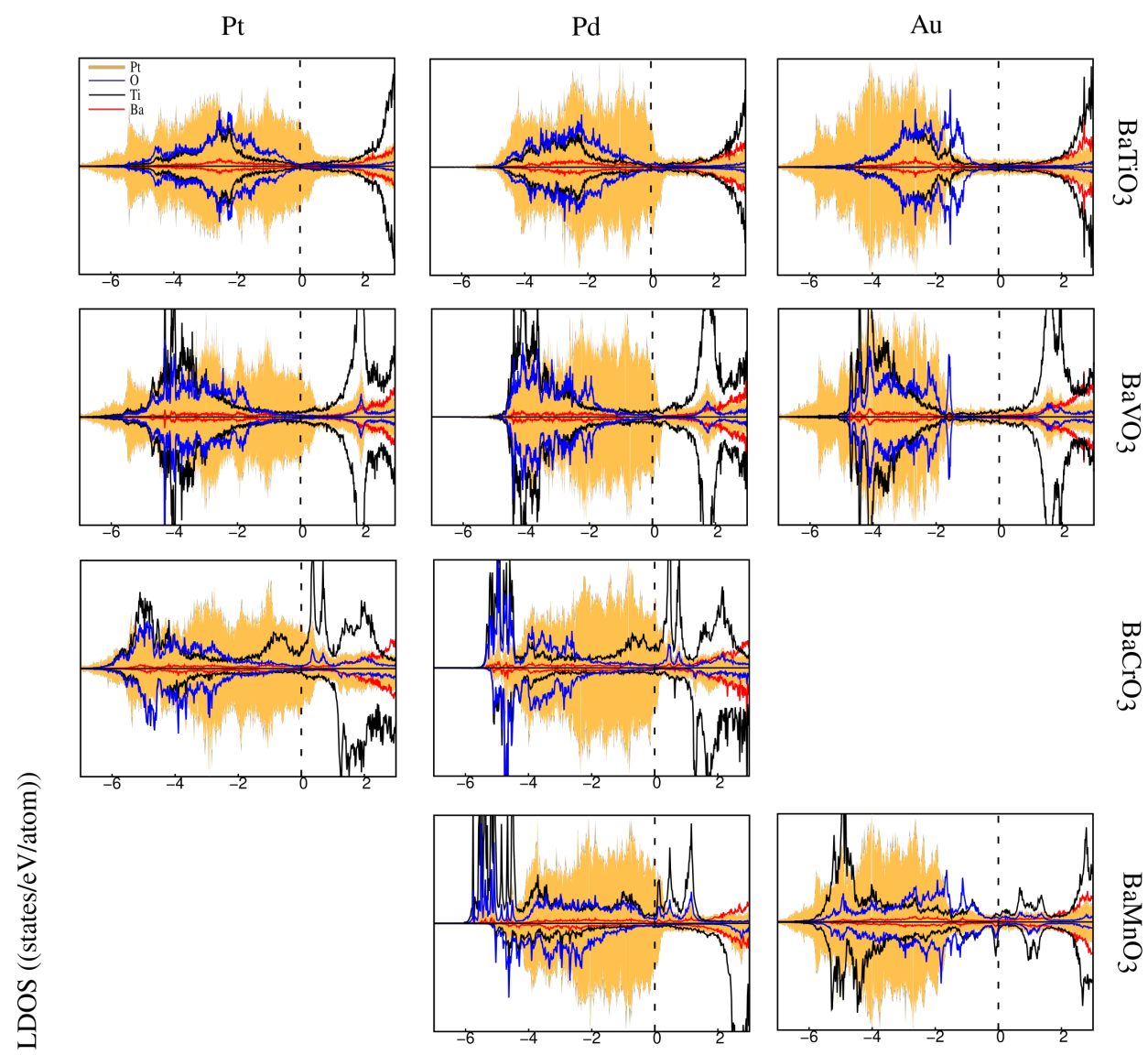

శึ
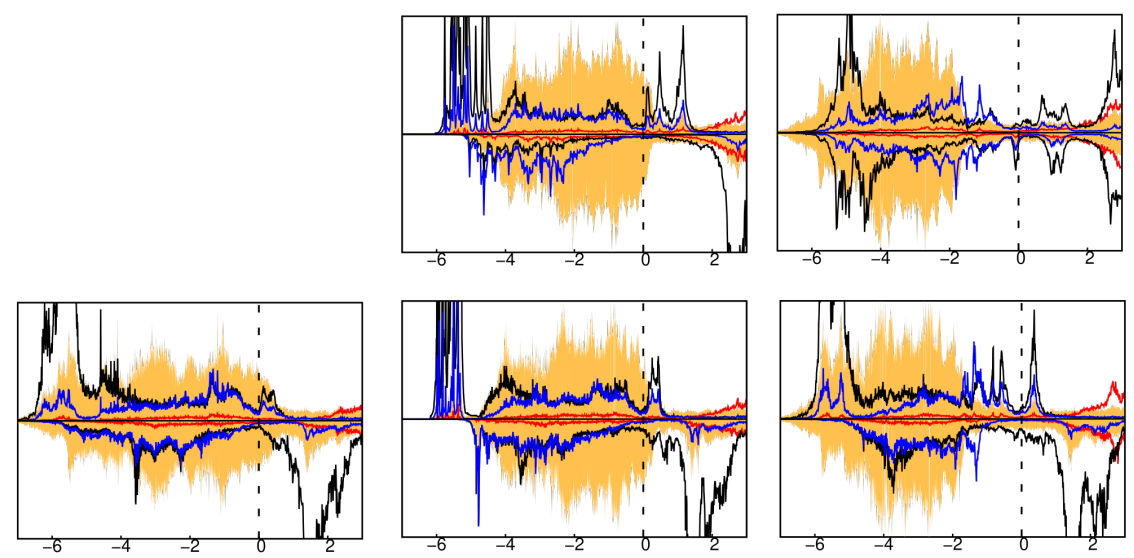

$$
\text { 总 }
$$
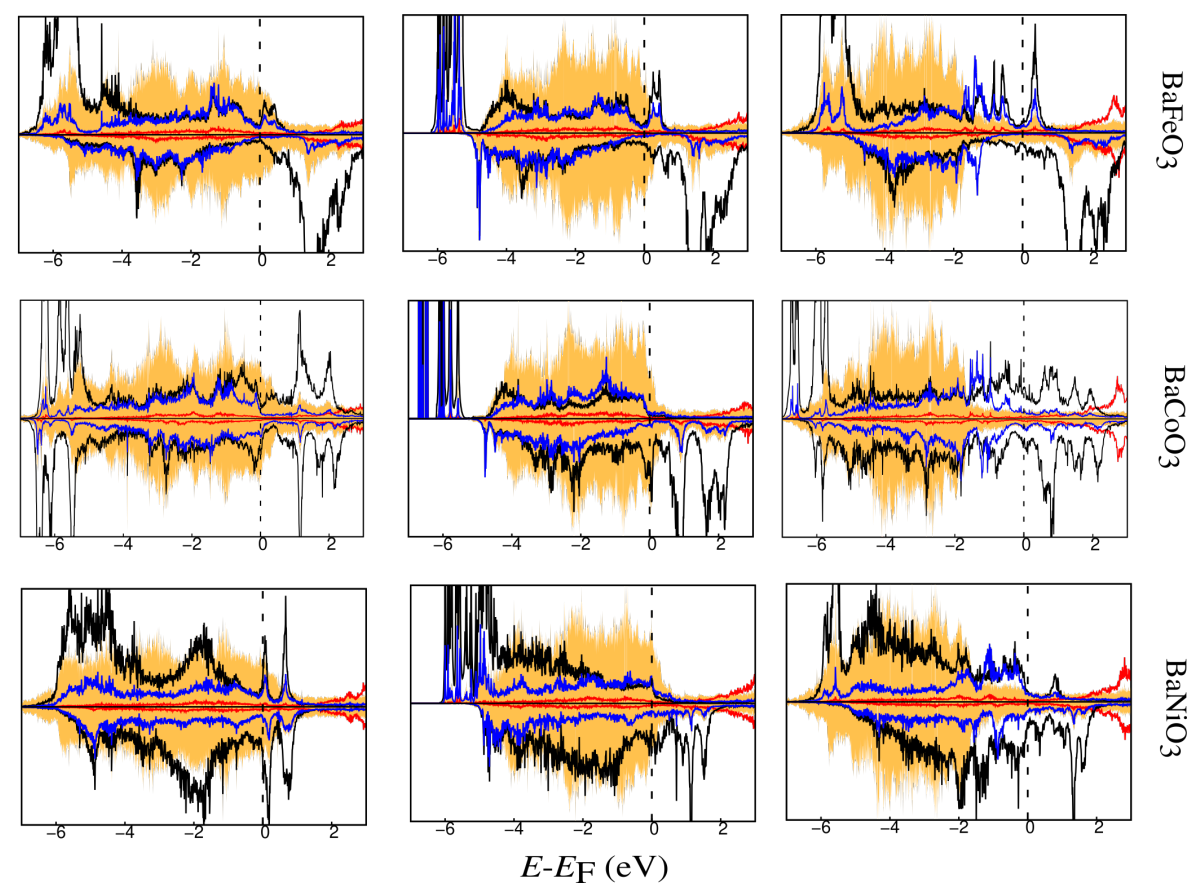

Figure S18: LDOS per atom for $\mathrm{BaBO}_{3}(B=\mathrm{Ti}, \mathrm{V}, \mathrm{Cr}, \mathrm{Mn}, \mathrm{Fe}, \mathrm{Co}, \mathrm{Ni})$ with $\mathrm{Pt}, \mathrm{Pd}$, and Au substrates. $M e, \mathrm{Ba}$, $B$, and $\mathrm{O}$ are represented by orange, red, black, and blue colors, respectivelly, as indicated in the top-left plot. 


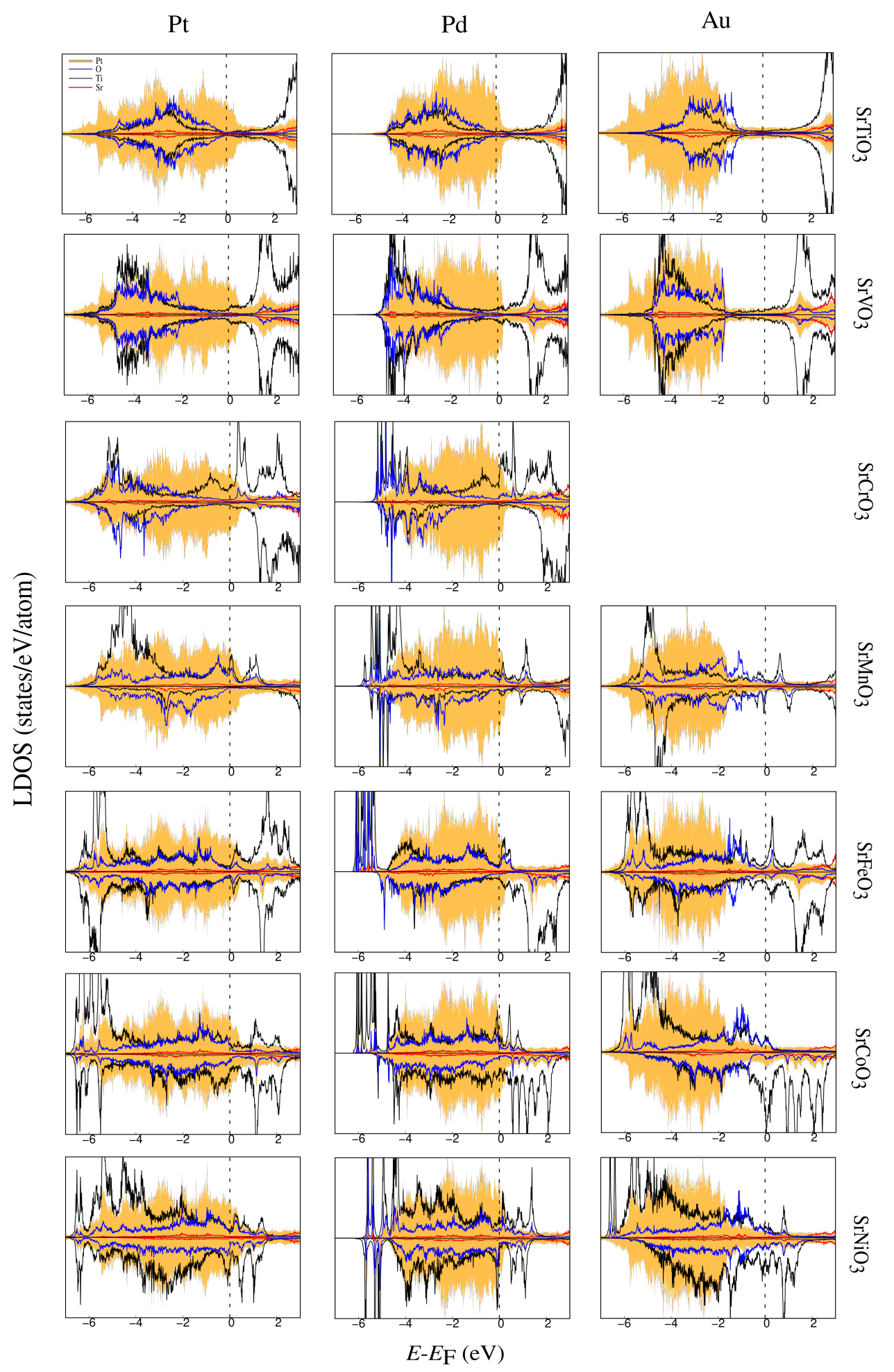

Figure S19: LDOS per atom for $\mathrm{Sr}_{B} \mathrm{O}_{3}(B=\mathrm{Ti}, \mathrm{V}, \mathrm{Cr}, \mathrm{Mn}, \mathrm{Fe}, \mathrm{Co}, \mathrm{Ni})$ with $\mathrm{Pt}, \mathrm{Pd}$, and $\mathrm{Au}$ substrates. $M e, \mathrm{Sr}$, $B$, and $\mathrm{O}$ are represented by orange, red, black, and blue colors, respectivelly, as indicated in the top-left plot. 

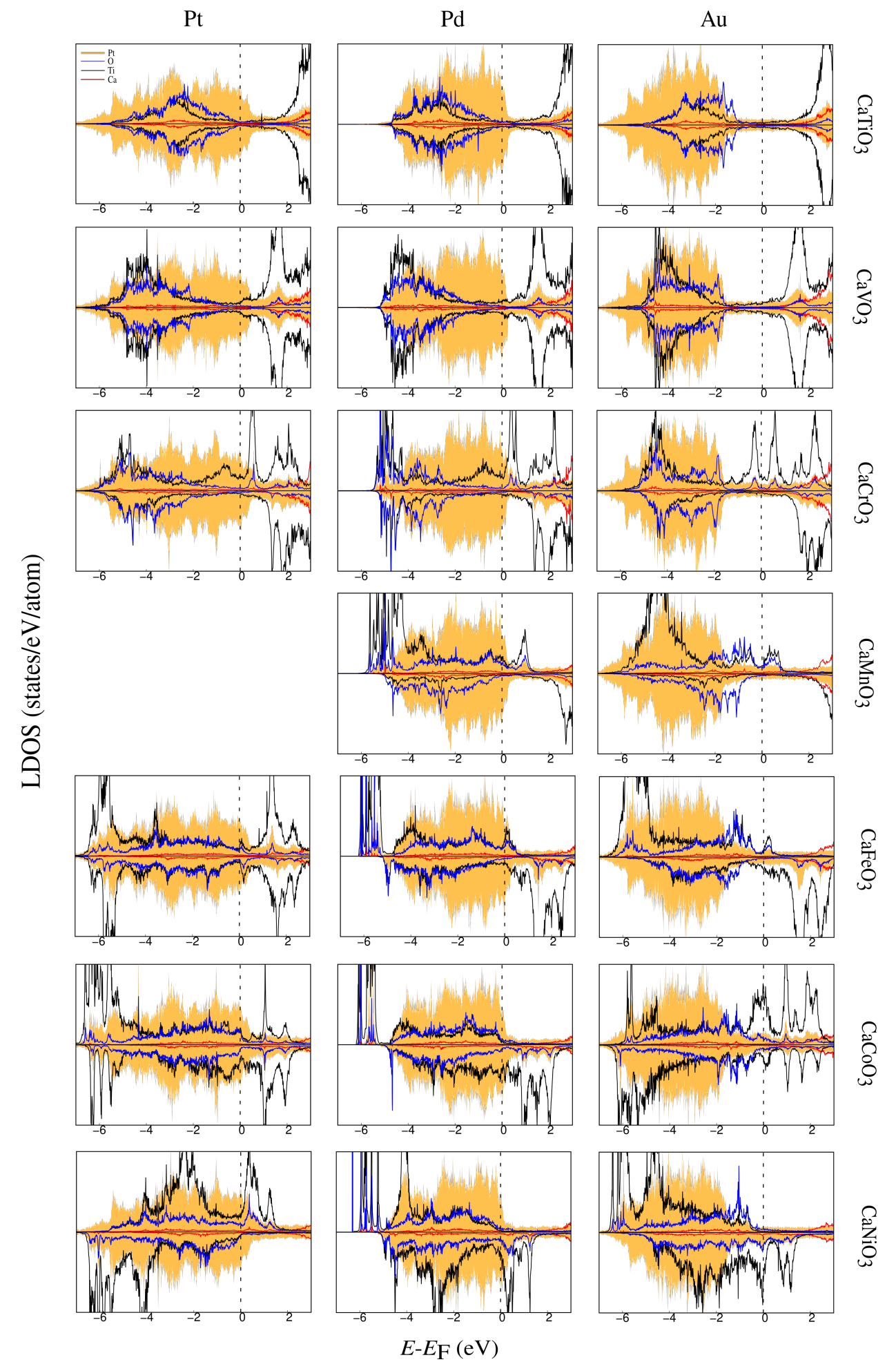

ڤ్రి

Figure S20: LDOS per atom for $\mathrm{CaBO}_{3}(B=\mathrm{Ti}, \mathrm{V}, \mathrm{Cr}, \mathrm{Mn}, \mathrm{Fe}, \mathrm{Co}, \mathrm{Ni})$ with Pt, Pd, and Au substrates. $M e, \mathrm{Ca}$, $B$, and $\mathrm{O}$ are represented by orange, red, black, and blue colors, respectivelly, as indicated in the top-left plot. 

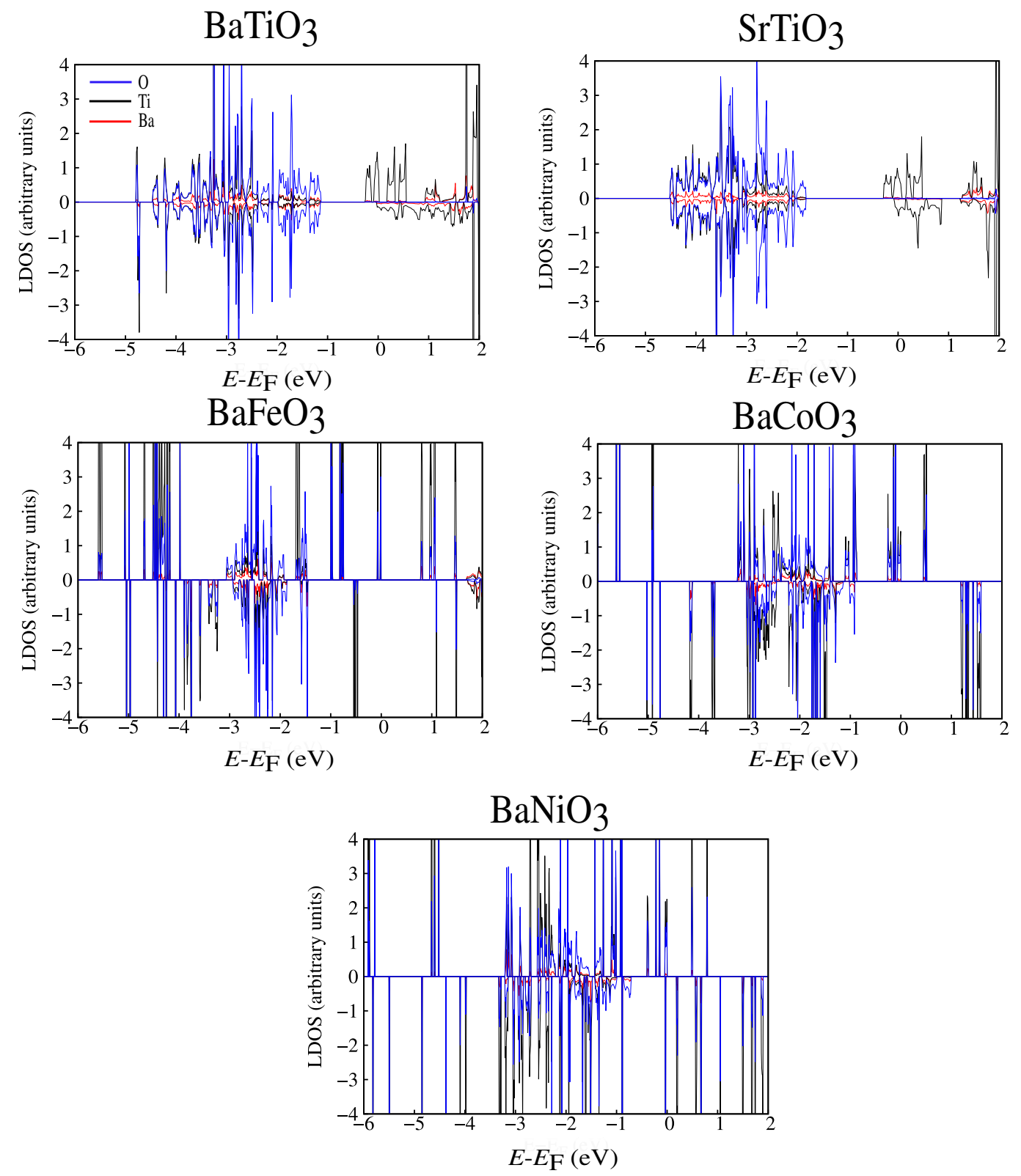

Figure S21: LDOS per atom for the oxide freestanding layers. Ba, $B$, and $\mathrm{O}$ are represented by red, black, and blue colors, respectivelly, as indicated in the top-left plot. 


\section{COHP and ICOHPs}

(a) $\mathrm{Ti}-\mathrm{Pt}$

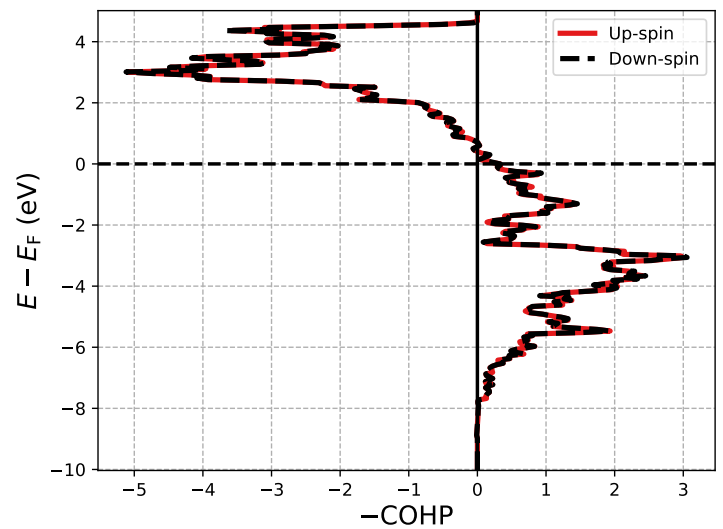

(c) $\mathrm{Fe}-\mathrm{Pt}$

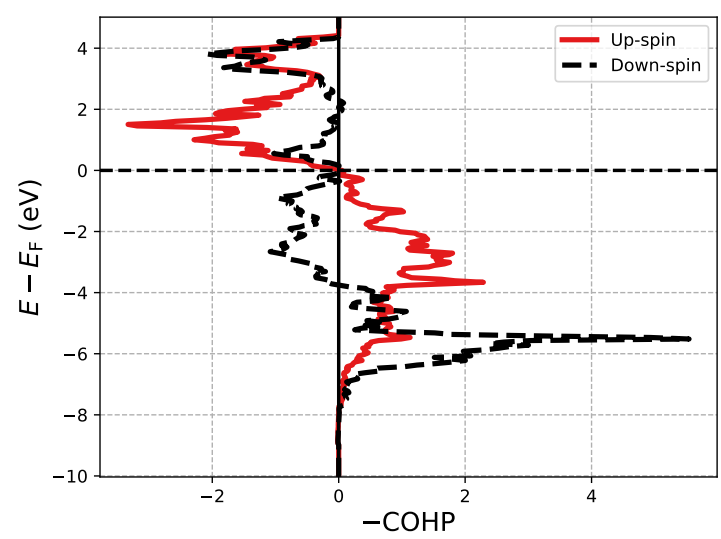

(b) $\mathrm{Ti}-\mathrm{Au}$

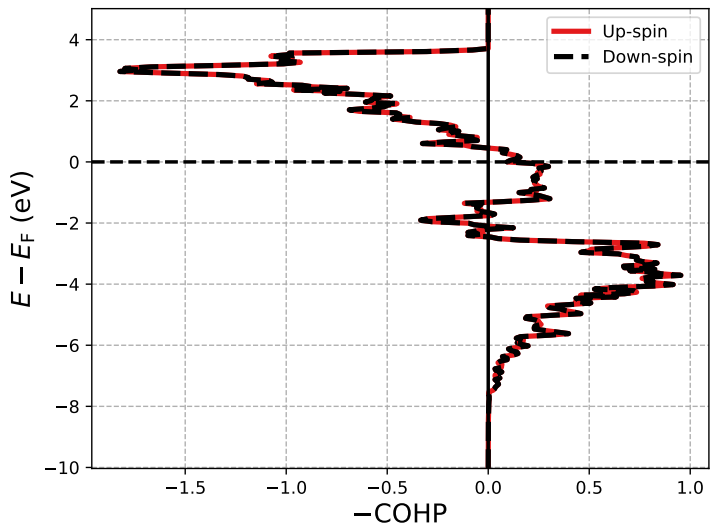

(d) $\mathrm{Fe}-\mathrm{Au}$

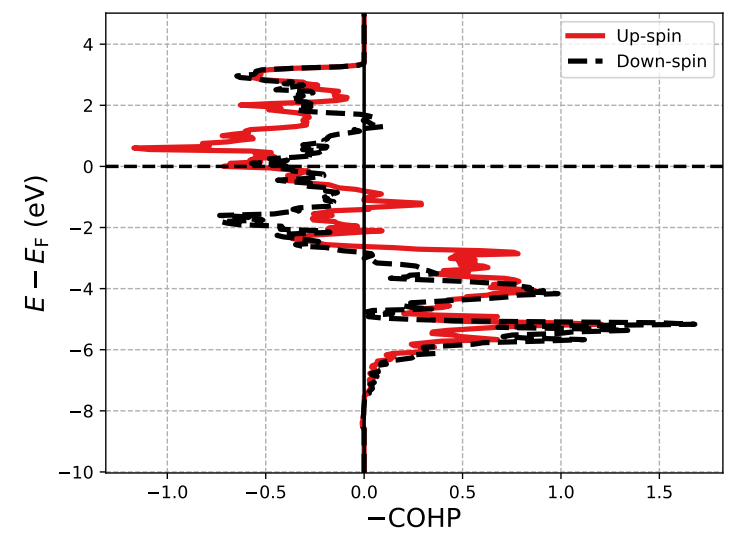

Figure S22: COHPs between all bonds up to $3 \AA$ in the $\mathrm{Ba} B O_{3} / \mathrm{Pt}(111)$ systems (with $B=\mathrm{Ti}, \mathrm{Fe}$ ). 
(a) $\mathrm{Co}-\mathrm{Pt}$

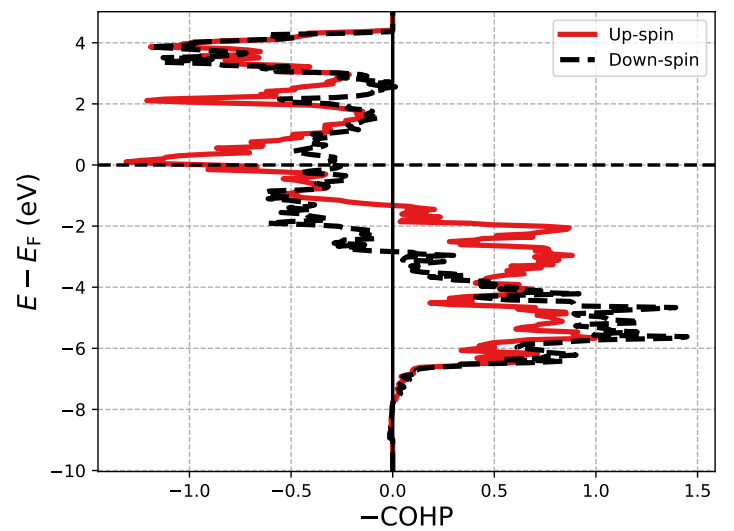

(c) $\mathrm{Ni}-\mathrm{Pt}$

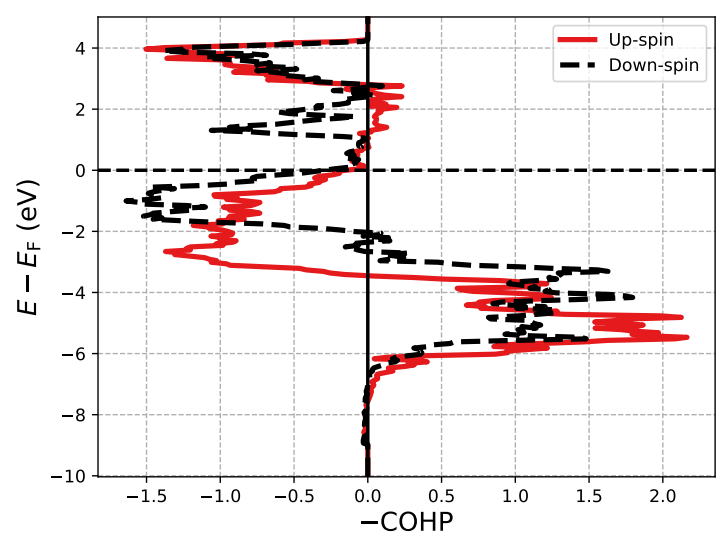

(b) $\mathrm{Co}-\mathrm{Au}$

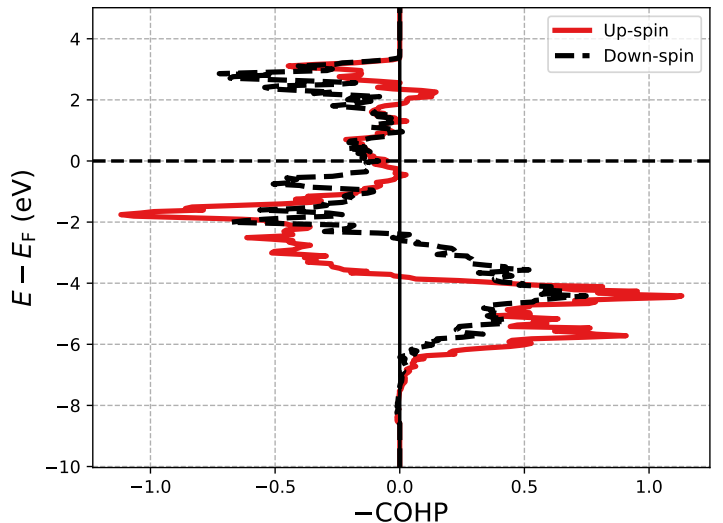

(d) $\mathrm{Ni}-\mathrm{Au}$

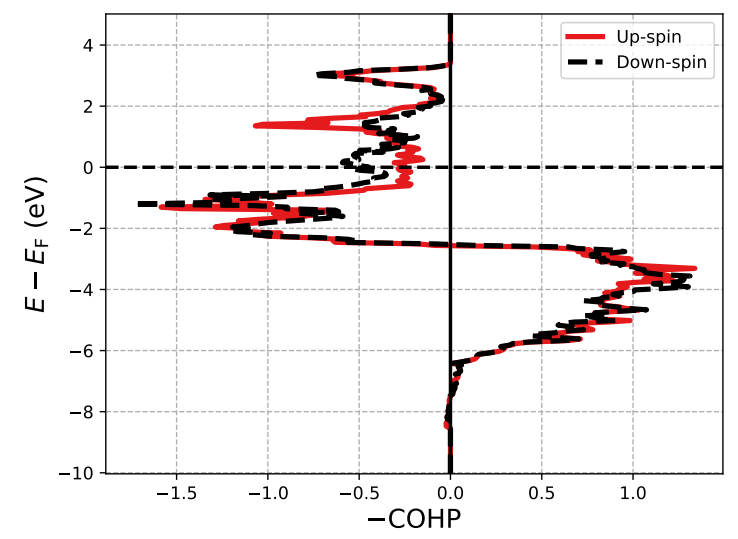

Figure S23: COHPs between all bonds up to $3 \AA$ in the $\mathrm{Ba}_{3} \mathrm{O}_{3} / \mathrm{Pt}(111)$ systems (with $B=\mathrm{Co}, \mathrm{Ni}$ ). 
(a) $\mathrm{Ti}-\mathrm{O}($ with $\mathrm{Pt})$

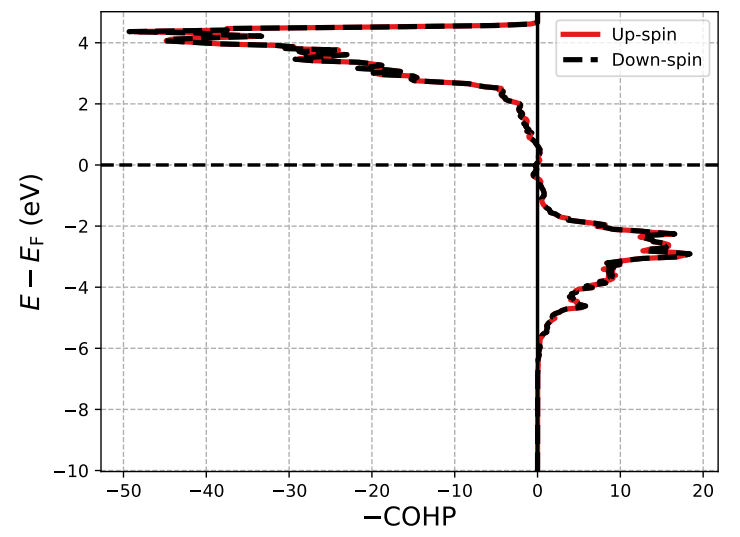

(c) $\mathrm{Fe}-\mathrm{O}($ with $\mathrm{Pt})$

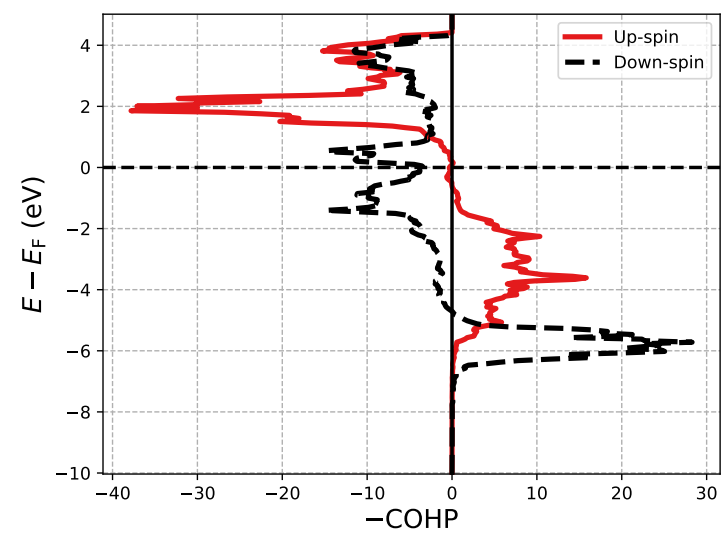

(b) $\mathrm{Ti}-\mathrm{O}($ with $\mathrm{Au})$

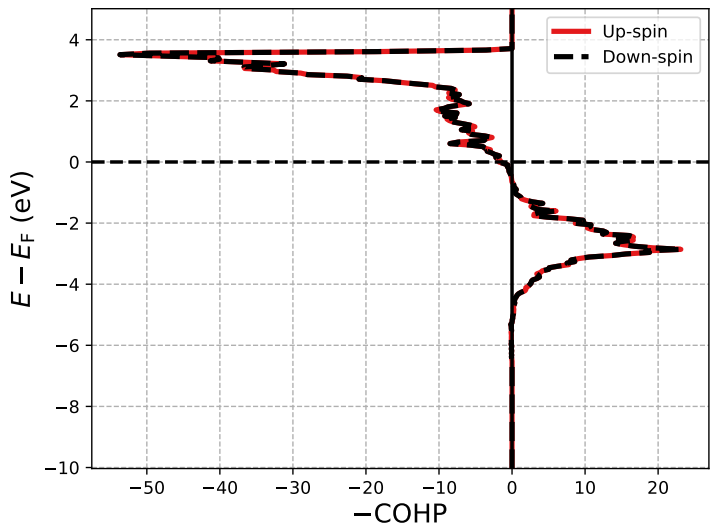

(d) $\mathrm{Fe}-\mathrm{O}($ with $\mathrm{Au})$

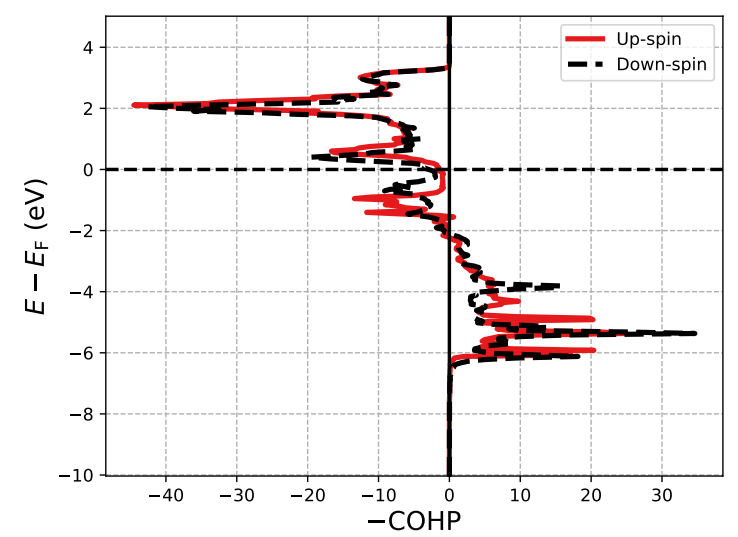

Figure S24: COHPs between all bonds up to $3 \AA$ in the $\mathrm{Ba}_{3} \mathrm{O}_{3} / \mathrm{Me}(111)$ systems (with $B=\mathrm{Ti}, \mathrm{Fe}$ ). 
(a) $\mathrm{Co}-\mathrm{O}($ with $\mathrm{Pt})$

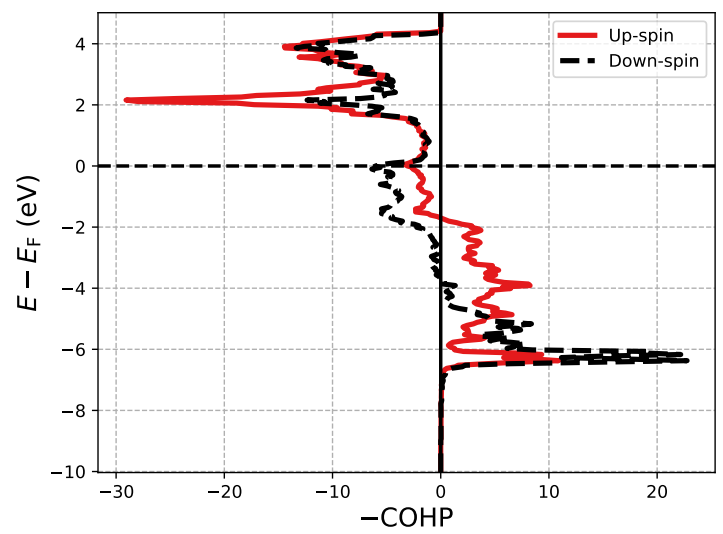

(c) $\mathrm{Ni}-\mathrm{O}($ with $\mathrm{Pt})$

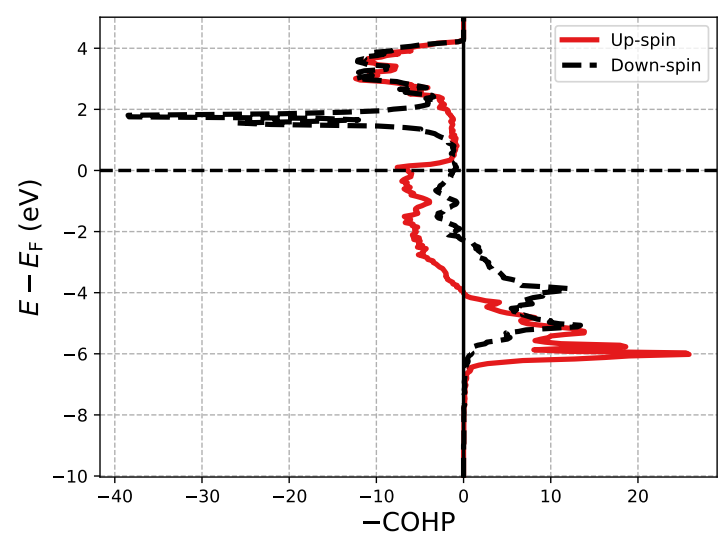

(b) $\mathrm{Co}-\mathrm{O}($ with $\mathrm{Au})$

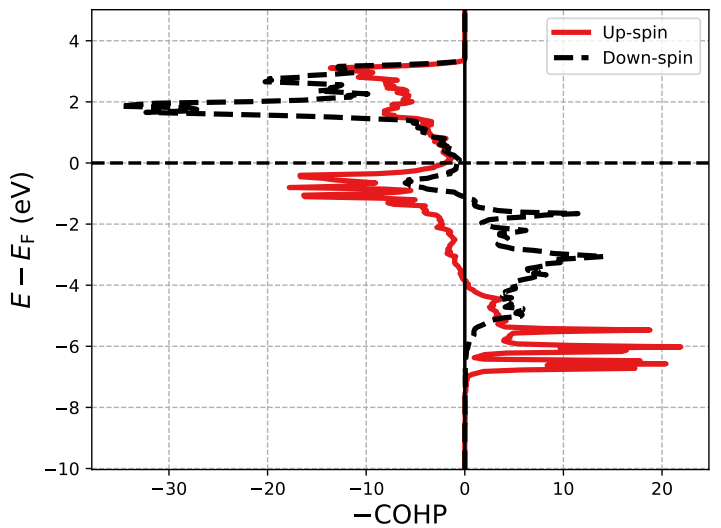

(d) $\mathrm{Ni}-\mathrm{O}($ with $\mathrm{Au})$

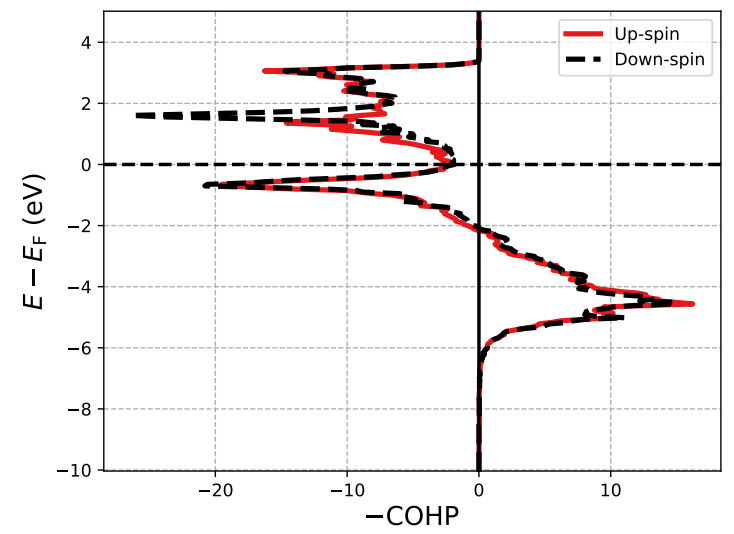

Figure S25: COHPs between all bonds up to $3 \AA$ in the $\mathrm{Ba}_{3} \mathrm{O}_{3} / \mathrm{Pt}(111)$ systems (with $B=\mathrm{Co}, \mathrm{Ni}$ ). 
(a) $\mathrm{Pt}-\mathrm{O}$ (with $\mathrm{Ti}$ )

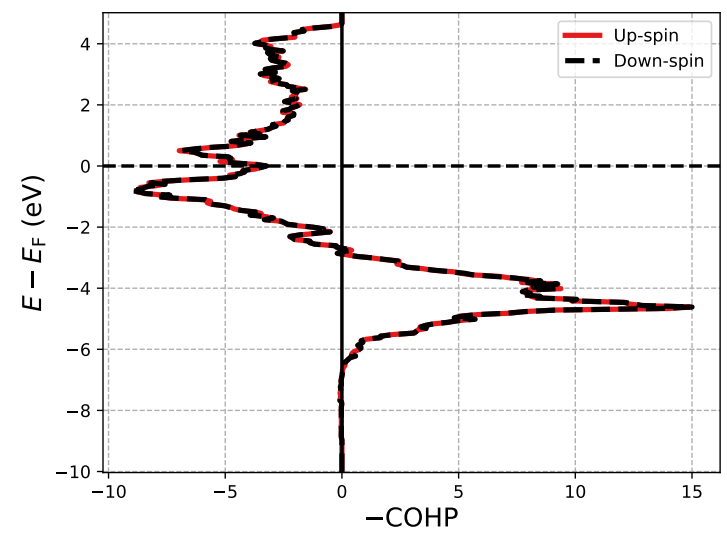

(c) $\mathrm{Pt}-\mathrm{O}($ with $\mathrm{Fe})$

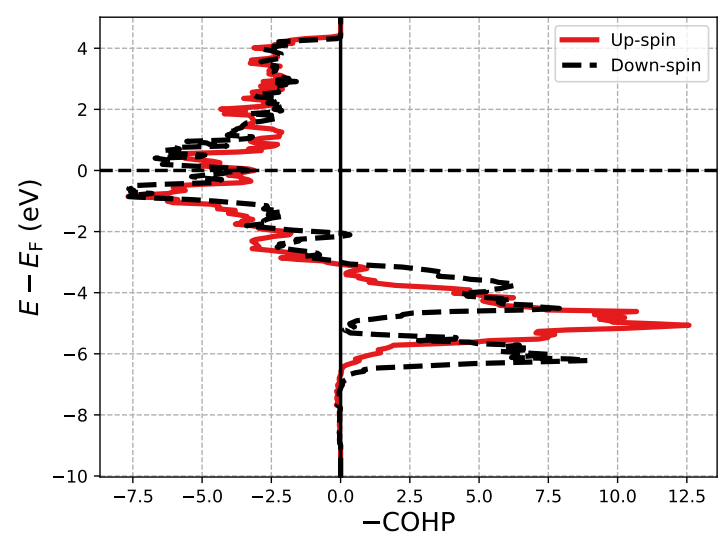

(b) $\mathrm{Au}-\mathrm{O}$ (with $\mathrm{Ti}$ )

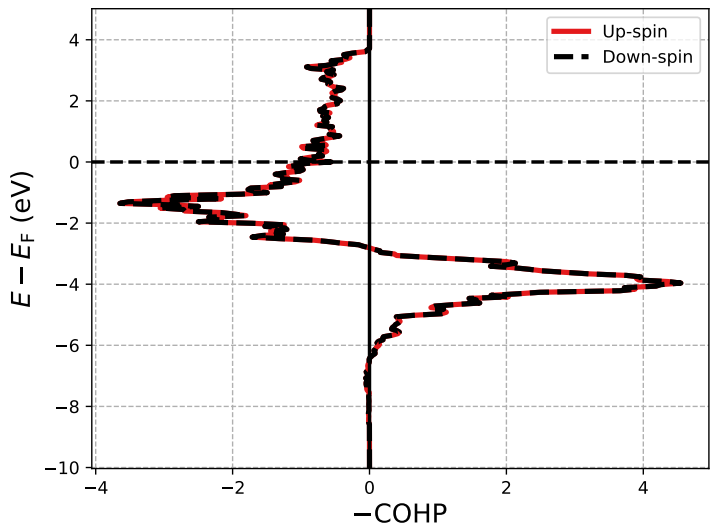

(d) $\mathrm{Au}-\mathrm{O}($ with $\mathrm{Fe})$

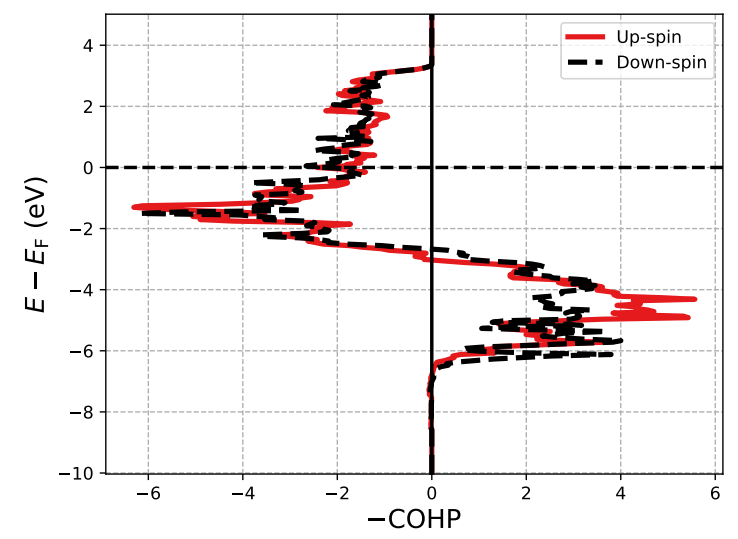

Figure S26: COHPs between all bonds up to $3 \AA$ in the $\mathrm{Ba}_{3} \mathrm{O}_{3} / \mathrm{Me}(111)$ systems (with $B=\mathrm{Ti}, \mathrm{Fe}$ ). 
(a) Pt-O (with Co)

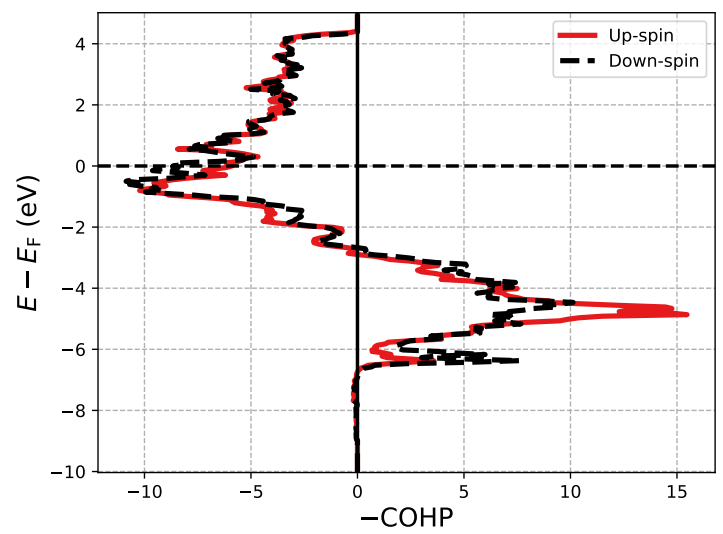

(c) Pt-O (with Ni)

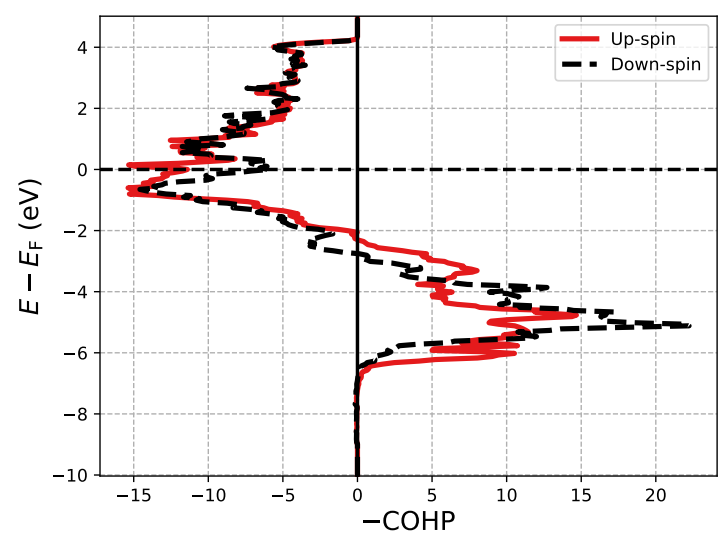

(b) $\mathrm{Au}-\mathrm{O}($ with $\mathrm{Co})$

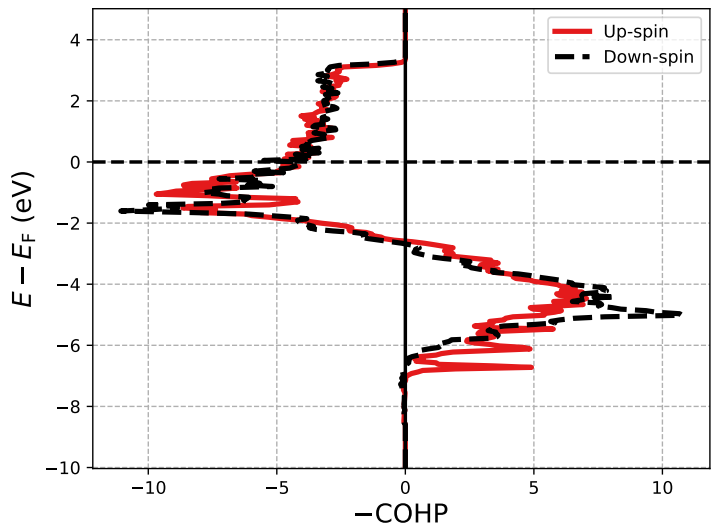

(d) $\mathrm{Au}-\mathrm{O}($ with $\mathrm{Ni})$

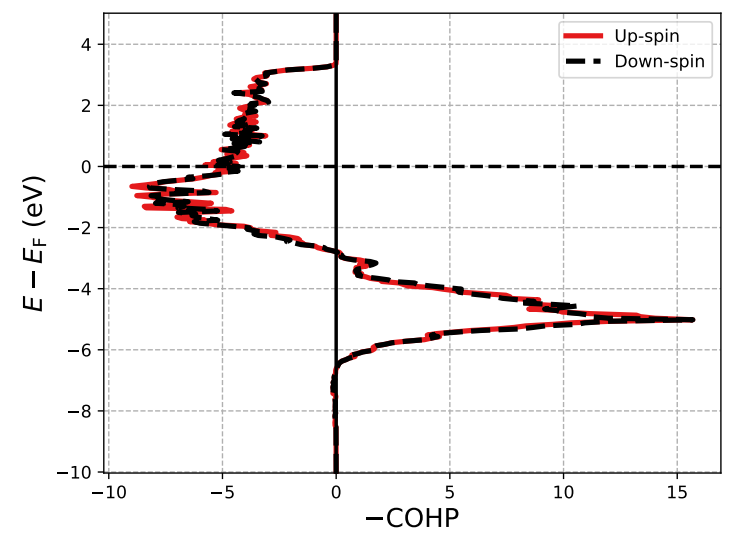

Figure S27: COHPs between all bonds up to $3 \AA$ in the $\mathrm{Ba}_{3} \mathrm{O}_{3} / \mathrm{Pt}(111)$ systems (with $B=\mathrm{Co}, \mathrm{Ni}$ ). 


\section{Elemental metals and bulk perovskites}

Table S9: Lattice parameters, space groups, cohesive energies of the metals taken as references to calculate the formation enthalpies of OQAs and SHSs.

\begin{tabular}{|c|c|c|c|c|c|}
\hline Metal & Structure & $a(\AA)$ & $c(\AA)$ & Cohesive energy (eV/at.) & Ref. \\
\hline $\mathrm{Ba}$ & bcc $(\operatorname{Im} \overline{3} m)$ & $\begin{array}{l}4.99 \\
5.03 \\
5.01\end{array}$ & & $\begin{array}{l}-1.91 \\
-1.88 \\
-1.91\end{array}$ & $\begin{array}{l}\text { this work } \\
\mathrm{PBE}^{1} \\
\text { exp. }^{2,3}\end{array}$ \\
\hline $\mathrm{Sr}$ & fcc $(F m \overline{3} m)$ & $\begin{array}{l}6.02 \\
6.02 \\
6.08\end{array}$ & & $\begin{array}{l}-1.57 \\
-1.62 \\
-1.73\end{array}$ & $\begin{array}{c}\text { this work } \\
\mathrm{PBE}^{1} \\
\text { exp. }\end{array}$ \\
\hline $\mathrm{Ti}$ & hcp $\left(P 6_{3} m m c\right)$ & $\begin{array}{l}2.93 \\
2.95 \\
2.93 \\
2.95\end{array}$ & $\begin{array}{l}4.64 \\
4.68 \\
4.67 \\
4.68\end{array}$ & $\begin{array}{l}-5.17 \\
-5.47 \\
-5.45 \\
-4.85\end{array}$ & $\begin{array}{c}\text { this work } \\
\text { PBE }^{1,5} \\
\text { PBE }^{6} \\
\text { exp. } .^{3,4}\end{array}$ \\
\hline V & bcc $(\operatorname{Im} \overline{3} m)$ & $\begin{array}{l}2.98 \\
3.00 \\
2.98 \\
3.03\end{array}$ & & $\begin{array}{l}-5.45 \\
-5.92 \\
-6.03 \\
-5.31\end{array}$ & $\begin{array}{c}\text { this work } \\
\text { PBE }^{1} \\
\text { PBE }^{6} \\
\text { exp. } .^{3,4}\end{array}$ \\
\hline $\mathrm{Fe}$ & bcc $(\operatorname{Im} \overline{3} m)$ & $\begin{array}{l}2.83 \\
2.83 \\
2.83 \\
2.86\end{array}$ & & $\begin{array}{l}-4.97 \\
-4.32 \\
-4.85 \\
-4.28\end{array}$ & $\begin{array}{c}\text { this work } \\
\text { PBE }^{6} \\
\text { PBE }^{1} \\
\text { exp. }{ }^{3,4}\end{array}$ \\
\hline Co & hcp $\left(P 6_{3} m m c\right)$ & $\begin{array}{l}2.50 \\
2.49 \\
2.50 \\
2.51\end{array}$ & $\begin{array}{l}4.02 \\
4.01 \\
4.09 \\
4.07\end{array}$ & $\begin{array}{l}-4.89 \\
-4.44 \\
-5.14 \\
-4.39\end{array}$ & $\begin{array}{c}\text { this work } \\
\text { PBE }^{6} \\
\text { PBE }^{1} \\
\text { exp. }{ }^{3,7}\end{array}$ \\
\hline $\mathrm{Ni}$ & fcc $(F m \overline{3} m)$ & $\begin{array}{l}3.53 \\
3.52 \\
3.52 \\
3.92\end{array}$ & & $\begin{array}{l}-4.75 \\
-4.48 \\
-4.83 \\
-4.44\end{array}$ & $\begin{array}{c}\text { this work } \\
\text { PBE }^{6} \\
\text { PBE }^{1} \\
\text { exp. } .^{3,4}\end{array}$ \\
\hline $\mathrm{Pt}$ & fcc $(F m \overline{3} m)$ & $\begin{array}{l}3.99 \\
3.95 \\
3.98 \\
3.92\end{array}$ & & $\begin{array}{l}-5.63 \\
-5.87 \\
-5.32 \\
-5.84\end{array}$ & $\begin{array}{c}\text { this work } \\
\text { PBE }^{6} \\
\text { PBE }^{1} \\
\text { exp. }\end{array}$ \\
\hline $\mathrm{Au}$ & fcc $(F m \overline{3} m)$ & $\begin{array}{l}4.18 \\
4.17 \\
4.16 \\
4.07\end{array}$ & & $\begin{array}{l}-3.18 \\
-3.83 \\
-3.11 \\
-3.81\end{array}$ & $\begin{array}{l}\text { this work } \\
\mathrm{PBE}^{6} \\
\mathrm{PBE}^{1} \\
\text { exp. }\end{array}$ \\
\hline
\end{tabular}


Table S10: Lattice parameters, space groups and formation enthalpies of perovskites considered in the thermodynamic model.

\begin{tabular}{ccccccc}
\hline Perovskite & Structure & $a(\AA)$ & $b(\AA)$ & $c(\AA)$ & Formation enthalpy (eV/at.) & Ref. \\
\hline $\mathrm{BaTiO}_{3}$ & $P m \overline{3} m$ & 4.05 & & & -3.35 & this work \\
& $R 3 m$ & $4.08\left(\alpha=89.67^{\circ}\right)$ & & -3.50 & $\mathrm{PBE}^{8}$ \\
\hline $\mathrm{SrTiO}_{3}$ & $P m \overline{3} m$ & 3.96 & & & -3.38 & this work \\
& $P m \overline{3} m$ & 3.94 & & & -3.56 & $\mathrm{PBE}^{8}$ \\
\hline $\mathrm{BaFeO}_{3}$ & $P m \overline{3} m$ & 4.01 & & & -2.07 & this work \\
& $P m \overline{3} m$ & 4.03 & & & -2.25 & $\mathrm{PBE}^{8}$ \\
\hline $\mathrm{BaCoO}_{3}$ & $C m c m$ & 5.70 & 9.99 & 4.81 & -1.83 & this work \\
& $P 6{ }_{3} m m c$ & 5.74 & & 5.77 & -2.11 & PBE $^{8}$ \\
\hline $\mathrm{BaNiO}_{3}$ & $P 6_{3} m m c$ & 5.71 & & 4.80 & -1.48 & this work \\
& $P 6_{3} m m c$ & 5.72 & 4.83 & -1.48 & PBE $^{8}$ \\
\hline
\end{tabular}

\section{Magnetic stability}

Table S11: Magnetic stability considering, as the initial magnetic moment, a ferromagnetic (FM) and an antiferromagnetic (AFM) state of the $B(B=\mathrm{Cr}, \mathrm{Mn}, \mathrm{Fe}, \mathrm{Co}, \mathrm{Ni})$ elements in the approximant structure. Since there are four $B$ atoms in the approximant with two equivalent positions, we consider the initial AFM state with the $m_{B}$ of the non-equivalent positions in opposite directions. RMS = Resulting magnetic moment; IMC = Initial magnetic configuration; SIC = Stable as initial configuration.

\begin{tabular}{|c|c|c|c|c|c|c|c|}
\hline Formula & Energy FM (eV/at.) & Energy AFM (eV/at.) & $\mathrm{RMC}(\mathrm{IMC}=\mathrm{FM})$ & RMS $(\mathrm{IMC}=\mathrm{AFM})$ & $\bar{m}_{B}\left(\mu_{\mathrm{B}}\right)(\mathrm{IMS}=\mathrm{FM})$ & $\bar{m}_{B}\left(\mu_{\mathrm{B}}\right)(\mathrm{IMS}=\mathrm{AFM})$ & SIC \\
\hline $\mathrm{Pt}_{120} \mathrm{Ba}_{5} \mathrm{Cr}_{4} \mathrm{O}_{12}$ & -3.15717 & -3.15781 & FM & AFM & 1.09 & -0.03 & AFM \\
\hline $\mathrm{Pt}_{120} \mathrm{Ba}_{5} \mathrm{Fe}_{4} \mathrm{O}_{12}$ & -3.09922 & -3.09826 & FM & $\mathrm{AFM}$ & 3.32 & -0.12 & FM \\
\hline $\mathrm{Pt}_{120} \mathrm{Ba}_{5} \mathrm{Co}_{4} \mathrm{O}_{12}$ & -3.02495 & -3.02418 & AFM & FM & 0.04 & -2.69 & FM \\
\hline $\mathrm{Pt}_{120} \mathrm{Ba}_{5} \mathrm{Ni}_{4} \mathrm{O}_{12}$ & -2.98047 & -2.96809 & FM & AFM & 0.59 & -0.67 & FM \\
\hline $\mathrm{Pt}_{120} \mathrm{Sr}_{5} \mathrm{Cr}_{4} \mathrm{O}_{12}$ & -3.13384 & -3.13454 & FM & FM & 1.16 & 1.17 & AFM \\
\hline $\mathrm{Pt}_{120} \mathrm{Sr}_{5} \mathrm{Fe}_{4} \mathrm{O}_{12}$ & -3.07669 & -3.07763 & AFM & AFM & -0.12 & -0.14 & $\mathrm{AFM}$ \\
\hline $\mathrm{Pt}_{120} \mathrm{Sr}_{5} \mathrm{Co}_{4} \mathrm{O}_{12}$ & -2.99597 & -2.99534 & AFM & $\mathrm{AFM}$ & -0.04 & -0.04 & FM \\
\hline $\mathrm{Pt}_{120} \mathrm{Sr}_{5} \mathrm{Ni}_{4} \mathrm{O}_{12}$ & -2.9303 & -2.95691 & AFM & AFM & 0.69 & 0.32 & $\mathrm{AFM}$ \\
\hline $\mathrm{Pt}_{120} \mathrm{Ca}_{5} \mathrm{Fe}_{4} \mathrm{O}_{12}$ & -3.08253 & -3.08354 & AFM & $\mathrm{AFM}$ & -0.26 & -0.2 & $\mathrm{AFM}$ \\
\hline $\mathrm{Pt}_{120} \mathrm{Ca}_{5} \mathrm{Co}_{4} \mathrm{O}_{12}$ & -3.0078 & -3.00612 & $\mathrm{AFM}$ & $\mathrm{AFM}$ & -0.11 & -0.11 & FM \\
\hline $\mathrm{Pt}_{120} \mathrm{Ca}_{5} \mathrm{Ni}_{4} \mathrm{O}_{12}$ & -2.95689 & -2.9563 & AFM & FM & 0.03 & 1.44 & FM \\
\hline $\mathrm{Pd}_{120} \mathrm{Ba}_{5} \mathrm{Cr}_{4} \mathrm{O}_{12}$ & -2.08172 & 1 & AFM & 1 & 0.59 & 1 & FM \\
\hline $\mathrm{Pd}_{120} \mathrm{Ba}_{5} \mathrm{Mn}_{4} \mathrm{O}_{12}$ & -2.01345 & / & AFM & / & 0.92 & / & FM \\
\hline $\mathrm{Pd}_{120} \mathrm{Ba}_{5} \mathrm{Fe}_{4} \mathrm{O}_{12}$ & -2.02899 & -2.03089 & FM & FM & 3.58 & 3.58 & AFM \\
\hline $\mathrm{Pd}_{120} \mathrm{Ba}_{5} \mathrm{Co}_{4} \mathrm{O}_{12}$ & -1.95797 & -1.95604 & FM & FM & 2.57 & -2.57 & FM \\
\hline $\mathrm{Pd}_{120} \mathrm{Ba}_{5} \mathrm{Ni}_{4} \mathrm{O}_{12}$ & -1.89289 & -1.9067 & FM & AFM & 1.49 & -0.03 & $\mathrm{AFM}$ \\
\hline $\mathrm{Pd}_{120} \mathrm{Sr}_{5} \mathrm{Cr}_{4} \mathrm{O}_{12}$ & -2.05863 & -2.05942 & FM & FM & 1.21 & 1.23 & AFM \\
\hline $\mathrm{Pd}_{120} \mathrm{Sr}_{5} \mathrm{Fe}_{4} \mathrm{O}_{12}$ & -2.01027 & -2.01489 & FM & FM & 3.47 & 3.76 & AFM \\
\hline $\mathrm{Pd}_{120} \mathrm{Sr}_{5} \mathrm{Co}_{4} \mathrm{O}_{12}$ & -1.94105 & / & FM & / & 2.59 & / & FM \\
\hline $\mathrm{Pd}_{120} \mathrm{Sr}_{5} \mathrm{Ni}_{4} \mathrm{O}_{12}$ & -1.88425 & -1.88285 & FM & AFM & -0.48 & 0.4 & FM \\
\hline $\mathrm{Pd}_{120} \mathrm{Ca}_{5} \mathrm{Cr}_{4} \mathrm{O}_{12}$ & -2.072 & / & FM & / & 1.14 & l & FM \\
\hline $\mathrm{Pd}_{120} \mathrm{Ca}_{5} \mathrm{Fe}_{4} \mathrm{O}_{12}$ & -2.01331 & -2.01448 & FM & $\mathrm{AFM}$ & 3.5 & 0.26 & AFM \\
\hline $\mathrm{Pd}_{120} \mathrm{Ca}_{5} \mathrm{Co}_{4} \mathrm{O}_{12}$ & -1.93052 & -1.93402 & AFM & $\mathrm{AFM}$ & 1.04 & 0.12 & AFM \\
\hline $\mathrm{Pd}_{120} \mathrm{Ca}_{5} \mathrm{Ni}_{4} \mathrm{O}_{12}$ & -1.89952 & -1.89853 & AFM & FM & 0.7 & 1.45 & FM \\
\hline $\mathrm{Au}_{120} \mathrm{Ba}_{5} \mathrm{Mn}_{4} \mathrm{O}_{12}$ & -0.72306 & / & AFM & / & 1.77 & / & FM \\
\hline $\mathrm{Au}_{120} \mathrm{Ba}_{5} \mathrm{Fe}_{4} \mathrm{O}_{12}$ & -0.72789 & -0.73004 & $\mathrm{AFM}$ & FM & -0.0 & 3.4 & AFM \\
\hline $\mathrm{Au}_{120} \mathrm{Ba}_{5} \mathrm{Co}_{4} \mathrm{O}_{12}$ & -0.6368 & -0.6345 & $\mathrm{FM}$ & FM & -2.77 & 2.76 & FM \\
\hline $\mathrm{Au}_{120} \mathrm{Ba}_{5} \mathrm{Ni}_{4} \mathrm{O}_{12}$ & -0.56556 & -0.57633 & FM & AFM & 1.17 & -0.05 & AFM \\
\hline $\mathrm{Au}_{120} \mathrm{Sr}_{5} \mathrm{Fe}_{4} \mathrm{O}_{12}$ & -0.69417 & -0.69365 & AFM & $\mathrm{AFM}$ & 1.5 & -0.03 & FM \\
\hline $\mathrm{Au}_{120} \mathrm{Sr}_{5} \mathrm{Co}_{4} \mathrm{O}_{12}$ & -0.61276 & -0.61436 & FM & AFM & -2.41 & -0.11 & AFM \\
\hline $\mathrm{Au}_{120} \mathrm{Sr}_{5} \mathrm{Ni}_{4} \mathrm{O}_{12}$ & -0.56751 & -0.56264 & FM & AFM & 0.44 & -0.01 & FM \\
\hline $\mathrm{Au}_{120} \mathrm{Ca}_{5} \mathrm{Cr}_{4} \mathrm{O}_{12}$ & -0.75502 & / & AFM & / & 0.65 & / & FM \\
\hline $\mathrm{Au}_{120} \mathrm{Ca}_{5} \mathrm{Fe}_{4} \mathrm{O}_{12}$ & -0.70948 & -0.70957 & FM & AFM & 3.65 & 0.17 & AFM \\
\hline $\mathrm{Au}_{120} \mathrm{Ca}_{5} \mathrm{Co}_{4} \mathrm{O}_{12}$ & -0.61741 & -0.61429 & AFM & FM & -1.33 & 2.66 & FM \\
\hline $\mathrm{Au}_{120} \mathrm{Ca}_{5} \mathrm{Ni}_{4} \mathrm{O}_{12}$ & -0.56905 & / & FM & / & 1.24 & / & FM \\
\hline
\end{tabular}




\section{References}

(1) Lejaeghere, K.; Speybroeck, V. V.; Oost, G. V.; Cottenier, S. Error estimates for solid-state densityfunctional theory predictions: an overview by means of the ground-state elemental crystals. Critical Reviews in Solid State and Materials Sciences 2014, 39, 1-24.

(2) Barrett, C. S. The crystal structure of barium and europium at 293, 78 and 5 K. Journal of Chemical Physics 1956, 25, 1123-1124.

(3) Kittel, C. Introduction to Solid State Physics, 7th ed.; John Wiley \& Sons: USA, 1996.

(4) Villars, P.; Calvert, L. D. Pearson's Handbook of Crystallographic Data for Intermetallic Phases; ASM International: Metals Park, Ohio, USA, 1998.

(5) Spreadborough, J.; Christian, J. The measurement of the lattice expansions and Debye temperatures of titanium and silver by X-ray methods. Proceedings of the Physical Society (1958-1967) 1959, 74, 609.

(6) Janthon, P.; Luo, S.; Kozlov, S. M.; Vines, F.; Limtrakul, J.; Truhlar, D. G.; Illas, F. Bulk Properties of Transition Metals: A Challenge for the Design of Universal Density Functionals. J. Chem. Theory Comput. 2014, 10, 3832-3839.

(7) Hofer, L. J. E.; Peebles, W. C. Preparation and X-Ray Diffraction Studies of A New Cobalt Carbide. $J$. Am. Chem. Soc. 1947, 69, 893-899.

(8) Jain, A.; Hautier, S. P. O. G.; Chen, W.; Richards, W. D.; Dacek, W.; Cholia, S.; Gunter, D.; Skinner, D.; Ceder, G.; Persson, K. A. Commentary: The Materials Project: A materials genome approach to accelerating materials innovation. APL Mater. 2013, 1, 011002. 